\title{
Report Title \\ Laser Drilling - Drilling with the Power of Light
}

High Energy Laser Perforation and Completion Techniques

\author{
Type of Report: Annual Technical Progress Report \\ Reporting Period Start Date: $\quad$ October 2004 \\ Reporting Period End Date: $\quad$ September 2005 \\ Principal Authors(s): $\quad$ Brian C. Gahan, P.E. \\ Dr. Samih Batarseh \\ Date Report was issued: N N N N N 2006 \\ DOE Award Number: $\quad$ DE-FC26-00NT40917 \\ Submitting Organization: Gas Technology Institute \\ Address: $\quad 1700$ South Mount Prospect Road \\ Des Plaines, Illinois 60018
}




\section{Disclaimer}

This report was prepared as an account of work sponsored by an agency of the United States Government. Neither the United States Government nor any agency thereof, nor any of their employees, makes any warranty, express or implied, or assumes any legal liability or responsibility for the accuracy, completeness, or usefulness of any information, apparatus, product, or process disclosed, or represents that its use would not infringe privately owned rights. Reference herein to any specific commercial product, process, or service by trade name, trademark, manufacturer, or otherwise does not necessarily constitute or imply its endorsement, recommendation, or favoring by the United States Government or any agency thereof. The views and opinions of authors expressed herein do not necessarily state or reflect those of the United States Government or any agency thereof. 


\section{Abstract}

Gas Technology Institute (GTI) has been the leading investigator in the field of high power laser applications research for well construction and completion applications. Since 1997, GTI (then as Gas Research Institute) has investigated several military and industrial laser systems and their ability to cut and drill into reservoir type rocks. In this report, GTI continues its investigation with a recently acquired $5.34 \mathrm{~kW}$ ytterbium-doped multi-clad high power fiber laser (HPFL). The HPFL represents a potentially disruptive technology that, when compared to its competitors, is more cost effective to operate, capable of remote operations, and requires considerably less maintenance and repair.

To determine how this promising laser would perform under high pressure in-situ conditions, GTI performed a number of experiments with results directly comparable to previous data. Experiments were designed to investigate the effect of laser input parameters on representative reservoir rock types of sandstone and limestone. The focus of the experiments was on completion and perforation applications, although the results and techniques apply to well construction and other rock cutting applications.

All previous laser/rock interaction tests were performed on samples in the lab at atmospheric pressure. To determine the effect of downhole pressure conditions, a sophisticated tri-axial cell was designed and tested. For the first time, Berea sandstone, limestone and clad core samples were lased under various combinations of confining, axial and pore pressures. Composite core samples consisted of steel cemented to rock in an effort to represent material penetrated in a cased hole. The results of this experiment will assist in the development of a downhole laser perforation prototype tool.

In the past, several combinations of laser and rock variables were investigated at standard conditions and reported in the literature. More recent experiments determined the technical feasibility of laser perforation on multiple samples of rock, cement and steel. The fiber laser was capable of penetrating these materials under a variety of conditions, to an appropriate depth, and with reasonable energy requirements. It was determined that fiber lasers are capable of cutting rock without causing damage to flow properties. Furthermore, the laser perforation resulted in permeability improvements on the exposed rock surface.

This report discusses the design and development of a customized laser pressure cell; experimental design and procedures, and the resulting data on pressure-charged samples exposed to the laser beam. An analysis provides the resulting effect of downhole pressure conditions on the laser/rock interaction process. 


\section{Table of Contents}

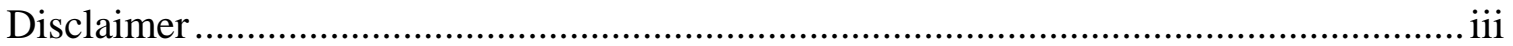

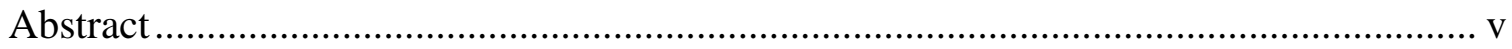

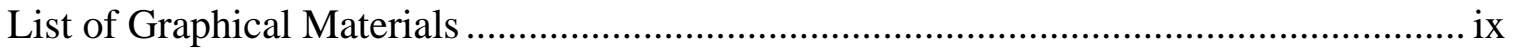

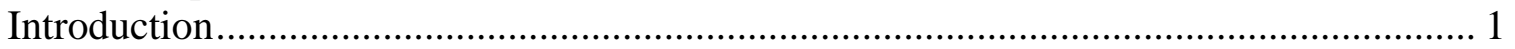

An Alternative Method: High Power Lasers.............................................................. 2

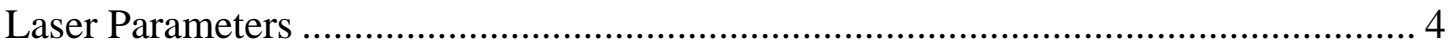

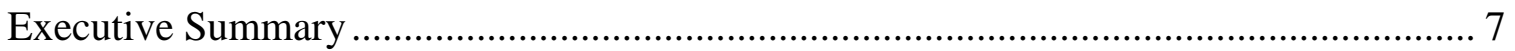

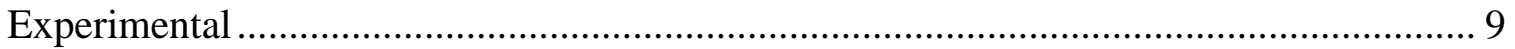

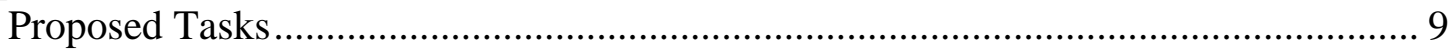

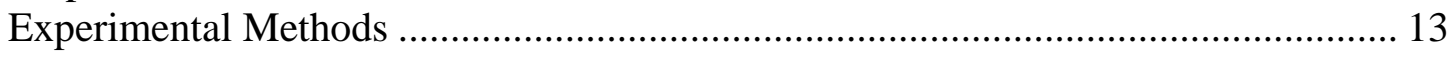

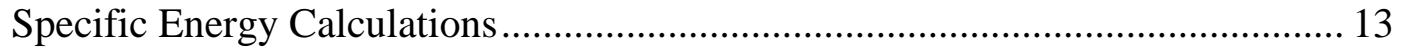

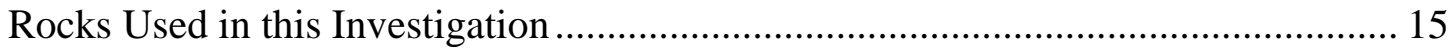

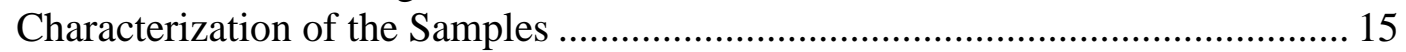

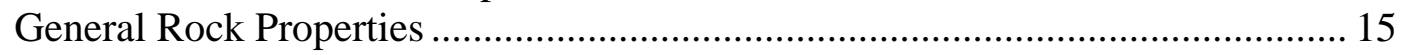

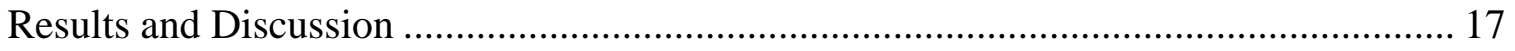

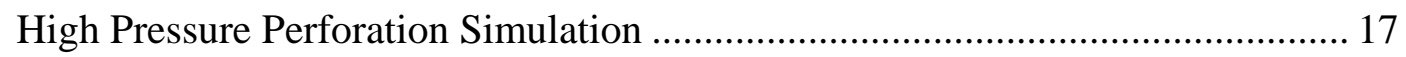

High Pressure Perforation Cell Design and Development................................... 18

Perforation of Core Samples under High Pressure Conditions............................. 27

Perforation of Saturated Core Samples under High Pressure Conditions ............. 35

Perforation of Composite Core Samples under High Pressure Conditions ........... 37

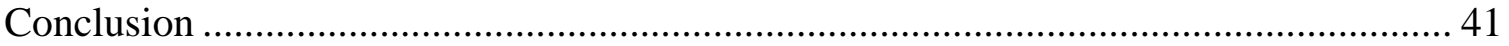

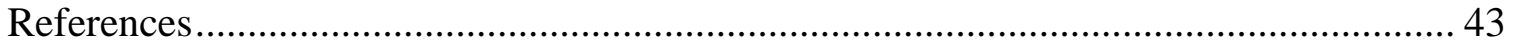

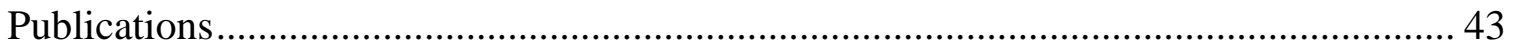

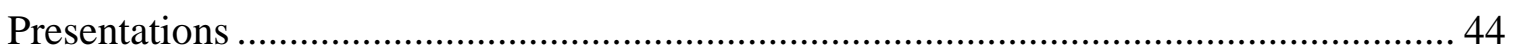

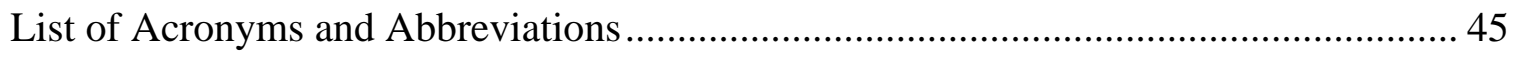

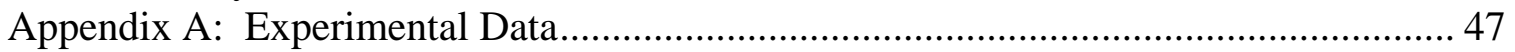

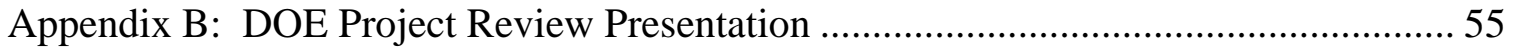




\section{List of Graphical Materials}

Figure 1. 2-D post-laser permeability map of perforation demonstration in $30.48 \mathrm{~cm}$ (12.0 in) per side block of Berea sandstone showing 15-30\% permeability increase along the lased tunnel surface.

Table 1. Comparison of laser characteristics for $\mathrm{CO}_{2}$; lamp-pumped and diodepumped Nd:YAG; and high power fiber lasers at $4 \mathbf{k W}$ output power..................... 3

Figure 2. Standard tri-axial cell design prior to modification for HPFL perforation. ..... 18

Figure 3. High pressure perforation cell proof-of-concept tube with a cover lens.......... 19

Figure 4. Cover lenses before and after lasing during high pressure perforation cell experiment.....

Figure 5. High pressure perforation cell proof-of-concept tube with funnel and a cover

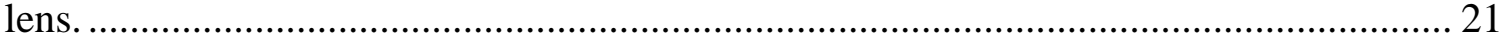

Figure 6. Experimental set-up of high pressure perforation cell proof-of-concept test... 22

Figure 7. Laser firing during high pressure perforation cell proof-of-concept test. ........ 22

Figure 8. Interior (A) and exterior (B) views of $5.08 \mathrm{~cm}$ (2.0 in) ID copper tube mockup used to test high pressure perforation test cell design............................................. 23

Figure 9. Copper tube mock-up with the purging connection. ....................................... 24

Figure 10. Copper tube mock-up assembly ready for laser application. .......................... 24

Figure 11. High pressure tri-axial cell concept for laser perforation testing under pressure

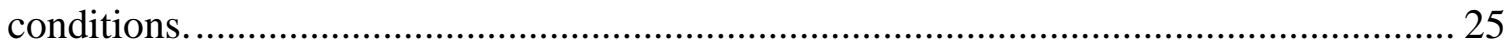

Figure 12. High pressure tri-axial cell design for laser perforation testing under pressure

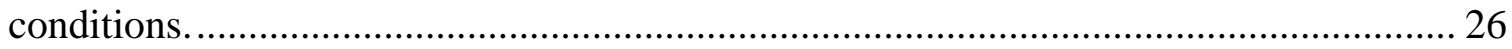

Figure 13. Completed high pressure tri-axial cell for in-situ laser perforation testing.... 26

Figure 14. Experimental set up for perforation test in high pressure cell....................... 28

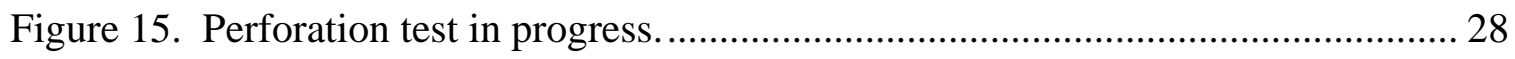

Figure 16. Comparison of SE values in sandstone as observed at various test cell pressure

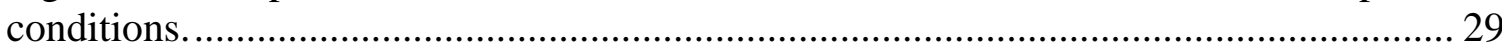

Figure 17. Comparison of SE values in limestone as observed at various test cell pressure conditions.

Figure 18. Comparison of SE values in limestone and sandstone as observed at various test cell pressure conditions.

Figure 19. Post-high pressure perforation test of limestone exhibiting stress fractures ... 32

Figure 20. Sandstone samples show no post-test stress fractures.................................. 32

Figure 21. Thin section analysis from limestone used in perforation tests show low porosity and permeability with close grain contact.

Figure 22. Heat transfer in sandstone by conduction (solid to solid) and convection (solid to air) 34 
Figure 23. Comparison of SE values in sandstone as observed at various test cell pressure conditions, including brine and oil saturated samples..................................... 35

Figure 24. Comparison of SE values in limestone as observed at various test cell pressure conditions, including brine and oil saturated samples. 36

Figure 25. Composite core samples were to simulate physical conditions of a competed wellbore.....

Figure 26. Composite sample as prepared for the high pressure cell, illustrating modified design to avoid melting of core sleeve. 38

Figure 27. CT scan image of $10.16 \mathrm{~cm}$ (4.0 in) diameter by $15.24 \mathrm{~cm}$ (6.0 in) length limestone clad sample and outline of penetration path after perforation of three $30 \mathrm{~s}$ shots by $5.34 \mathrm{~kW}$ ytterbium fiber laser with a $0.889 \mathrm{~cm}(0.35 \mathrm{in})$ diameter beam. 39

Figure 28. Pre- and post-lased images of $10.16 \mathrm{~cm}$ (4.0 in) diameter by $15.24 \mathrm{~cm}$ (6.0 in) length limestone core inset with $5.08 \mathrm{~cm}$ (2.0 in) diameter by $1.27 \mathrm{~cm}(0.5 \mathrm{in})$ thick steel

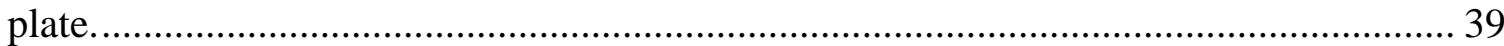




\section{Introduction}

The oil and gas industry has attempted for many years to find acceptable nonexplosive alternatives to creating downhole reservoir connectivity with the wellbore. Although some methods have proven capable in providing an economic and technical solution, the use of high shaped charges remains the preferred technology for most applications.

Shaped charge explosives have drawbacks which alternative perforation methods seek to improve, primarily by crushing the tunnel zone and inhibiting flow from the reservoir into the wellbore. Remedial work with some form of stimulation is often required to overcome this flow restriction. Other concerns voiced by the industry include the inherent safety concerns regarding transport, storing and use of the perforating assembly. Also, regulatory concerns focus on limitations that may be raised on the use of explosive charges, challenging the industries ability to economically complete wells around the world.

The application of high power lasers to create the path between the wellbore and reservoir could significantly reduce the primary drawbacks of using explosives. In addition to perforating, laser applications should perform other on-site tasks including cutting windows for side exiting casing or laterals, extended perforations that connect additional reservoir rock to the wellbore, and removal of objects lost downhole that would normally require drill out or fishing operations.

Laser perforation experiments in the past have been performed using combinations of laser input parameters on several rock lithologies to determine specific cause and effect relationships. Optimized variables were identified and demonstrations conducted to show the capability of lasers to cut tunnels of at least $30.48 \mathrm{~cm}$ (12.0 in) deep into sandstone and limestone. One notable advantage resulting from laser perforation on sandstone is the improvement of near-tunnel fluid flow characteristics. Measured permeability increased 15-30\% along the tunnel face of a perforation demonstration on a $30.48 \mathrm{~cm}$ (12.0 in) block of Berea sandstone (Figure 1).

Although the application of lasers for perforation provided promising results, downhole pressure conditions had not been investigated. All high power laser applications experiments performed to date had been conducted under ambient pressure conditions in the laboratory. In order to perform high pressure tests on rock, a tri-axial pressure cell would need to be designed to allow multiple pressure conditions, a simulated pressurized wellbore, a window for the laser beam to interface with the sample, and ejection ports for lased material. 


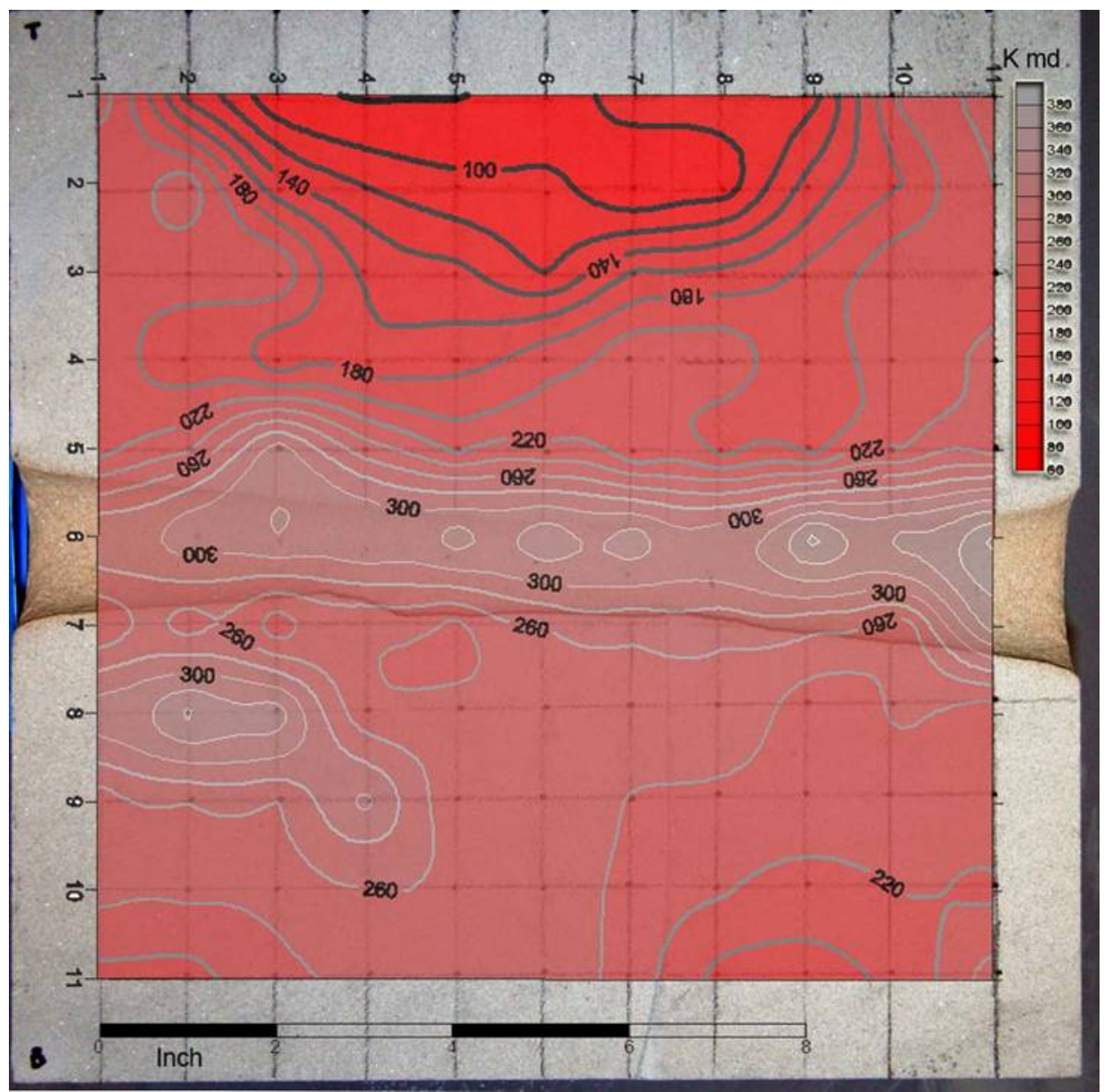

Figure 1. 2-D post-laser permeability map of perforation demonstration in $30.48 \mathrm{~cm}$ (12.0 in) per side block of Berea sandstone showing 15-30\% permeability increase along the lased tunnel surface.

\section{An Alternative Method: High Power Lasers.}

Reducing costs and eliminating problems of current drilling and completion methods would have a significant positive impact on the oil and gas industry. New technologies and tools operate using basic rock destruction mechanisms like thermal spalling, fusion and vaporization, mechanical stresses and chemical reactions ${ }^{1}$. All of these destruction mechanisms can be achieved using lasers. For example, at low laser power, spalling (chipping) can be obtained. Increase in the laser power, with a fixed beam diameter, results in phase changes and reactions in the rock, like dehydration of clays, releasing of gases and inducing thermal stresses. At a certain power, the rock will melt (fuse) and at higher power the rock will vaporize.

Laser technology applied to drilling and completion operations has the potential to reduce drilling time, eliminate the necessity to remove and dispose of drilling

\footnotetext{
${ }^{1}$ Maurer, 1968, 1980
} 
cuttings and improve well performance through improved perforation operations.

Although initial GRI laser drilling investigations utilized megawatt-class military lasers, it was soon apparent that an oversized laser could effectively remove a rock mass, however, it did so quite inefficiently due to material phase change and other phenomenon unrelated to cutting and removing rock.

Less powerful industrial lasers were then utilized providing improved SE values when exposed to the same or similar rock types. Under lab conditions, the researchers were successful in proving that the current generation of industrial lasers was capable of removing rock with energy levels comparable to those of existing mechanical rock drilling methods. However, for a laser system to be applied under field conditions, a number of conditions would have to be met, including requisite power delivery to target, reliability, portability, and greater efficiency. Although the overall size or footprint per kilowatt output was improving, industrial class lasers were not necessarily designed to withstand field conditions and would be difficult to economically operate given their low wall plug efficiencies.

\section{Characteristics of Fiber Lasers}

Recently, high power fiber lasers have become commercially available and have positioned themselves as a serious alternative to other solid-state and carbon dioxide lasers for industrial material-processing. Over the past two years, fiber lasers have increased in power from several watts to kilowatts, and are fully capable of delivering sufficient rock cutting power via fiber optics.

Of interest to the GTI research team were the nearly 10x higher wall plug efficiency; and greater mobility through a smaller overall size and solid state design. In addition, the beam quality was improved, and projected diode failure was in excess of 50,000 continuous hours, projecting low or no maintenance operations (Table 1).

Table 1. Comparison of laser characteristics for $\mathrm{CO}_{2}$; lamp-pumped and diode-pumped Nd:YAG; and high power fiber lasers at $4 \mathrm{~kW}$ output power.

\begin{tabular}{|l|c|c|c|c|}
\hline & $\mathbf{C O}_{\mathbf{2}}$ & $\begin{array}{c}\text { LP } \\
\text { Nd:YAG }\end{array}$ & $\begin{array}{c}\text { DP } \\
\text { Nd:YAG }\end{array}$ & HPFL \\
\hline E/O Efficiency, \% & $5-10$ & $2-3$ & $4-6$ & $16-20$ \\
\hline $\begin{array}{l}\text { Electric Power, kW } \\
\text { (no chiller) }\end{array}$ & $\sim 50$ & $\sim 130$ & $\sim 80$ & $20-25$ \\
\hline $\begin{array}{l}\text { Footprint, } \mathrm{m}^{2} \text { (no } \\
\text { chiller) }\end{array}$ & 6 & 5 & 3 & 0.5 \\
\hline Water, m³/hr & $6-8$ & $20-25$ & $\sim 15$ & $<2$ \\
\hline Maintenance, Khrs & $1-2$ & 0.5 & $2-3$ & $10-15$ \\
\hline Pump Replace, Khrs & $\mathrm{n} / \mathrm{a}$ & $0.5-1$ & 2.5 & $>50$ \\
\hline
\end{tabular}

Source: IPG Photonics Corporation 
Together, these improvements have rapidly advanced fiber lasers as a leading candidate for on-site applications, including hard rock mining, tunneling, pavement cutting and rock drilling.

GTI acquired an IPG Photonics $5.34 \mathrm{~kW}$ ytterbium-doped multi-clad fiber laser in 2003, at the time the most powerful of its kind available for research in the United States. Power output is rapidly increasing, as more powerful fiber lasers have been manufactured.

For oil and gas industry applications, the fiber laser presents itself as the most likely near-term candidate for successful laser applications in remote locations, capable of delivering a beam to a rock target some 1 to $2 \mathrm{~km}$ (3281 to $6562 \mathrm{ft}$ ) beneath the Earth's surface. Given the improvement in the fiber laser's wall plug efficiency (16\%) over a comparable diode pumped Nd:YAG (6\%), an ytterbium fiber laser requires about 62.5\% less electrical energy to produce the same output power beam.

For many of the same reasons fiber lasers represent a breakthrough for field applications in oil and gas, it is also being considered for other applications that include cutting or breaking rock and/or similar materials in remote locations, including those in the energy, mining, defense, space, demolition and construction industries.

Results from experiments to date continued to suggest the application of photonic energy may prove to offer a non-explosive alternative for perforating oil and gas wells. By applying this technique downhole through casing and cement, perforations and other directionally controlled completion and stimulation methods could be employed without creating damage to the reservoir. Clearly, with the use of photonic energy, no perforating materials or explosive products are left to contaminate the wellbore and the perforation tunnel; therefore cleaning the perforated tunnel and the wellbore around the perforation area are not required. In fact, the use of lasers in downhole completions techniques, including perforation, has the potential to stimulate the perforation tunnel while it is constructed.

\section{Laser Parameters}

LASER is an acronym for Light Amplification by Stimulated Emission of Radiation. Albert Einstein predicted the possibility of stimulated emission (generation of photons or discrete bundles of energy via transitions between atomic or molecular energy levels) in 1917. Laser use in many applications such as medical, metallurgical, and military, is becoming well understood. The principle of the laser is transforming different kinds of energy (chemical, electrical, etc.) into intense electromagnetic beams of monochromatic and coherent waves. The wavelength of a laser beam $(\lambda)$ depends on laser's active medium, and ranges from 0.1 micrometers $(\mu \mathrm{m})$ to $103 \mu \mathrm{m}$, spanning the 
ultraviolet, visible, infrared and sub-millimeter ranges of the photonic spectrum $^{2}$.

Laser drilling is a developing technology that has been applied to industrial uses such as creating small holes in metal and other materials. This research examines the possibility of expanding the use of lasers to remove rock for oil and gas exploration and production applications, including conventional and horizontal drilling, cutting windows in steel casing and cement, and other completion techniques.

In rock drilling, the type of laser used plays a crucial role in the efficiency and quality of the cut. Laser properties, including discharge type (continuous or pulsed), wavelength, peak power, average power, intensity, repetition rate, and pulse width define the type of laser rock interaction obtained, and thus, affect the amount of energy transfer to the rock. The results of the previous experimental work show that lasers penetrate well through rocks, as they have a low reflectivity of electromagnetic waves, resulting in a good coupling with the laser radiation. Also, the low thermal conductivity of rocks allows for a rapid heating of the rock sample in the vicinity of the beam.

\footnotetext{
${ }^{2}$ W.T. Silfvast, 1996
} 


\section{Executive Summary}

The overall objective of this study is to conduct research to establish the technical feasibility of using laser tools to drill and complete natural gas wells and conduct engineering studies leading to prototype tool development. The proposed tasks for this report include developing an in-situ laser/rock interaction test plan based on Phase I plan and results, including design of pressure vessel and data acquisition using pulsed and continuous wave lasers.

Experiments were performed at Gas Technology Institute in Des Plaines, IL at their High Power Laser Applications Laboratory. The 5.34 kW ytterbium-doped multi-clad fiber laser was used exclusively to perform the experimental work. Tests were conducted on Berea sandstone and Bedford limestone samples. Berea sandstone is a standard quarry rock used in the petroleum industry for laboratory testing. Bedford limestone was procured from a local Illinois quarry, and was selected due to its relatively consistent and uniform characteristics.

All laser/rock experiments performed to date have been conducted under ambient laboratory conditions. As part of a recent laser perforation proof-of-concept study, it was critical to understand how a laser would perform under downhole pressure conditions. In order to perform high pressure tests on rock, a tri-axial pressure cell was designed to allow multiple pressure conditions, a simulated pressurized wellbore, a window for the laser beam to interface with the sample, and ejection ports for lased material.

Initial tests were performed on cores of Berea sandstone and Bedford/Indiana limestone under various conditions of axial, pore and confining pressures. For all cases, the laser settings remained the same. Full output power of the ytterbium fiber laser, $5.34 \mathrm{~kW}$, was applied continuously to each sample through the sapphire window of the pressure cell with a beam diameter of $0.889 \mathrm{~cm}(0.35 \mathrm{in})$ for $8.0 \mathrm{~s}$.

Additional tests were performed on sandstone and limestone core saturated in a brine solution and oil. Finally, composite cores consisting of rock, cement and steel plate were constructed to simulate laser perforation in a completed wellbore under in-situ pressure conditions.

The results from these tests were successful in proving the ability of the high power fiber laser to perforate the samples under high pressure conditions. Next steps include design and testing of a downhole prototype laser perforation tool. 


\section{Experimental}

\section{Proposed Tasks}

The work performed by GTI during the 2005 fiscal period was based on the following overall scope of work presented and accepted by DOE (Work performed during this period and presented in this report are in bold):

Task 2.0: Continuation of Fundamental Research and Development GTI shall continue previous investigations into the feasibility of using highpowered lasers for the purpose of drilling and completing natural gas wells. The objectives of the project are to:

a) Experimentally determine the best laser parameters for creating a hole of a given size, deep into a given lithology under in-situ conditions.

b) Develop a model for the laser/rock interaction process, and

c) Develop the conceptual design of a laser drilling system based on the results of a) and b).

d) Experimentally determine the effect of liquid saturated lithologies on laser beam-rock interactions

e) Ability of lasers to interact with rock in a liquid filled pressure vessel

f) Advantages and disadvantages of pulsed vs. continuous wave $\mathrm{CO}_{2}$ lasers

g) Specific Energy (SE) dependencies on laser and other process parameters, and

h) Mineralogy changes that occur with exposure to laser energy.

\section{Task 2.1 Experimental Plans}

1. Develop an in-situ laser/rock interaction test plan based on Phase I plan and results, including design of pressure vessel and data acquisition using pulsed and continuous wave lasers

2. Develop a laser/rock interaction test plan to be performed using a highpower free electron (FE) laser to determine effect of various beam wavelengths on rock samples

\section{Task 2.2 Rock Preparation and Analysis}

Acquire and prepare sandstone, shale and limestone target samples for all planned tests, and analyze rock properties pre- and post-test.

Task 2.3 Data Analysis

Collect and analyze diagnostic data, calculate SE and penetration rates, determine lithology-specific relationships and general relationships, and 
evaluate effect of pulsed vs. continuous wave lasers, wavelength, and in-situ conditions on the application of laser energy to remove rock.

\section{Task 2.4 Topical Report}

Prepare, as part of the Continuation Application, a draft topical report on the technical progress of the project. This report shall follow guidelines set forth in the Federal Assistance Reporting Checklist and accompanying reporting instructions and shall include, but not necessarily be limited to:

1. The diagnostic data, SE and penetration rate calculations for each lithology tested,

2. The conditions that result in spallation, melt, and vaporization mechanisms for rock removal in each lithology, including laser and rock properties

3. An analysis of changes in physical and chemical properties to rock samples following laser exposure

4. The contributory effects of laser beam wavelength on rock removal

\section{Task 2.5 Modeled Effects of Energy Transfer From Lasers to Non-} Homogeneous Porous Media

Develop a predictive model of the processes that occur during laser/rock interaction based principally on transport equations of mass, momentum and energy conservation.

\section{Task 3.0 Systems Development Issues in Laser Well Construction}

GTI shall investigate the significant technical hurdles that are required to allow downhole laser applications in oil and gas wells, including energy delivery downhole, rock cuttings from the wellbore as a material resource for well construction, alternative techniques (i.e., clear water or other transparent coaxial jets) for drilling with a weighted fluid environment.

This study will focus primarily on laser drilling systems development issues. Proposed is a two-phase program that encompasses idea/concept development and demonstration of concept. All phases and tasks proposed will be performed at Gas Technology Institute.

Task 3.1 Downhole Energy Delivery Assessment

Perform a literature review and analysis to determine available commercial options for laser systems and fiber optics, laser optics and lenses, conventional electric transmission applications and energy transfer issues.

Task 3.2 Laser Created Rock Melt Characteristic Study Investigate the material properties of rock melted by laser energy as a material resource in well construction (i.e., ceramic casing), including strength properties, mineralogy, structure, thermal properties, porosity and permeability, and influence of additives on melt properties. 


\section{Task 3.3 Experimental Plans}

Develop an in-situ laser/rock interaction test plan to simulate a variety of downhole drilling environments, including balanced, overbalanced, and underbalanced conditions, in combination with anticipated downhole fluids (i.e., drilling mud, water, brine, hydrocarbons).

\section{Task 3.4 Rock Preparation and Analysis}

Acquire and prepare sandstone, shale and limestone target samples for all planned tests, and analyze rock properties pre- and post-test.

\section{Task 3.5 Data Analysis}

Collect and analyze diagnostic data, calculate $\mathrm{SE}$ and penetration rates, determine lithology-specific relationships and general relationships, and evaluate effect of downhole drilling environments in combination with drilling fluids on these relationships.

Task 3.6 Topical Report

Prepare, as part of the Continuation Application (see Article 2.6, "Continuation Application" contained in Section II -Special Terms and Conditions), a draft topical report on the technical progress of the project. This report shall follow guidelines set forth in the Federal Assistance Reporting Checklist and accompanying reporting instructions, and shall include, but not necessarily be limited to:

- Bibliography and analysis from literature study,

- Laser Created Rock Melt Characteristic Study analysis and results,

- The diagnostic data, SE and penetration rate calculations for each material tested,

- The conditions that result in spallation, melt, and vaporization mechanisms for rock and cement removal in each lithology, including laser and rock properties, and conditions that optimize cutting through a steel liner,

- An analysis of changes in physical and chemical properties to rock, cement and steel samples following laser exposure.

Task 4.0: High Energy Laser Perforation and Completion Techniques GTI is currently investigating the feasibility of laser perforation and completion techniques with a major service company partner. A proof of concept with planned subsequent investigations are aimed at creating engineering systems for adapting laser energy to puncture steel casing and the cement bonding agent, into the formation deep enough to allow the free flow of hydrocarbons into the wellbore.

GTI proposes to perform investigations into understanding and modeling laser/material interactions involving composite perforation targets, representing steel casing, cement, and reservoir rock. Although literature exists on the use of 
lasers for cutting steel in controlled factory environments, limited information addresses laser cutting of steel in the extreme conditions that exist downhole. These investigations will directly complement GTI's existing systems analysis and prototype development with our industry partner.

As with Task 2.0, all tasks proposed will be performed at Gas Technology Institute, however in unforeseen situation where laser or other similar equipment from laser or petroleum industry partners would be required, GTI is confident that access would be made available and supported.

Task 4.1 Experimental Plans

Develop an in-situ laser/rock interaction test plan matrix, including design of pressure vessel and data acquisition using a laser(s) capable of cutting steel, cement and rock samples.

Task 4.2 Rock Preparation and Analysis

Acquire and prepare combinations of sandstone, limestone, cement and steel target samples (individual and composite) and analyze material properties pre- and post-test.

Task 4.3 Data Analysis

Collect and analyze diagnostic data, calculate $\mathrm{SE}$ and penetration rates, determine material-specific relationships and general relationships, and evaluate effect of laser energy to remove combination of materials.

\section{Task 4.4 Topical Report}

Prepare, as part of the Continuation Application (see Article 2.6, “Continuation Application" contained in Section II -Special Terms and Conditions), a draft topical report on the technical progress of the project. This report shall follow guidelines set forth in the Federal Assistance Reporting Checklist and accompanying reporting instructions, and shall include, but not necessarily be limited to:

- The diagnostic data, SE and penetration rate calculations for each material tested,

- The conditions that result in spallation, melt, and vaporization mechanisms for rock and cement removal in each lithology, including laser and rock properties, and conditions that optimize cutting through a steel liner

- An analysis of changes in physical and chemical properties to rock, cement and steel samples following laser exposure.

Task 4.5 Modeled Effects of Energy Transfer in a Laser Perforation Shot Develop a predictive model of the processes that occur during laser/material interaction based principally on transport equations of mass, momentum and energy conservation. 


\section{Experimental Methods}

Experiments were performed at Gas Technology Institute in Des Plaines, IL at their High Power Laser Applications Laboratory. This lab was developed as a means to investigate alternative methods to conventional rock removal in accessing targeted subsurface accumulations, including energy reserves, minerals, aquifers, and pollutants. The $5.34 \mathrm{~kW}$ ytterbium-doped multi-clad fiber laser was used exclusively to perform the experimental work.

\section{Specific Energy Calculations}

In order to break rock by mechanically or thermally induced stresses, sufficient power must be applied to the rock such that the induced stresses exceed the rock's strength. Similarly, when fusing rock, sufficient heat must be generated that exceed the melting temperature of the rock. Once these threshold values of power and energy are exceeded, the amount of energy required to break or remove a unit volume of rock remains nearly constant. This energy parameter, which is a measure of the efficiency of the rock destruction technique, is defined as specific energy (SE). The term SE is associated with various definitions and is commonly used by the drilling industry in discussions of the efficiency of mechanical drilling, particularly in measuring effectiveness of new bit designs. SE is defined in this experimental work as the amount of energy required to remove a unit volume of rock and is relationally represented as follows:

$$
\mathrm{SE}(\mathrm{kJ} / \mathrm{cc})=\text { Energy input / volume removed }
$$

\section{Parameters Affecting SE Measurements.}

There are three basic phenomena evident in the process of radiant energy transfer to solids: reflection, scattering and absorption of radiation. The flow of energy of an incident electromagnetic wave $\left(E_{\text {inc }}\right)$ is divided into these parts:

$$
\mathrm{E}_{\mathrm{inc}}=\mathrm{E}_{\mathrm{refl}}+\mathrm{E}_{\mathrm{sc}}+\mathrm{E}_{\mathrm{abs}}
$$

Where $\mathrm{E}_{\mathrm{refl}}, \mathrm{E}_{\mathrm{sc}}$, and $\mathrm{E}_{\mathrm{abs}}$ are reflected, scattered and absorbed fractions of the energy flow of the incident wave, respectively.

If a surface is a planar one, like a mirror, then much of the energy is reflected. Rough surfaces mainly scatter the incident radiation. The reflectivity is determined by the composition of the solid, while the scattering of radiation is determined by wavelength, $\lambda$. It is the absorbed energy that gives rise to the rock heating and destruction. Reflection and scattering represent energy losses that occur apart from the absorbed energy. Minimizing fractions of reflected and scattered energy losses will, consequently, maximize the energy available for transfer to a rock for destruction. 
There are factors that affect the amount of absorbed energy transferred to the rock samples, known as secondary effects, and include the creation of melted materials, beam absorbing exsolved gases in the lased hole and induced fractures in the surrounding rock. When applying high power lasers on rocks, the laser can spall, melt, or vaporize the rock as the energy transferred to the rock raises its temperature locally. Mineral melt begins to occur when the rate of heat dissipation by the rock is exceeded by the rate of energy absorbed by the rock. As time increases, energy accumulates in the form of heat, raising the local temperature of the minerals to their melting points, forming a glassy melt.

The amount of melt is a function of the mineralogy of the rock and the intergranular space of the rock matrix. The closer the grains are to one another, the more heat will be transferred, resulting in more melt in the rocks. However, for tightly packed grains, the heat conductivity could reach higher values dissipating the heat at a faster rate, reducing the amount of melted material. Also, some minerals decompose and produce gas. As a result, the melt and gases require part of the laser energy for their creation, so a smaller percentage of the total laser energy is transmitted to rock.

Fractures that form in the samples also have an impact on SE. It may be that fractures extending out from the laser created hole are beneficial to the removal process. However, it is our conclusion that the fractures seen in the tests are an artifact of the sample size and do not represent what will occur in the subsurface under in situ conditions.

For the purposes of this study, fractures represent losses of energy, which result in higher SE values. Fractures are classified as macro- and micro- fractures. The behavior of fractures is different from one rock type to another. This difference depends on intrinsic factors such as mineralogy, thermal properties of the rocks, volume of void space, dimension of the sample and the amount of stress applied. Mineralogy also affects fracture formation. Clays contain water and by subjecting the clays to higher temperatures, water will escape in the form of vapor. This increases the volume and pressure in the pore and can cause fractures. Sandstones and shales have high thermal conductivities and contain clays. Limestones, on the other hand, have low thermal conductivity and have low amounts of clay and quartz. Therefore, fractures are expected in sandstones and shales, but not in limestones.

Rocks, having a high thermal conductivity, transfer heat more efficiently and the temperature is more uniform within the rock. Therefore, for this type of rock, cooling occurs gradually along the core sample. For example, fractures in sandstones developed regularly, not randomly. High temperatures resulting from the energy of the laser beam causes quartz grains to expand. At $600{ }^{\circ} \mathrm{C}$ $\left(1112^{\circ} \mathrm{F}\right)$ quartz grains expand by $1.75 \%$ of the original size. In the case of full 
grain contact (low void space), grains have less space to expand and fractures develop ${ }^{3}$.

The dimensions of the sample can affect the behavior of the fractures. It has been observed from the previous tests ${ }^{4}$ that the $2.54 \mathrm{~cm}$ (1.0 in.) diameter cores are highly fractured around the hole, while the $5.08 \mathrm{~cm}$ ( $2.0 \mathrm{in}$.) diameter cores are less fractured. Finally, stress applied to the core minimizes the macro fractures, while the micro fractures will still remain.

\section{Rocks Used in this Investigation}

\section{Characterization of the Samples}

Tests were conducted on sandstone and limestone samples. Berea sandstone is a standard quarry rock used in the petroleum industry for laboratory testing. Other notable Berea sandstone characteristics include: relative homogeneous physical characteristics including high silica content; common use in laboratory studies of rock; and extensive body of experimental data and literature.

Bedford limestone was procured from a local Illinois quarry, and was selected due to its relatively consistent and uniform characteristics.

For both rock types selected, it was important that both were available in large block sizes due to experimental design. Although actual sandstone and limestone reservoir core samples were available, sample size and consistent physical characteristics were more limited than quarry samples.

\section{General Rock Properties}

Microscopic properties, such as mineralogy, clay content, and microfractures, were determined using a scanning electron microscope with the energy dispersive system (SEM-EDS), x-ray diffraction (XRD), and thin sections. Melting temperatures of these rocks were measured using differential thermal analysis (DTA).

The Pressure Decay Profile Permeameter (PDPK) was used to characterize the rocks before and after lasing. The PDPK measures point permeability at ambient conditions, Klinkenberg slip factor and the non-Darcy flow coefficient (Forchheimer). The PDPK is reliable down to a permeability of $0.001 \mathrm{md}$ and experience has shown it to be repeatable and accurate. This non-destructive, unsteady-state test can measure permeability on irregular shapes, therefore, it an excellent tool to analyze permeability before and after beam exposure.

\footnotetext{
${ }^{3}$ W.H. Somerton, 1992.

${ }^{4}$ R.M. Graves and D.G. O'Brien, 1998
} 


\section{Results and Discussion}

\section{High Pressure Perforation Simulation}

Objective: To simulate perforation under in-situ conditions by applying axial, pore and confining pressures on sandstone and limestone core samples.

Procedure: In order to perform high pressure tests on rock, a tri-axial pressure cell was designed to allow multiple pressure conditions, a simulated pressurized wellbore, a window for the laser beam to interface with the sample, and ejection ports for lased material.

As part of the laser perforation study, tests were conducted with the tri-axial pressure cell to give us an initial understanding on how high pressure conditions similar to that found downhole influence the laser/rock interaction process. The laser used in this experiment was a $5.34 \mathrm{~kW}$ ytterbium-doped multiclad fiber laser with an emission wavelength of 1.07 microns. The tri-axial pressure cell rated at 20,684 $\mathrm{kPa}$ (3000 psig) was designed for this experiment to allow laser beam exposure to a $10.16 \mathrm{~cm}$ (4.0 in) diameter by $15.24 \mathrm{~cm}$ (6.0 in) length pressure-charged rock core by means of a sapphire window. Maximum testing pressures performed by the manufacturer were $31,026 \mathrm{kPa}$ (4500 psig).

Between the window and the core is a chamber that simulates a wellbore, and can be independently charged with pressure to simulate over-balanced conditions. At-balance conditions are simulated with ambient pressure in the wellbore chamber and no pore pressure in the rock sample. Underbalanced conditions are simulated with ambient conditions in the wellbore chamber and pore pressure in the rock sample.

Ports located in the wellbore chamber allow ejection of cuttings and other materials. The design of the wellbore chamber minimizes the exposure of the optics to all material ejected from the sample during the lasing process. The design has proven successful in this application, and will be incorporated in future field prototype tool designs.

The concepts integrated into this high pressure perforation cell were developed at GTI and tested several times before the test chamber was built. Concepts that were developed for the cell included:

- Simultaneous application of axial, confining and pore pressure

- Testing of effective purge system under confined volume at high pressure (Removing debris from confined volume at high pressure was a major issue)

- Lasing core inside a cell at high pressure with minimum temperature rise of cell parts (safety issue)

Pressure transducers for confining, axial and pore pressure ports were calibrated, connected to cell assembly and tested for tri-axial pressure conditions. 


\section{High Pressure Perforation Cell Design and Development}

When designing the high pressure laser perforation cell, the following key design criteria where identified as part of the unique application and complexity of the operation:

- Safety

- $\quad$ Pore pressure flexibility

- Purging under tri-axial pressure conditions

- Maintaining clear optics path and clean lenses

Operating the laser perforation testing cell under high pressure conditions and with a high power laser beam presents a serious safety issue. The cell also required the capability to apply multiple combinations of confining, axial and pore pressure, while circulating a fluid to remove cuttings in a manner to keep the optics clean and a clear path for the beam.

The original design for the laser perforation cell was of a conventional tri-axial cell used for flow measurement (Figure 2). Evaluation of this design determined that major modifications would need to be identified, designed, and tested before a prototype could be built.

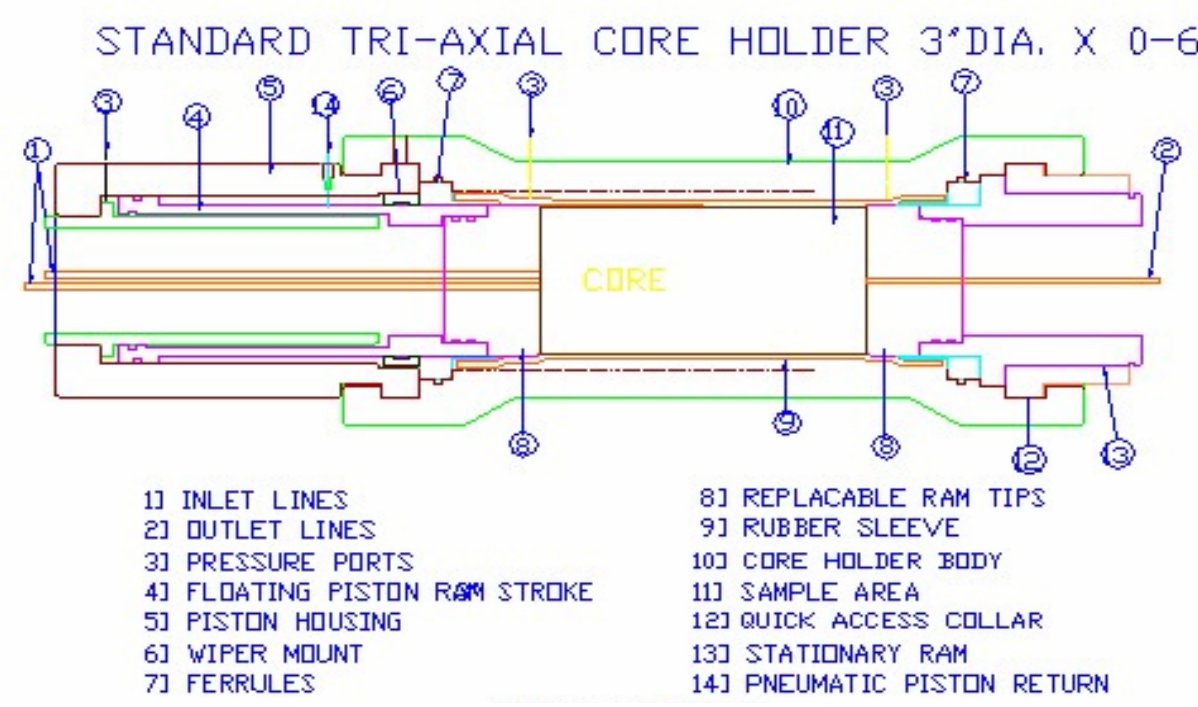

Figure 2. Standard tri-axial cell design prior to modification for HPFL perforation. 
Concept experiments where designed and tested to understand how best to circulate a fluid, while lasing, to assist in the cuttings removal. An initial test was conducted with a $5.08 \mathrm{~cm}$ (2.0 in) ID tube fitted with a cover lens window on one end, a target rock core on the other and ventilation holes to allow debris to exit. Compressed air is used to keep the cover lens free of cuttings dust and debris, as well as provide an assist for material removal for the beam (Figure 3). The purpose of this experiment was to determine if the rock cuttings could be removed from inside the tubing without material accumulating on the cover lens window.

The result of this experiment was as expected: Dust had accumulated on the cover lens. Energy from the beam was transferred to the dust, and then to the cover lens. The temperature of the glass increased non-uniformly and lead to its failure. Figure 4 shows the lens before and after the experiment.

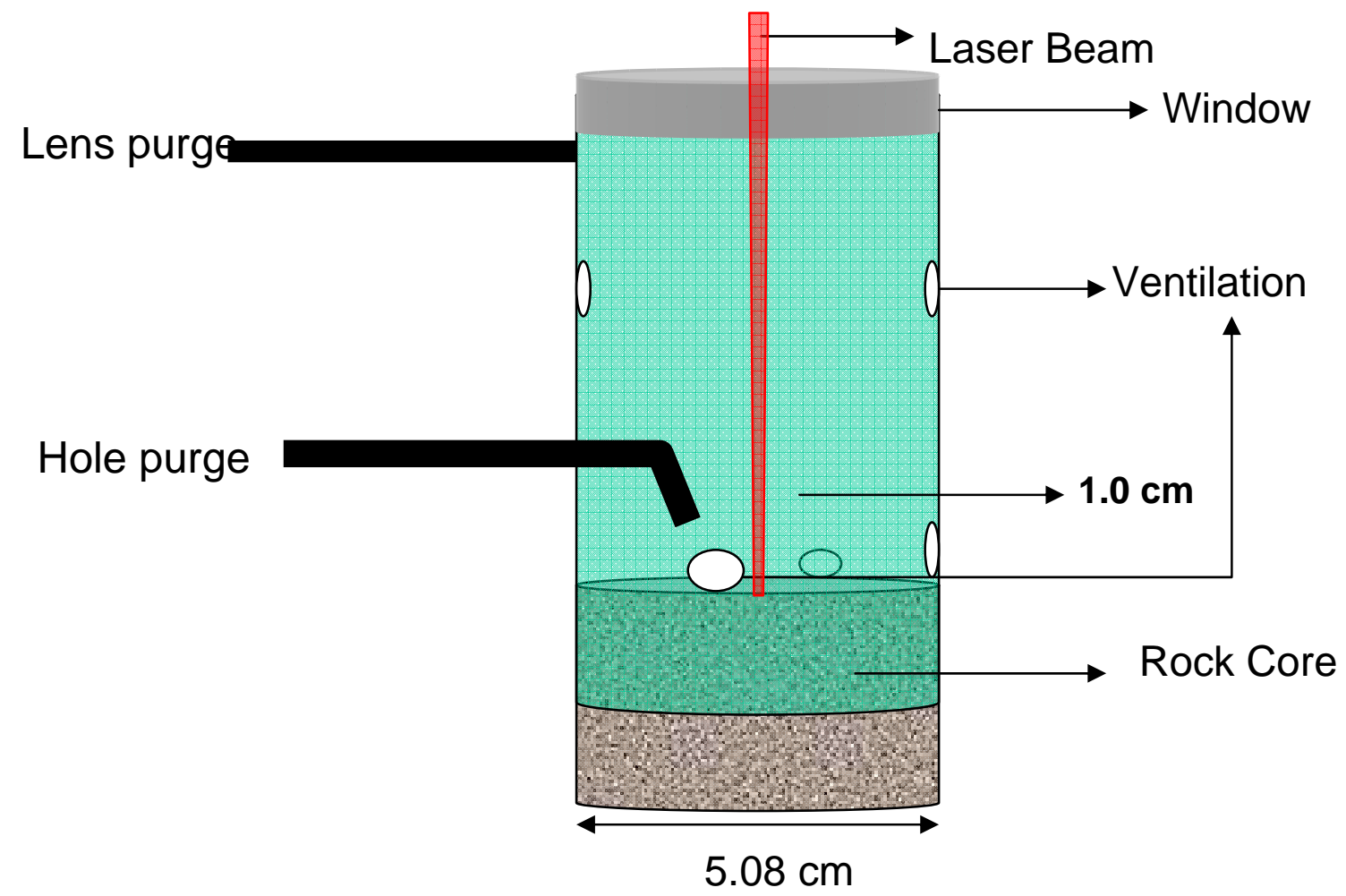

Figure 3. High pressure perforation cell proof-of-concept tube with a cover lens. 
Before lasing

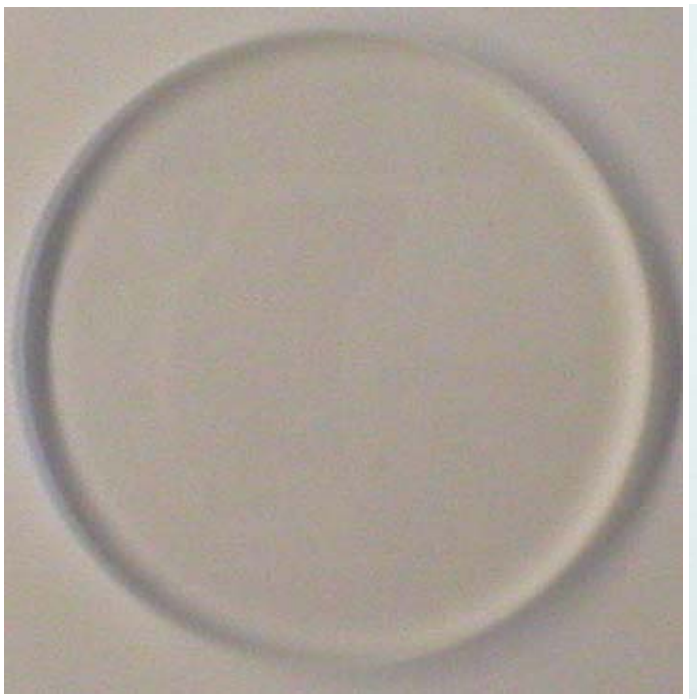

After lasing

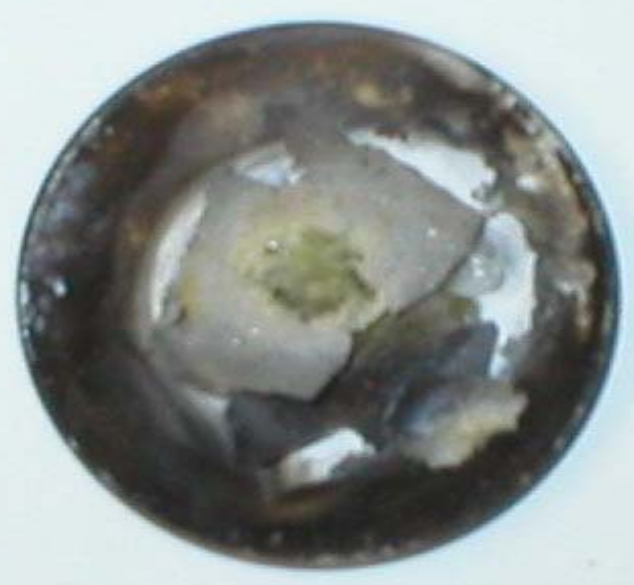

Figure 4. Cover lenses before and after lasing during high pressure perforation cell experiment.

Since lasing directly through tube resulted in dust accumulation and beam blocking, an alternative design was needed to prevent dust from reaching the cover lens. A conical design was investigated that would reduce the area available for dust to reach the cover lens. In this experiment, the same set-up was used with a conical restriction put in place between the cover lens and the sample. The larger diameter of the cone was closer to the cover glass. The purging tube was inserted between the cone and the cover lens such that the compressed air flowed through the narrow opening in the direction of and coaxially with the laser beam, thereby deflecting debris away from the cover lens and toward the ventilation holes (Figure 5).

Ventilation holes are located around the tube between the cone and the rock sample which will allow the dust and the particles to exit. The shape of the cone assists in directing debris to the ventilation holes. Figure 6 shows the experimental set-up for the cone structure, while Figure 7 shows the chamber while the laser is firing.

The cone was inserted in a transparent tube to allow visibility and monitoring particle and dust behavior in the tube. Modifications were made to optimize location of system elements, including the distance between the cover lens and the surface of the sample, the purging angle and ventilation opening diameter. 


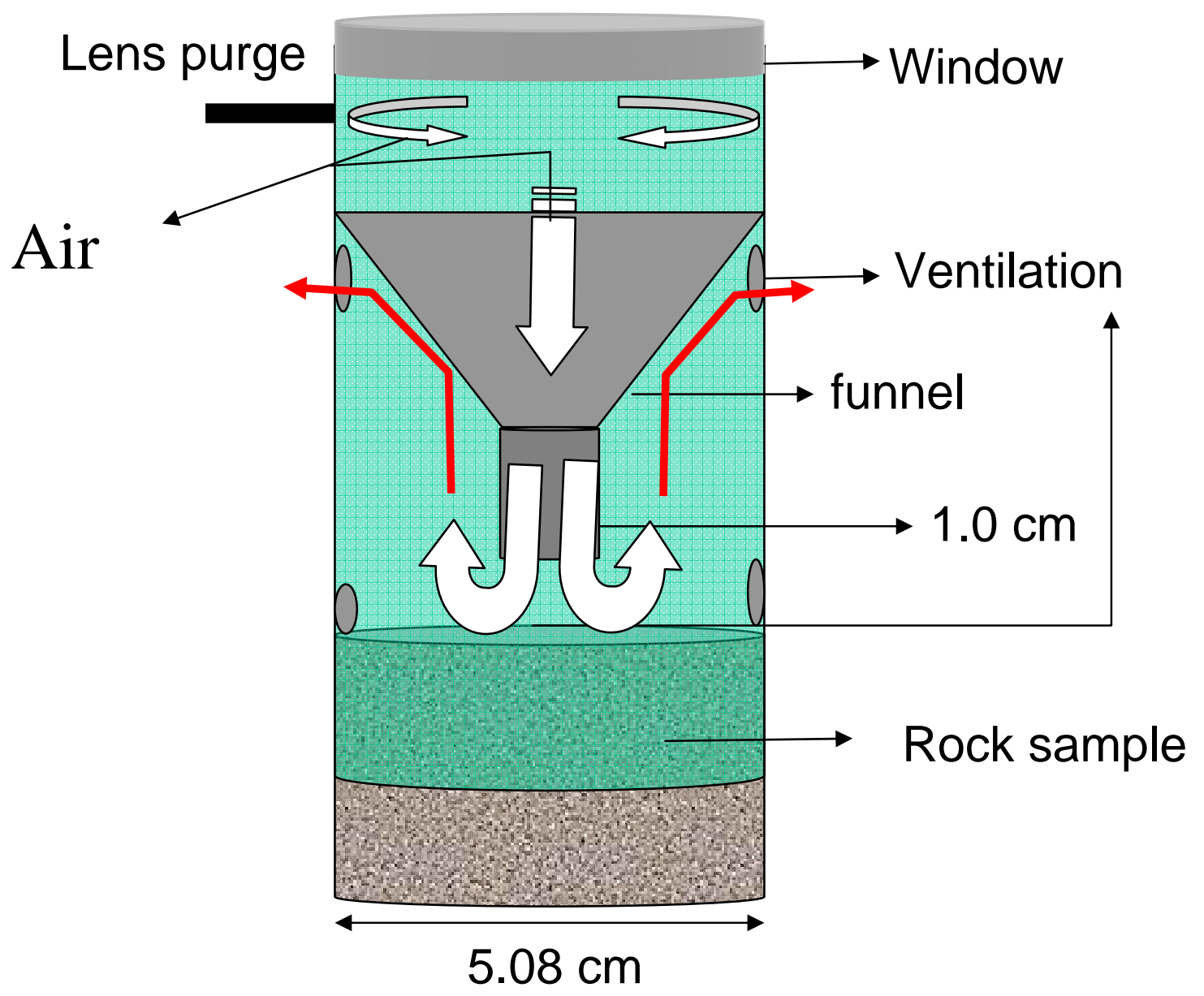

Figure 5. High pressure perforation cell proof-of-concept tube with funnel and a cover lens. 


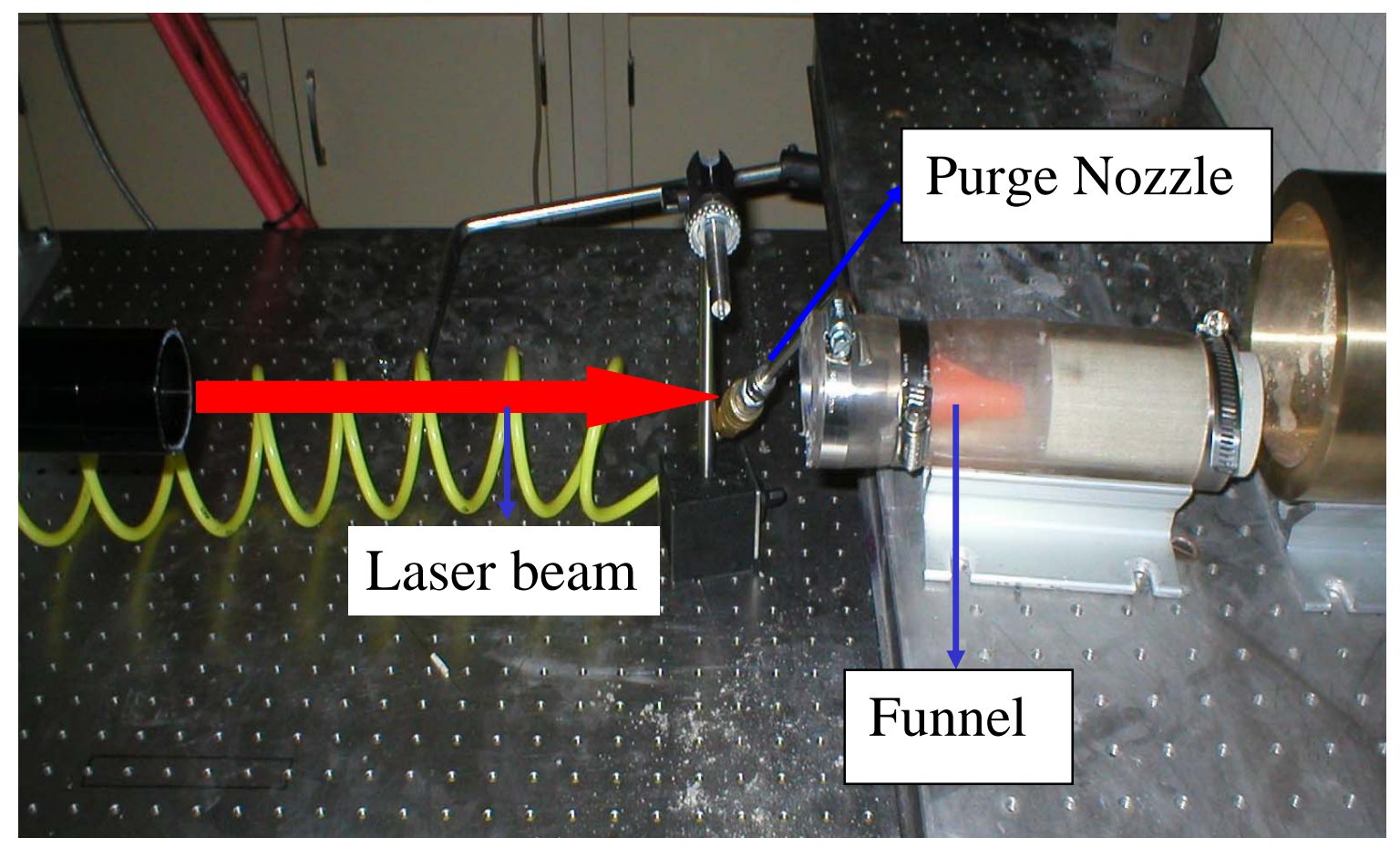

Figure 6. Experimental set-up of high pressure perforation cell proof-of-concept test.

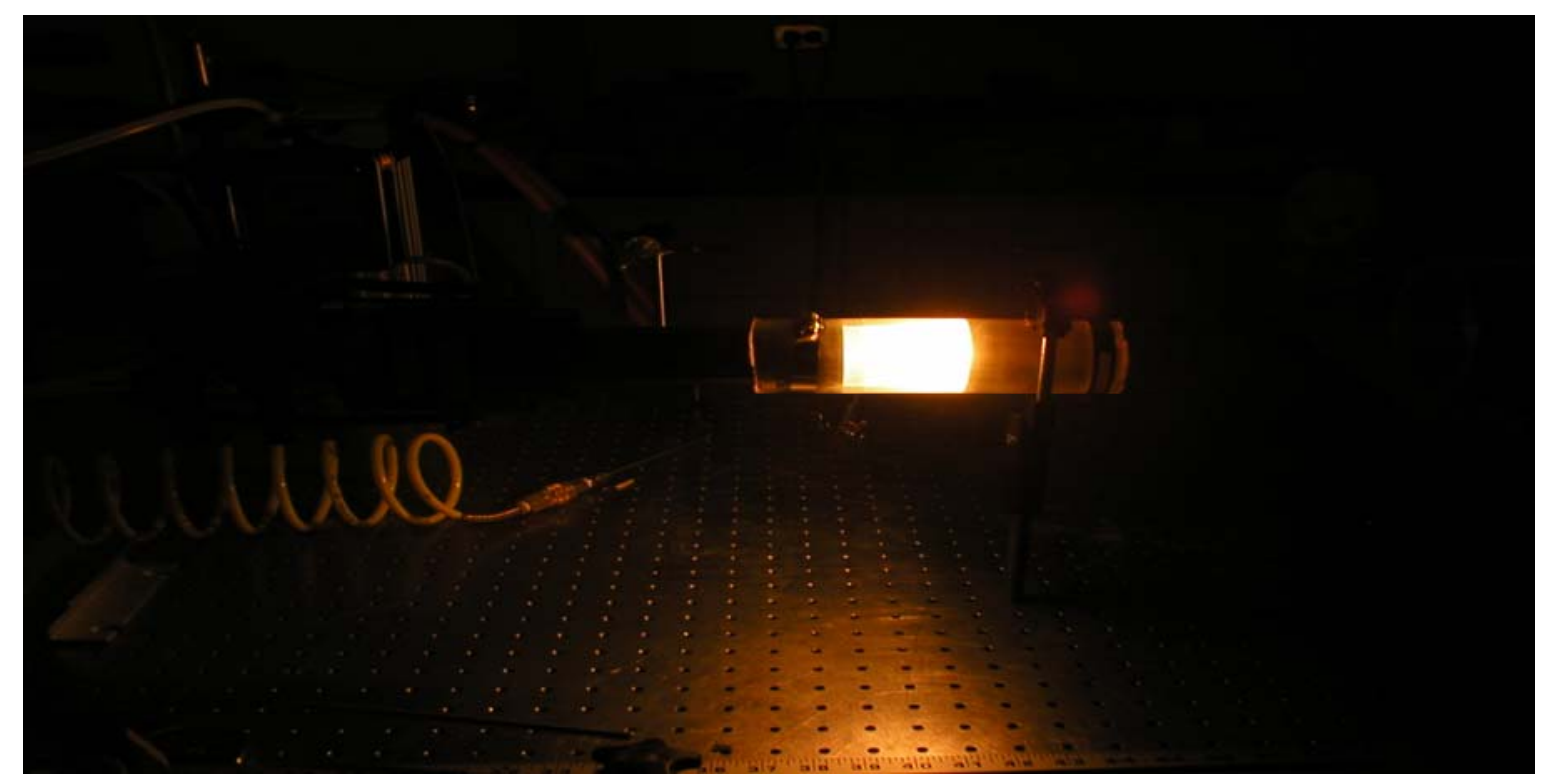

Figure 7. Laser firing during high pressure perforation cell proof-of-concept test.

Once the chamber design was optimized on the transparent plastic tube prototype, a $5.08 \mathrm{~cm}$ (2.0 in) ID copper test chamber was assembled. In the Figure 8A, the interior of the chamber is shown with cone and ventilation holes. Figure $8 \mathrm{~B}$ depicts the exterior view of the chamber with the ventilation holes. 


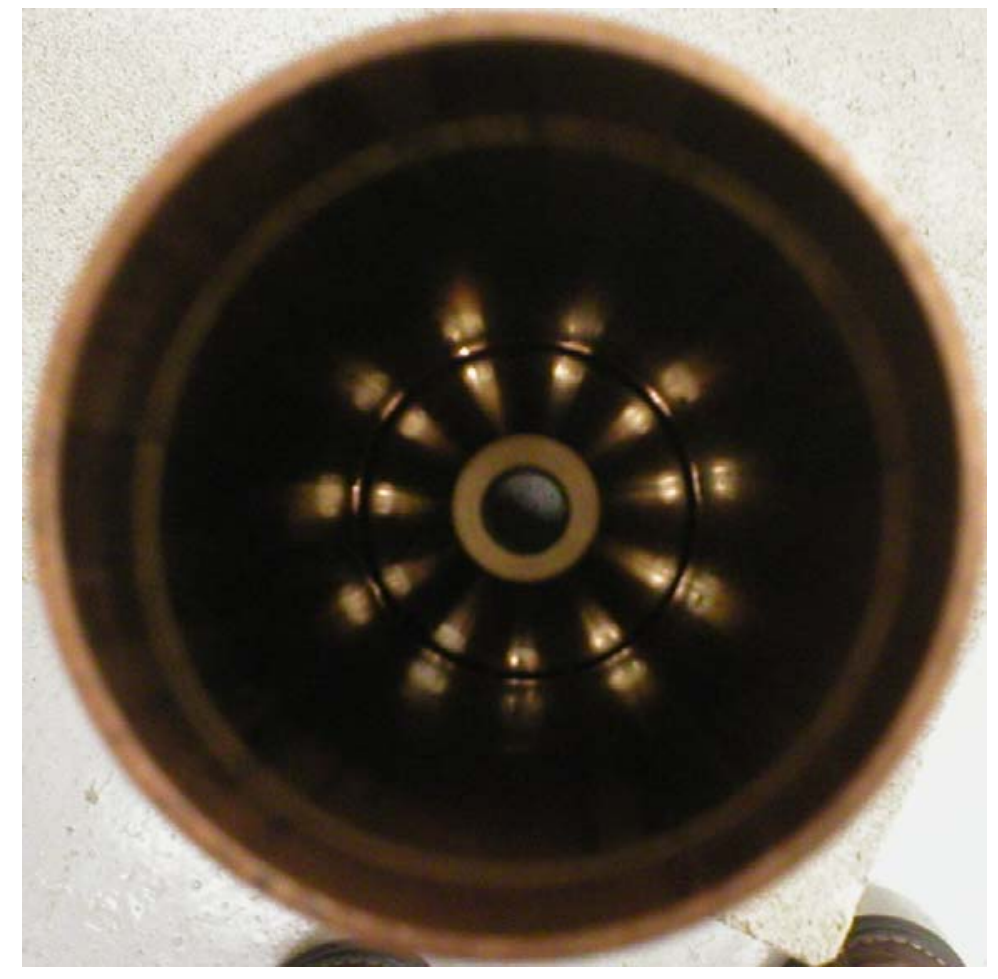

A

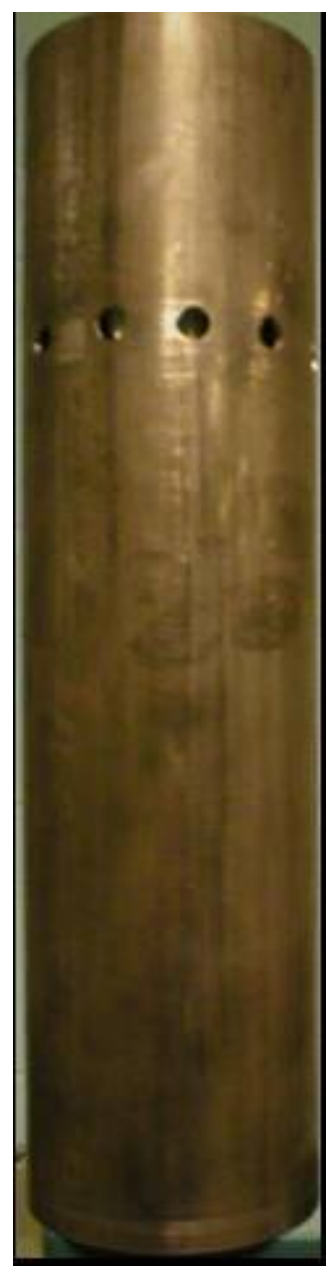

$B$

Figure 8. Interior (A) and exterior (B) views of $5.08 \mathrm{~cm}$ (2.0 in) ID copper tube mock-up used to test high pressure perforation test cell design.

Figure 9 shows the connection of the chamber tube with the purging system ready for the laser beam, and Figure 10 shows the tube in the dust enclosure before lasing. 


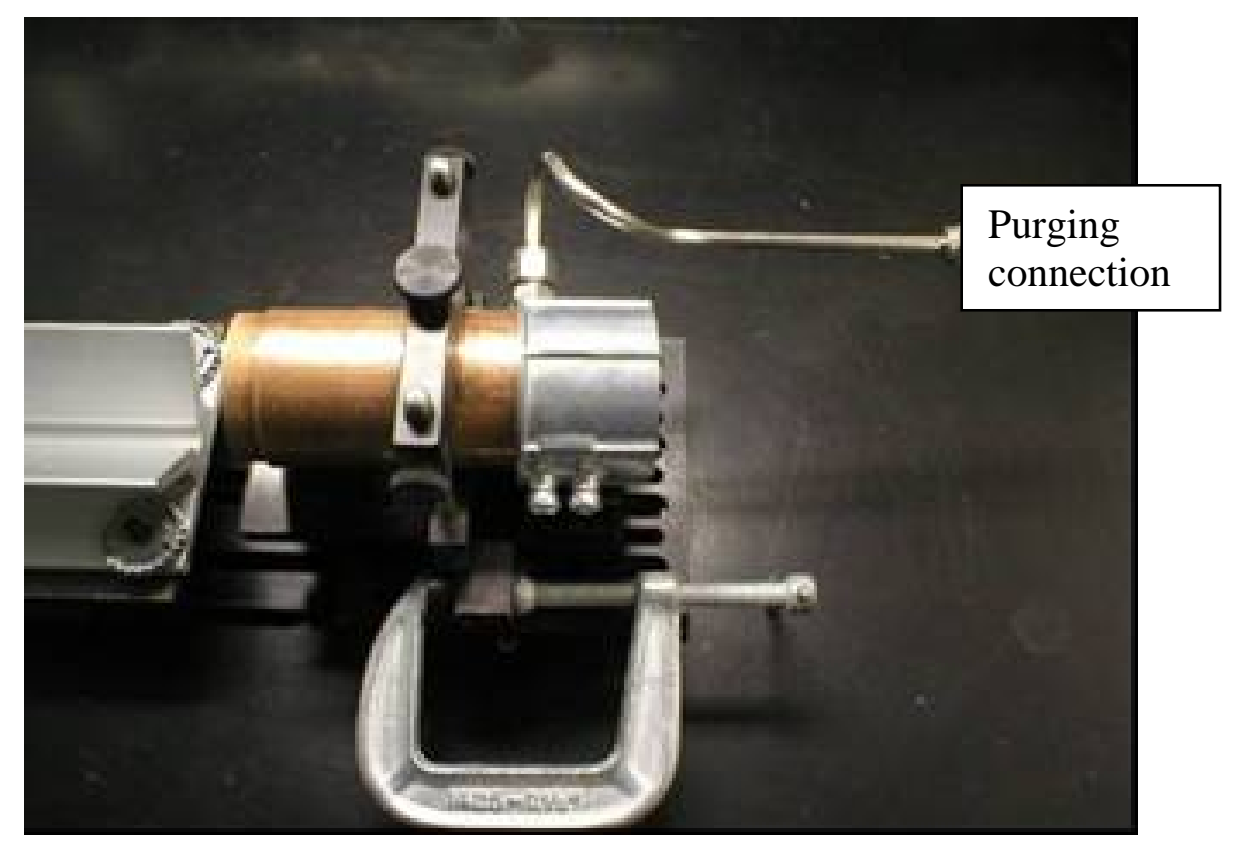

Figure 9. Copper tube mock-up with the purging connection.

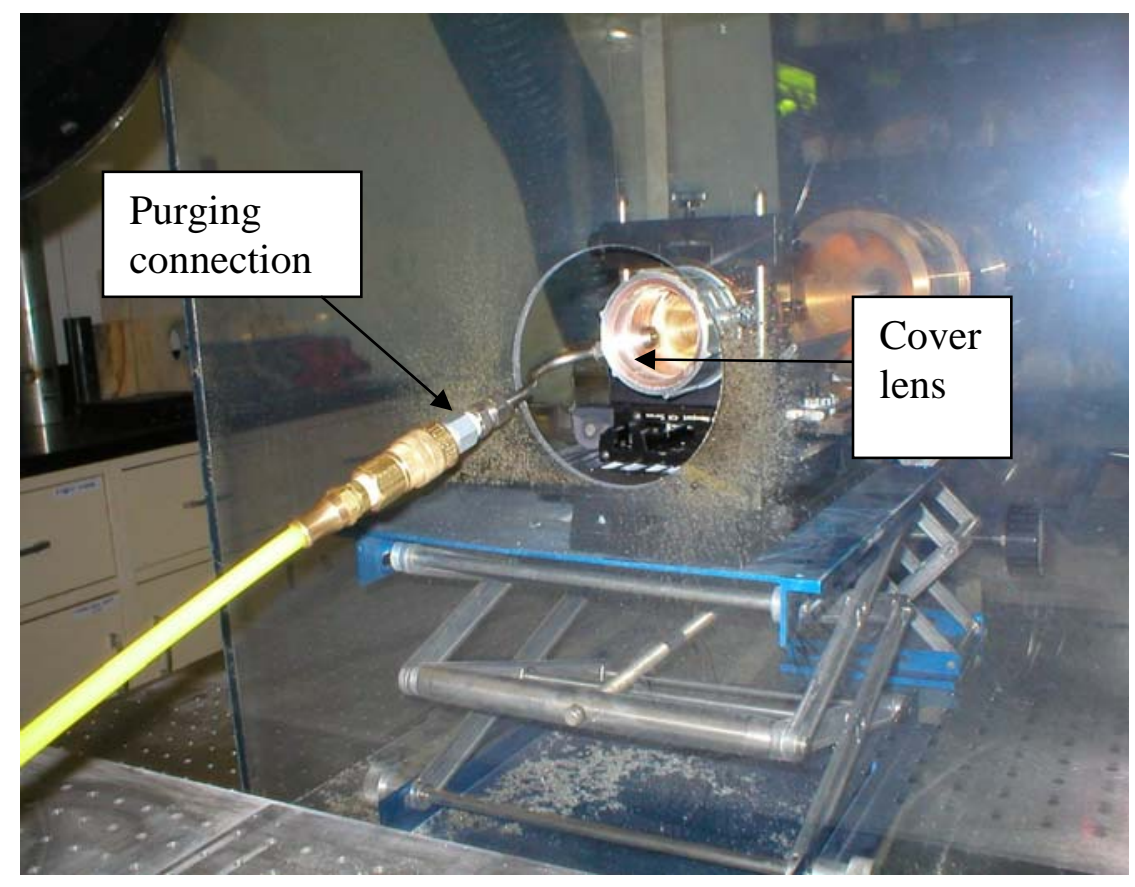

Figure 10. Copper tube mock-up assembly ready for laser application. 
An initial concept drawing of the high pressure laser perforation test cell is represented in Figure 11. The design incorporates the elements tested thus far, including optimized purging and ventilation with a cone structure.

Additionally, safety chambers have been added with in the event a breach occurs in an optical window. Relief valves were also added for safety.

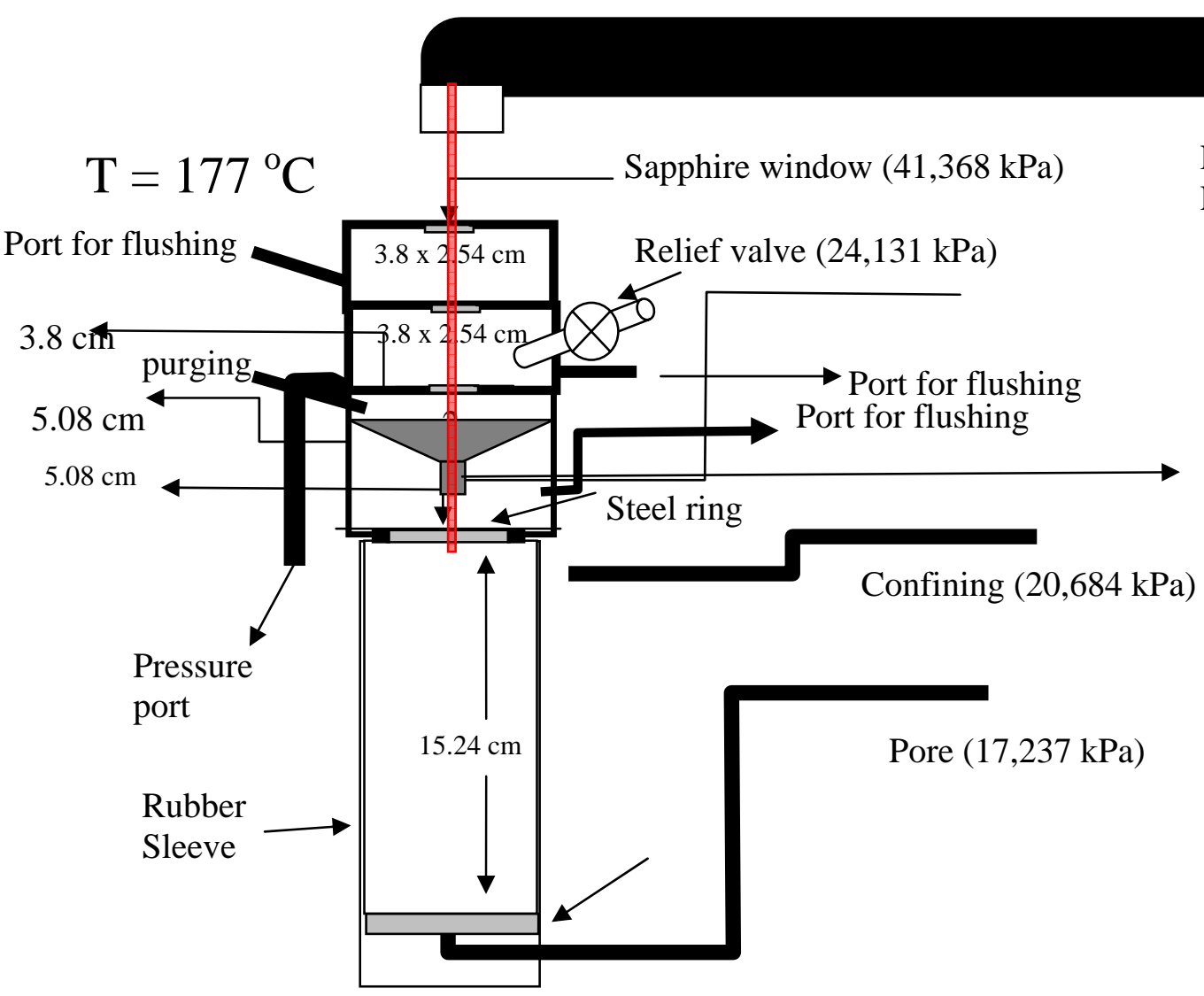

Figure 11. High pressure tri-axial cell concept for laser perforation testing under pressure conditions.

The high pressure laser perforation cell has the flexibility to

1. Perforate in under- or over-balanced conditions up to $20,684 \mathrm{kPa}$ (3000 psig)

2. Apply pore pressure and tri-axial pressure conditions

3. Purge with gas or liquid fluid

4. Test samples up to $10.16 \mathrm{~cm}$ (4.0 in) in diameter and $15.24 \mathrm{~cm}$ (6.0 in) length

5. Test wellbore simulated samples of rock, cement and steel 
Three chambers were designed through which the laser beam is transferred to the target. The chamber closest to the sample incorporates the deflection cone, purging fluid line and exhaust ports for ventilation. The remaining two chambers were designed to contain the system should an optical window fail. A pressure port is available to provide a positive pressure differential for simulating overbalanced conditions. Sapphire optical windows are rated up to 41,368 kPa (6000 psig). Relief valves allow excess pressure to exit the cell.

The final design of the high pressure cell is presented in Figure 12, and the disassembled cell is pictured in Figure 13.

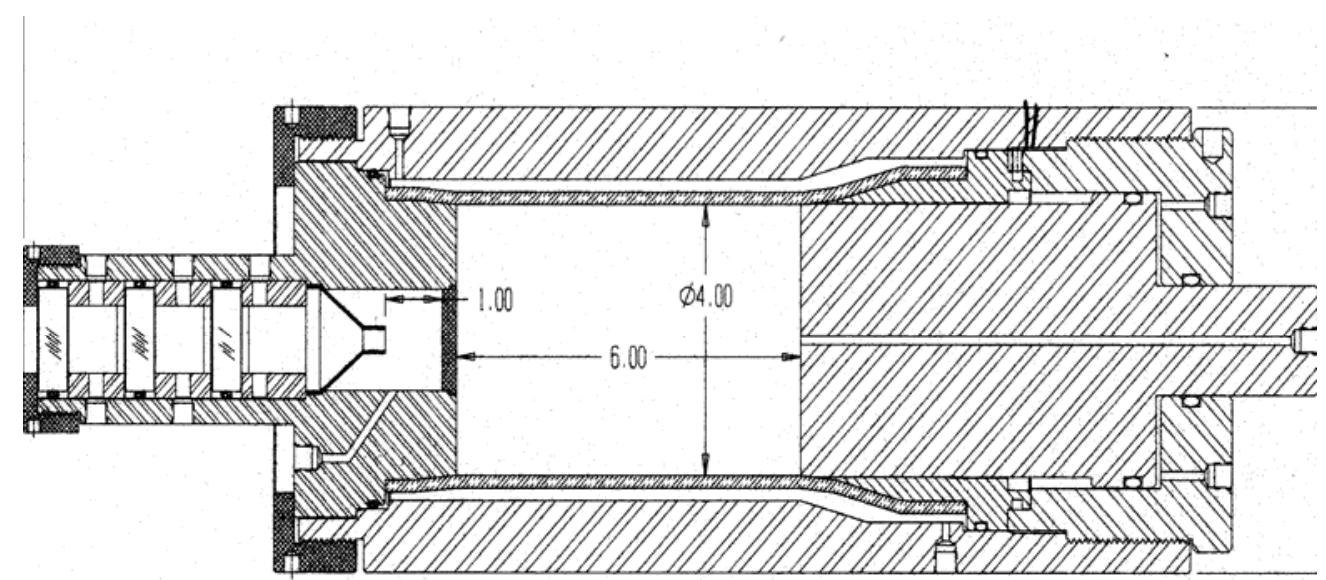

Figure 12. High pressure tri-axial cell design for laser perforation testing under pressure conditions.

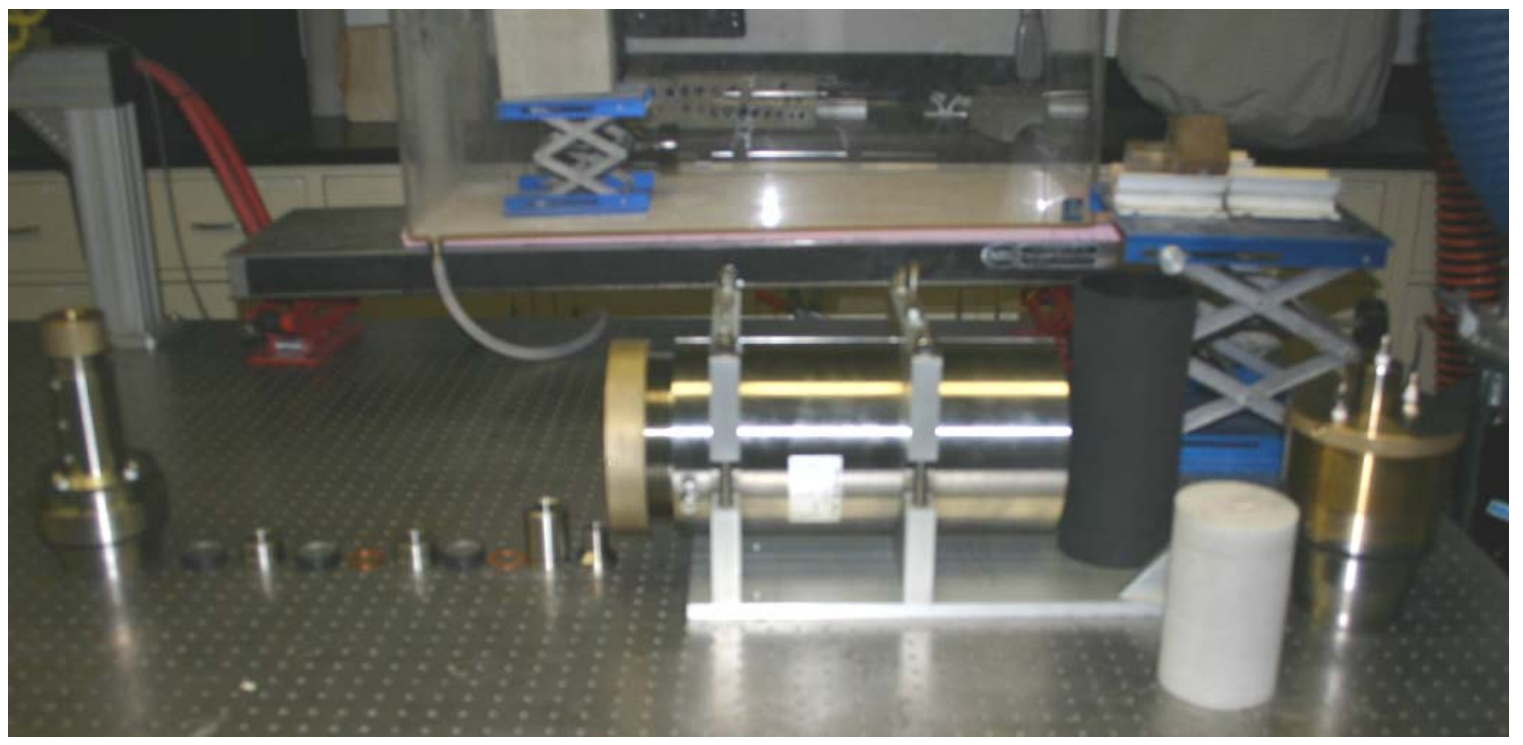

Figure 13. Completed high pressure tri-axial cell for in-situ laser perforation testing. 


\section{Perforation of Core Samples under High Pressure Conditions}

Objective: To simulate perforation under downhole conditions by applying axial and confining pressures (tri-axial load) on sandstone and limestone core samples.

Procedure: Initial tests were performed on cores of Berea sandstone and Bedford limestone under various conditions of axial, pore and confining pressures. For all cases, the laser settings remained the same. Full output power of $5.34 \mathrm{~kW}$ was applied continuously to each sample through the sapphire window of the pressure cell with a focused beam diameter of $0.889 \mathrm{~cm}(0.35 \mathrm{in})$ over $8.0 \mathrm{~s}$. The $0.889 \mathrm{~cm}(0.35 \mathrm{in})$ diameter beam was previously found to generate no boundary effects with $10.16 \mathrm{~cm}$ (4.0 in) diameter core. The amount of laser exposure time was calculated from previous laser rock interactions to allow penetration into the core without risk of penetrating the core's full length and avoiding possible damage to the pressure cell.

Results and Analysis

Five trials were performed on unsaturated samples of each rock type. A base case was established for each rock type by lasing samples in the cell at ambient pressure conditions. A second condition was tested on each rock type with confining and axial stress limited to about $6895 \mathrm{kPa}$ (1000 psig). Since the cores were not charged with pore pressure, a high pressure gas purge of 620.5 $\mathrm{kPa}$ (90 psig) through a $0.635 \mathrm{~cm}$ (0.25 in) nozzle assisted in particle removal.

A third condition was then tested for each rock type combined confining and axial stress limited to about $6895 \mathrm{kPa}$ (1000 psig), while charging the core to a pore pressure. No gas purge was provided as underbalanced conditions (greater pore pressure than wellbore pressure) served to eject particles from the charged core through pressure cell exit ports. Two additional trials were performed at balanced and underbalanced conditions with double the pressure settings.

To better understand the in-situ performance of lasers in the presence of reservoir fluids, sandstone and limestone cores were saturated in brine and liquid hydrocarbon prior to high pressure lasing. Pressure conditions for each rock type included confining and axial stress limited to about $6895 \mathrm{kPa}$ (1000 psig) with no pore pressure.

Figure 14 shows the experimental set up and Figure 15 shows the high pressure cell during the experiment. 


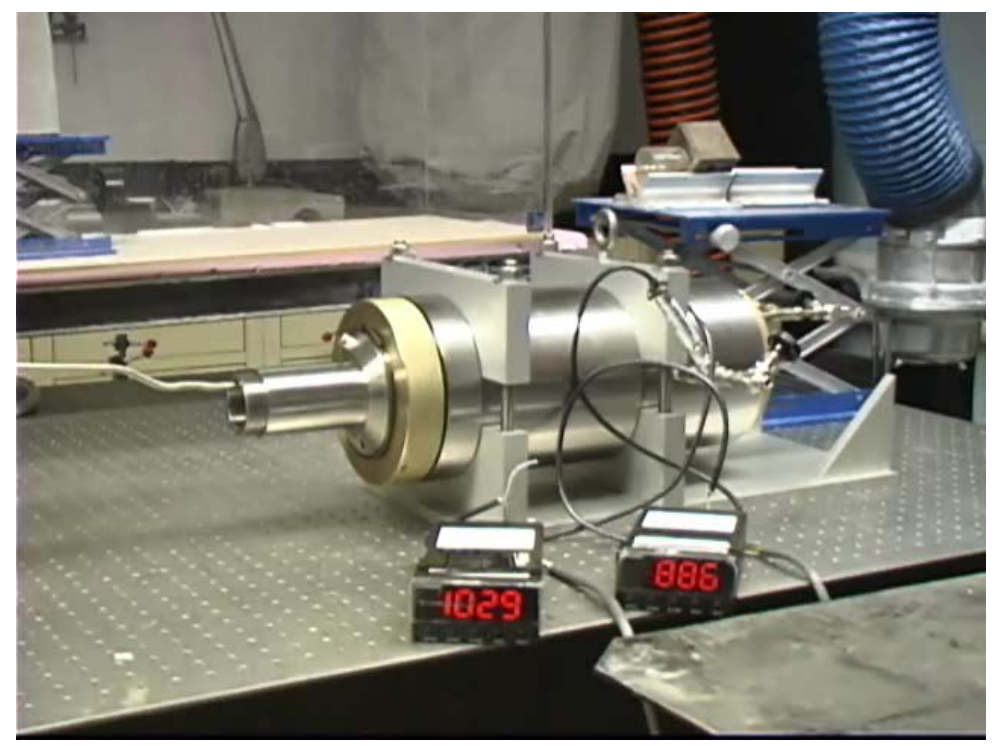

Figure 14. Experimental set up for perforation test in high pressure cell

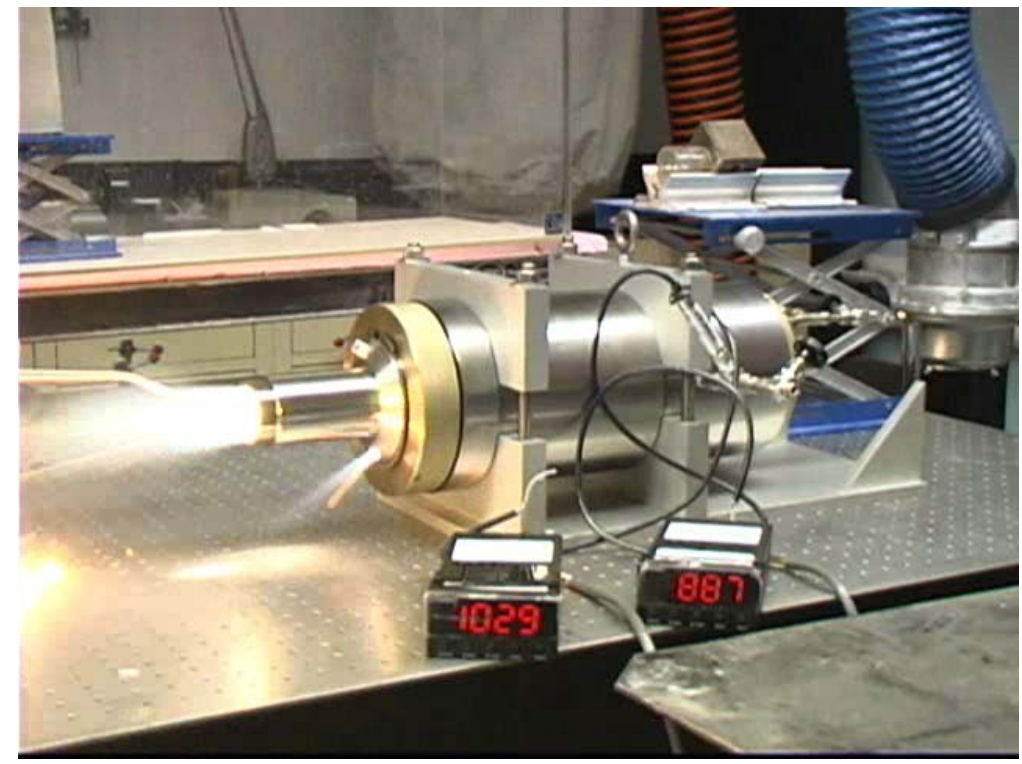

Figure 15. Perforation test in progress. 


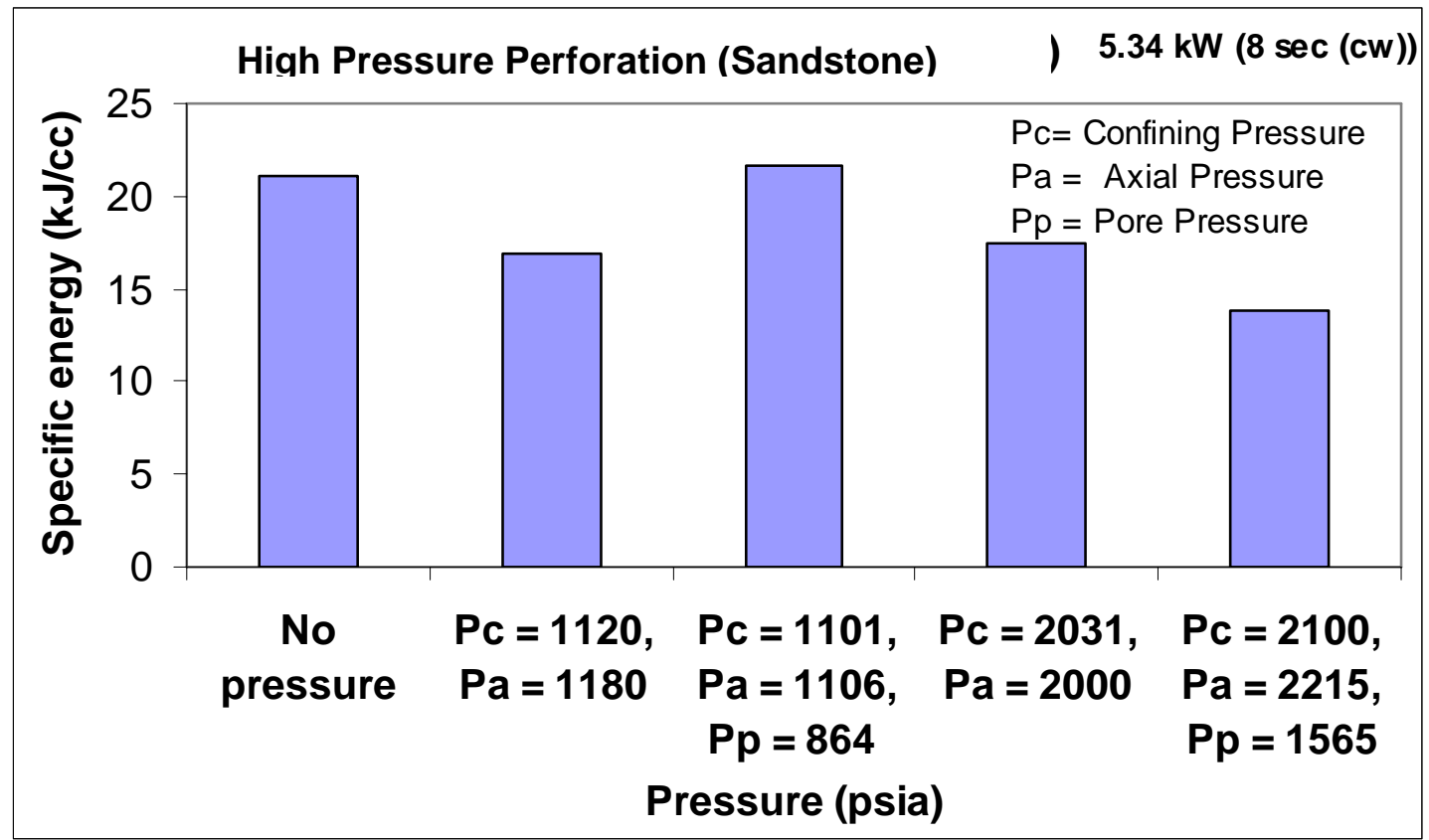

Figure 16. Comparison of SE values in sandstone as observed at various test cell pressure conditions.

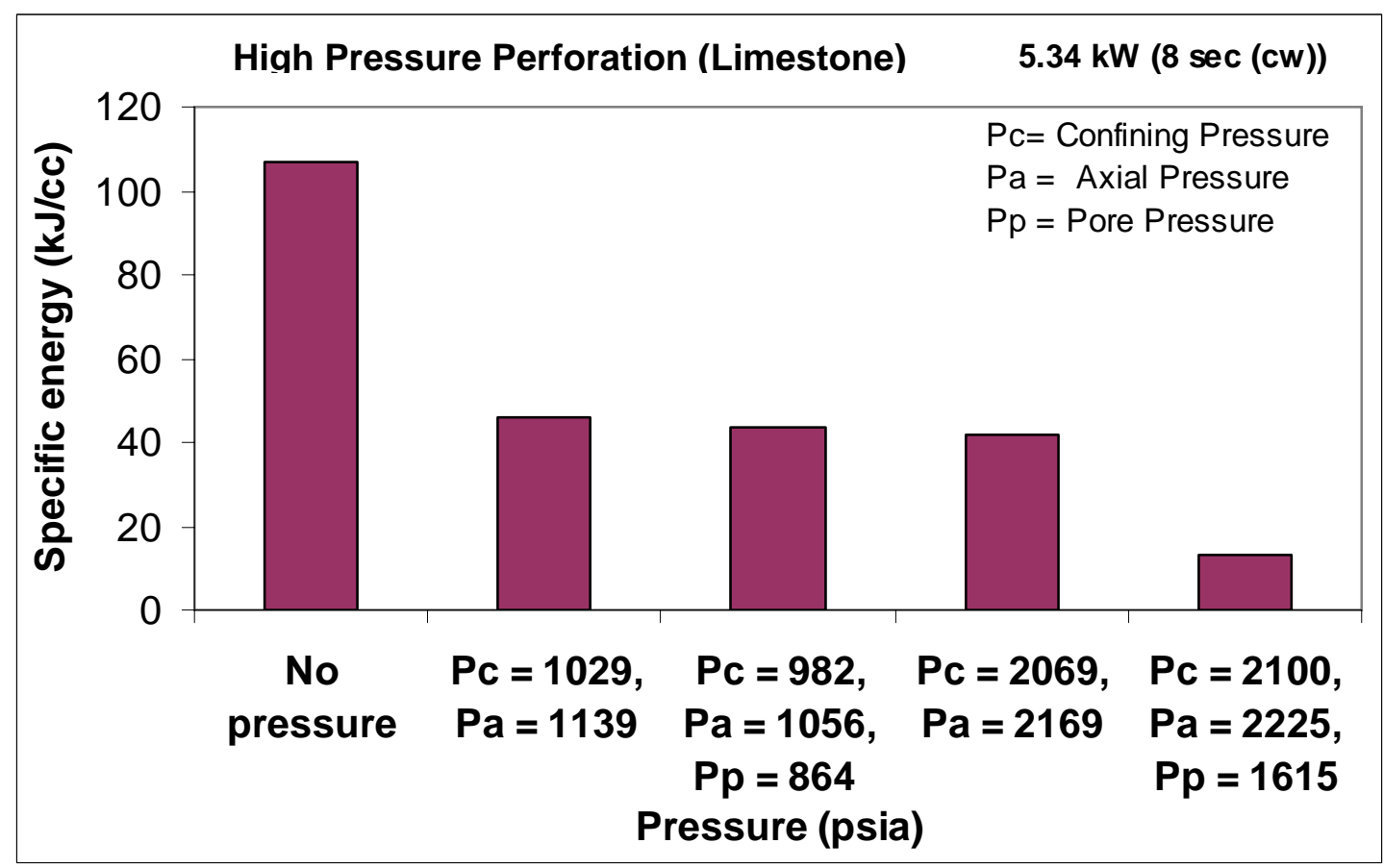

Figure 17. Comparison of SE values in limestone as observed at various test cell pressure conditions. 


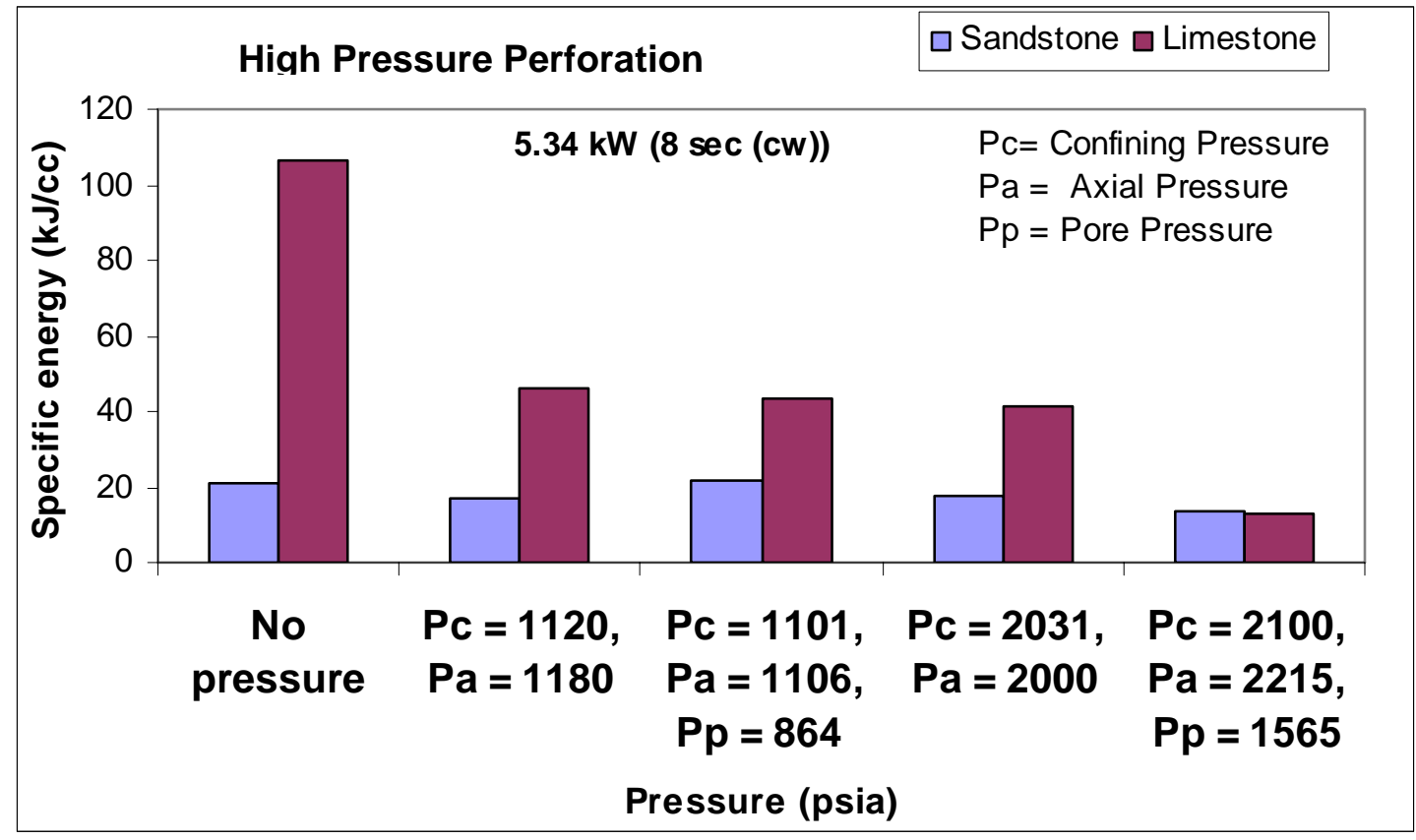

Figure 18. Comparison of SE values in limestone and sandstone as observed at various test cell pressure conditions.

The resulting data generated from the series of sample trials on sandstone and limestone have demonstrated that a laser perforation system will significantly benefit from the high pressure conditions encountered downhole. For both rock types, SE values decreased as confining and axial stresses increased. The effect was more apparent in the limestone than in the sandstone samples. Results from the sandstone and limestone core tests are presented in Figures 16, 17, and 18. Tabular results are presented in Appendix A.

Sandstone. The removal mechanism for Berea sandstone is spallation, where rapid differential thermal expansion causes grains and cementitious material to fracture. The base case for sandstone with no pressure had an SE value of 19.75 $\mathrm{kJ} / \mathrm{cc}$. The conditions are similar in many respects to much of the previous work performed in the lab. The sample is at ambient conditions during lasing and a gas purge nozzle assists in removing broken material.

The lowest SE value observed in sandstone was $12.91 \mathrm{~kJ} / \mathrm{cc}$, a 35\% reduction from the base case, resulting from the highest pressure values tested. Material removal was assisted with the differential between the pore pressure and wellbore chamber pressure. As this differential increases, material is more rapidly ejected from the tunnel, thus minimizing travel through the cutting beam and absorbing less beam energy after detaching from the rock matrix. With less beam energy absorbed by exiting particles, more is available for cutting, as evidenced by the drop in SE value.

At the pressures tested, confining and axial stress had a limited impact on SE values for sandstone. The stresses imparted on the sandstone matrix create 
tighter grain-to-grain contact and improved the thermal diffusivity of the rock. In both cases, material is purged with an assist gas with the same conditions for each trial.

Limestone. The removal mechanism for limestone is calcination where the energy of the laser beam causes a thermal dissociation of carbonates into carbon dioxide and calcium oxide (lime). Just as axial and confining stress compressed the sandstone, the effect was more evident in the limestone samples. This quarry limestone was originally unstressed, contributing to an SE drop of at least 60 percent due to closer grain-to grain contact and a more efficient calcination process.

The lowest SE value observed in limestone was at the highest pressure and stress conditions. Again, the differential pressure assisting in material removal was evident with a significantly lowered SE of $12.27 \mathrm{~kJ} / \mathrm{cc}, 88 \%$ lower than the base case.

The application of stress to the rock core allows the grains within the rock matrix to move closer to each other as the pore volume decreases. Failure of the rock can occur when the applied stress exceeds the strength of the rock. This failure was observed in the quarry limestone cores as they developed fractures along their length. Figure 19 shows a fracture that developed in a limestone test core when 15,272 kPa (2215 psig) stress was applied. Stress fractures were not evident in a similarly stressed sandstone sample in Figure 20. The strength properties of the sandstone were greater than the applied stress.

The sandstone core samples consist of grains bound by cementation, and have higher values of porosity and permeability than the limestone core samples (Figure 21). When a high power laser beam interacts with a core sample, heat transfer takes place from grain-to-grain by the more direct method of conduction, and across the void space by convection as seen in Figure 22. By applying stress to the limestone sample, more grains are in contact with one another, the void space is reduced, and heat is more efficiently transferred by conduction. This is evident in the data presented in Figure 17, as SE is substantially reduced from the base case under ambient conditions to each case under stressed conditions. 


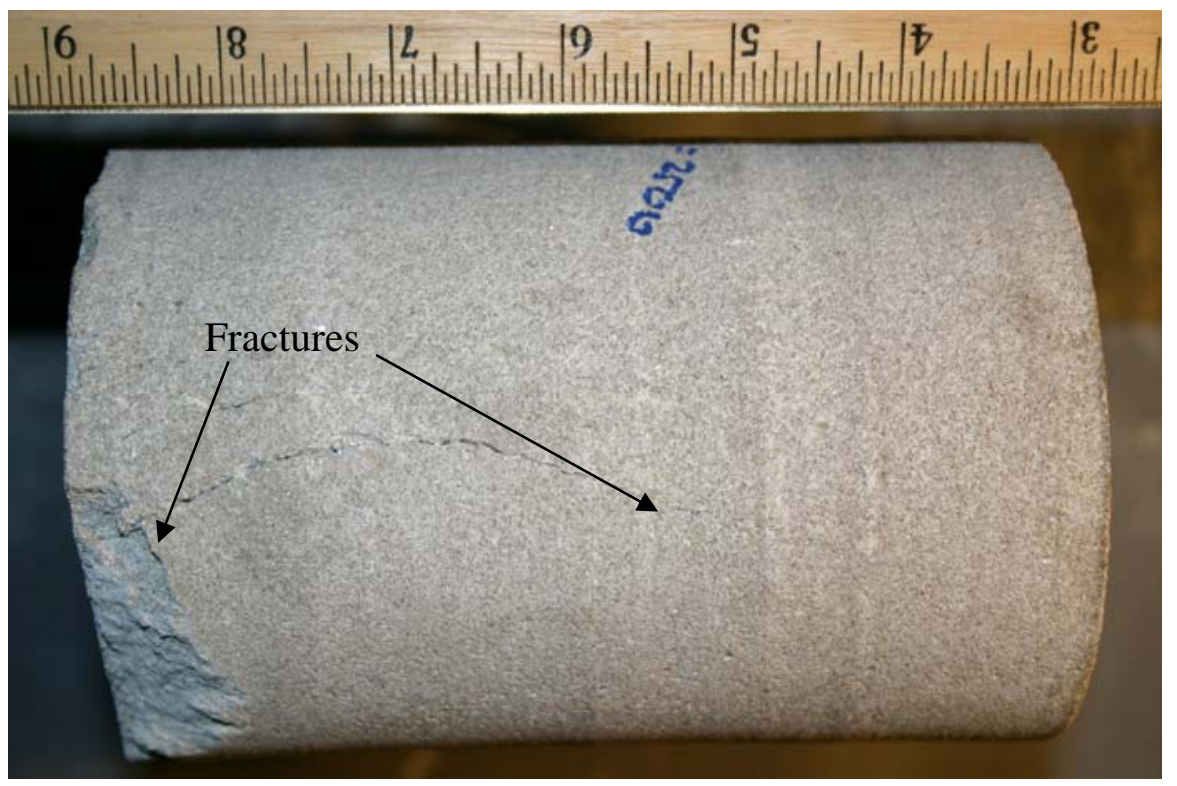

Figure 19. Post-high pressure perforation test of limestone exhibiting stress fractures

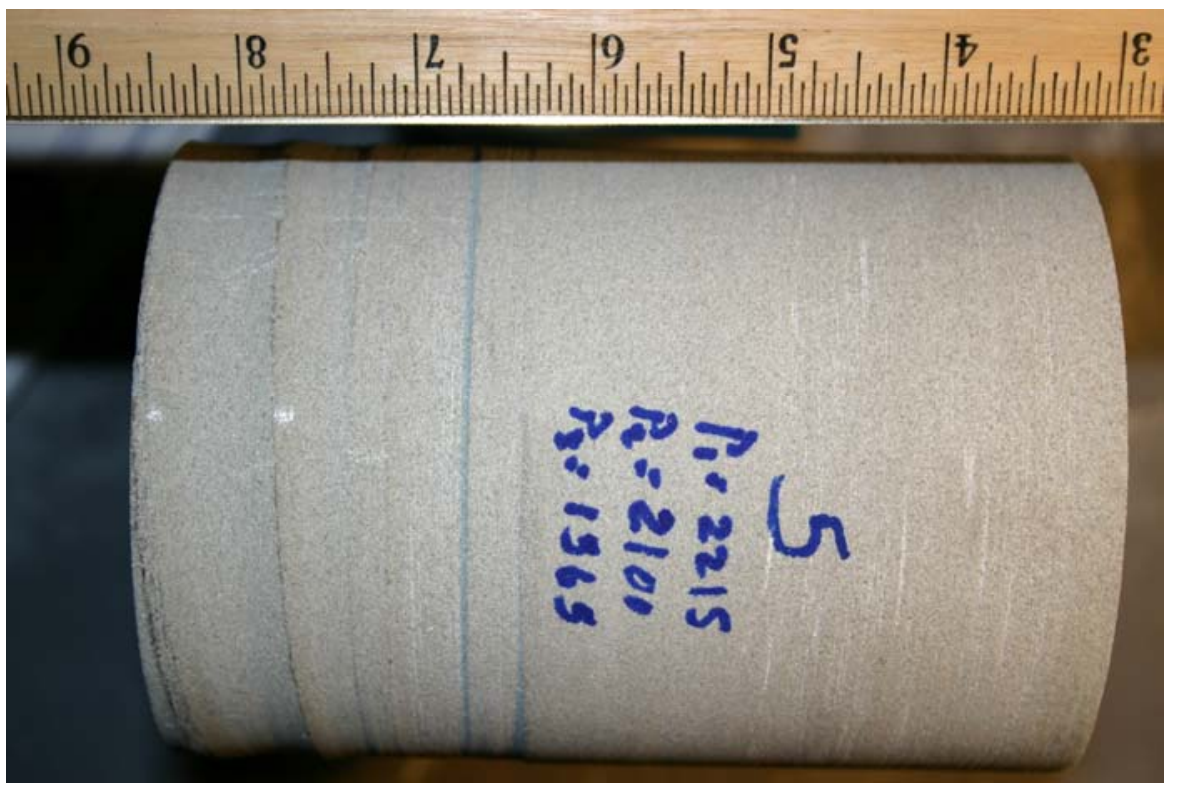

Figure 20. Sandstone samples show no post-test stress fractures. 


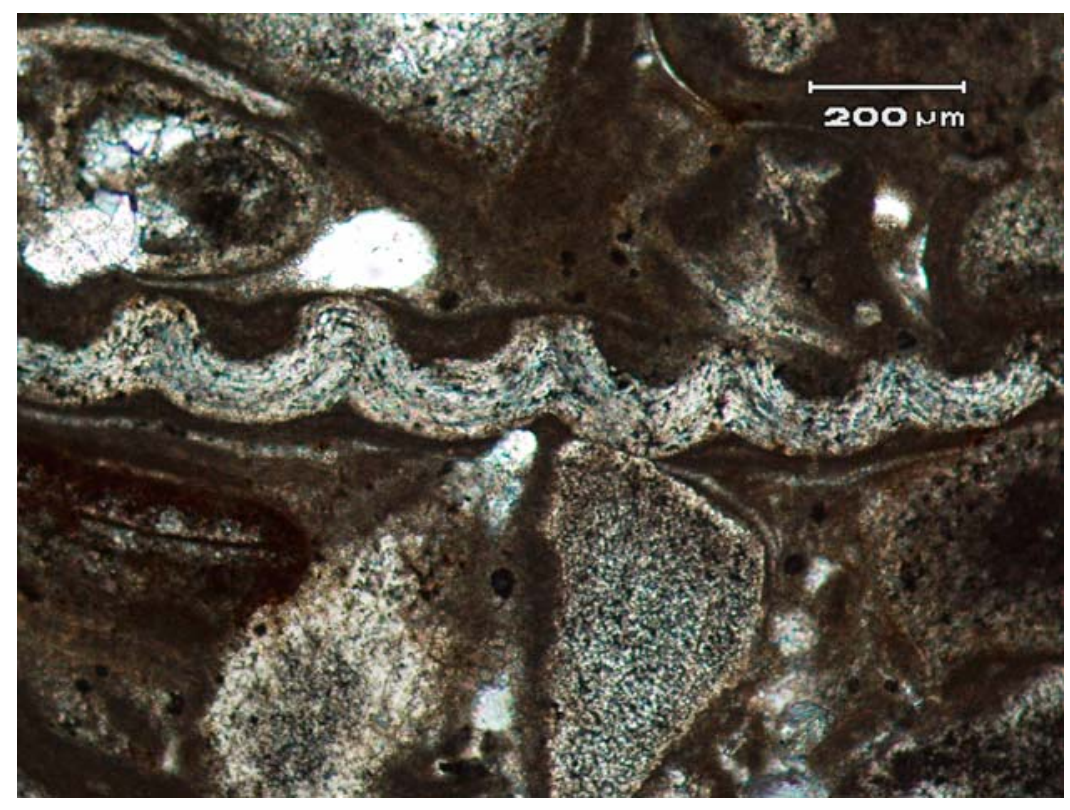

Figure 21. Thin section analysis from limestone used in perforation tests show low porosity and permeability with close grain contact. 


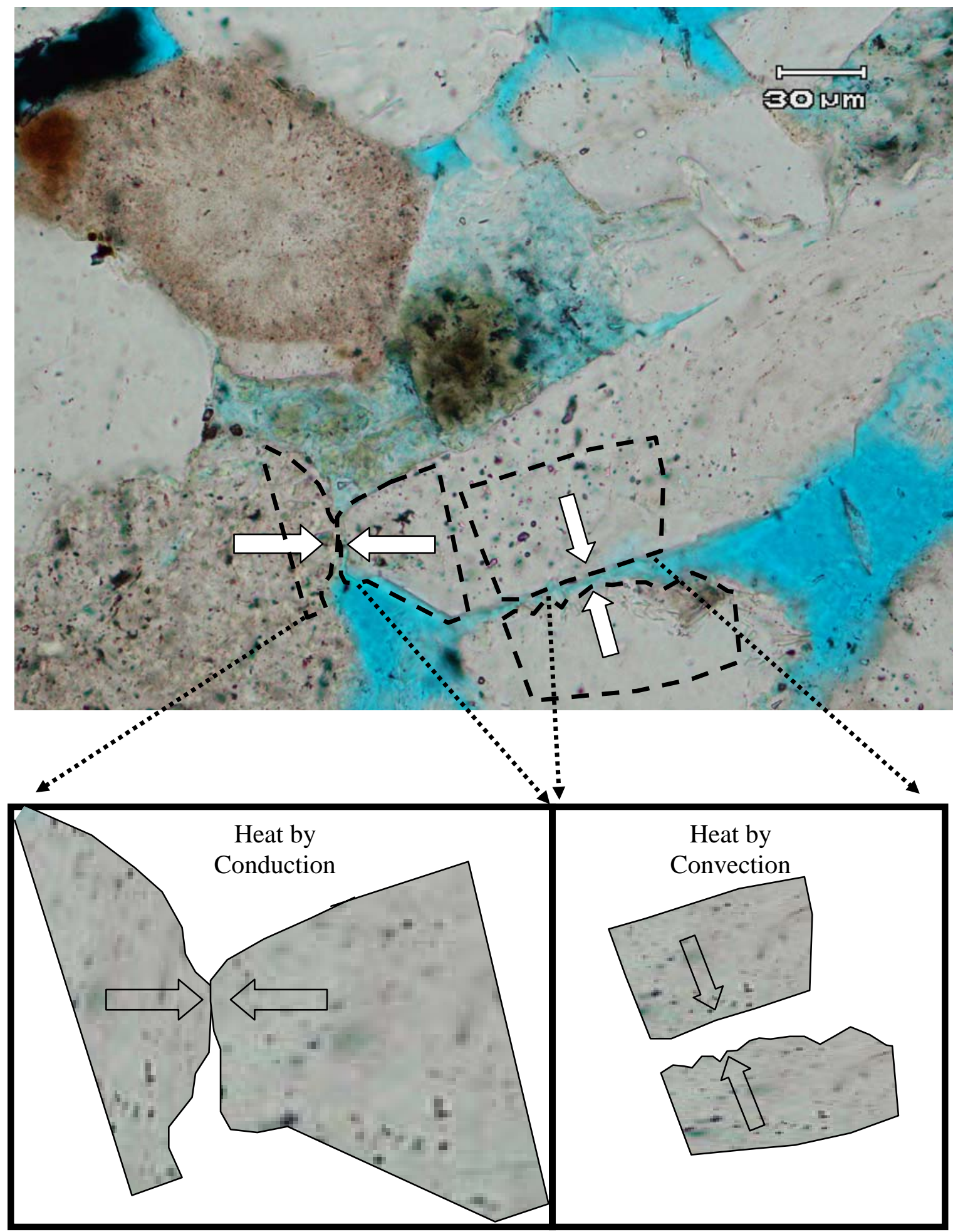

Figure 22. Heat transfer in sandstone by conduction (solid to solid) and convection (solid to air). 


\section{Perforation of Saturated Core Samples under High Pressure Conditions}

Objective: To simulate perforation under downhole conditions by applying axial and confining pressures (tri-axial load) on sandstone and limestone saturated core samples.

Procedure: Sandstone and limestone cores $10.16 \mathrm{~cm}$ (4.0 in) diameter and 15.24 $\mathrm{cm}$ (6.0 in) length were placed in a vacuum environment for about $6.0 \mathrm{hrs}$ and then saturated with brine solution or oil for at least $24 \mathrm{hrs}$.

The composition of the brine was a mixture of 25,000 ppm potassium chloride $(\mathrm{KCl})$ and $25,000 \mathrm{ppm}$ sodium chloride $(\mathrm{NaCl})$ in $1,000 \mathrm{ml}$ of water. The density of the brine was $1.039 \mathrm{~g} / \mathrm{cm}^{3}$. The oil used in testing had a density of $0.841 \mathrm{~g} / \mathrm{cm}^{3}$.

Each saturated sample was placed in the high pressure cell and was pressurized for confining and axial pressures to approximately 13,790 kPa (2000 psig). Each saturated sample was lased for $8.0 \mathrm{~s}$ with $5.34 \mathrm{~kW}$ laser power. Spot size was kept constant at $0.889 \mathrm{~cm}$ (0.35 in). Pore pressure was not applied to the saturated samples.

Results for both the rock types are shown in Figures 23 and 24 with previous data from unsaturated samples to compare SE values. Tabular results are presented in Appendix A.

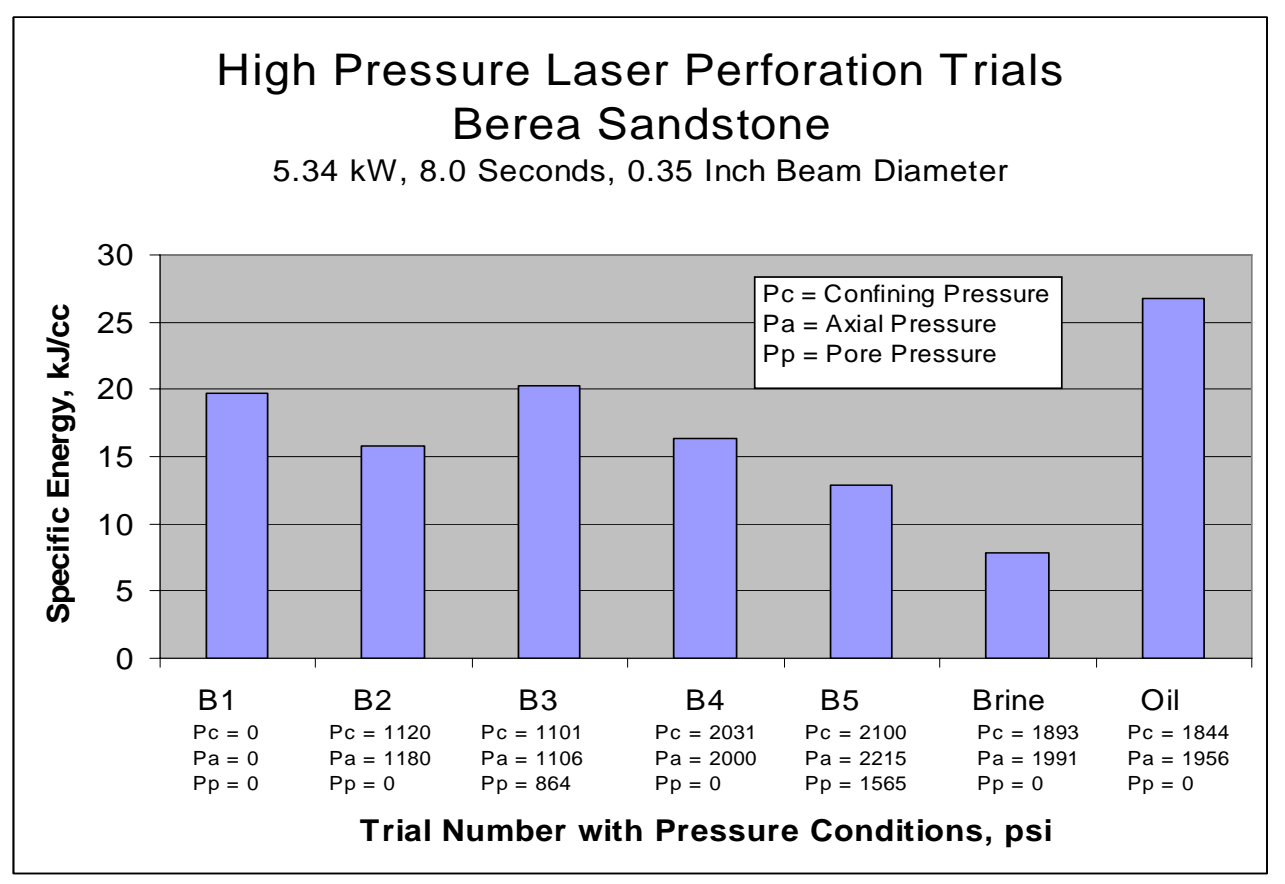

Figure 23. Comparison of SE values in sandstone as observed at various test cell pressure conditions, including brine and oil saturated samples. 


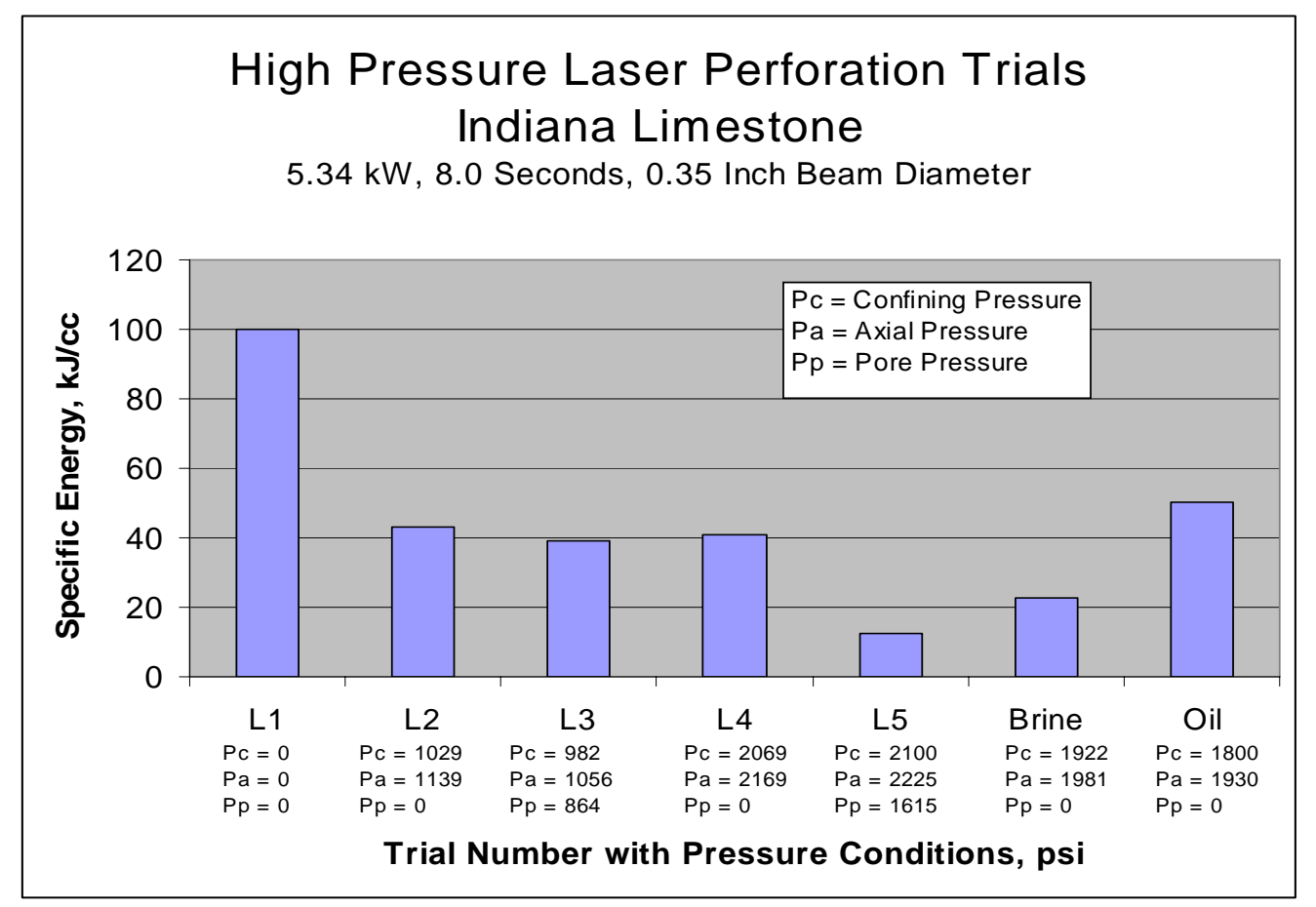

Figure 24. Comparison of SE values in limestone as observed at various test cell pressure conditions, including brine and oil saturated samples.

Results and Analysis:

The effect of liquid saturation on the rock samples gave us an indication as to how their presence in the reservoir may affect the laser's ability to create a perforation. Regarding brine, sandstone received an added boost in efficiency with an SE of $7.84 \mathrm{~kJ} / \mathrm{cc}$. This is 60\% lower than the base case (B1), and 50\% lower than the best stressed case (B2). Rapid vaporization of the brine is suspected to provide assistance in the spallation process, as has been previously observed with water saturated sandstone samples. The limestone also exhibited some improvement with an SE of $22.78 \mathrm{~kJ} / \mathrm{cc}$, a $77 \%$ reduction from the base case (L1), and a $42 \%$ reduction from the best stressed case (L3).

The presence of a hydrocarbon in sandstone raised the SE to $26.76 \mathrm{~kJ} / \mathrm{cc}$. This is a $35 \%$ increase in energy required from the base case (B1), and a $63 \%$ increase from a similar unsaturated case (B4). This effect may be a result of the hydrocarbon and its byproducts absorbing more beam energy than is provided by rapid vaporization in the pores. A similar result was observed in limestone, although not as pronounced. The observed SE in the oil saturated limestone sample was $50.36 \mathrm{~kJ} / \mathrm{cc}$, about 50\% lower than the base case (L1) SE, and $24 \%$ higher than the similar unsaturated case (L4).

As explained previously, the stress because grains to get closer there for more heat transfer. In figure 23 and 24 the graphs show sandstone and mile stone under confined, axial and saturation conditions. 
The figure shows that sample saturated with oil present the high SE value. Then lasing with oil saturation, the oil consumes energy to heat up and the vapor and the product of lasing is like a dark cloud with blocks the beam from reaching the sample. In the case of brine, the water evaporates and the sample path gets clear for the beam.

For limestone the same trend was observed where the Oil saturated sample shows more SE than the brine, but for limestone the SE value oil is still less than dry with no stress because there void space is very small in limestone, therefore the amount of the oil injected in the sample is very small or even insignificant.

\section{Perforation of Composite Core Samples under High Pressure Conditions}

Objective: To estimate the perforation depth for composite samples under triaxial pressure condition and simulate the perforation of a completed wellbore under in-situ pressure conditions.

Procedure: The design of the composite material sample for high pressure perforation was to allow the laser to penetrate materials as they would be encountered in a completed wellbore as depicted in Figure 25. Specific concerns were addressed in the design of the composite cores, given the thermal conductivity of the materials involved. With any exposure of the beam on steel, we could expect that thermal energy would rapidly rise evenly throughout the steel sample. Should this occur, the confining pressure sleeve would likely melt at any point where it came into contact with the hot steel. The system would be unable to maintain stress and pressure on the core, as well as potential safety concerns.

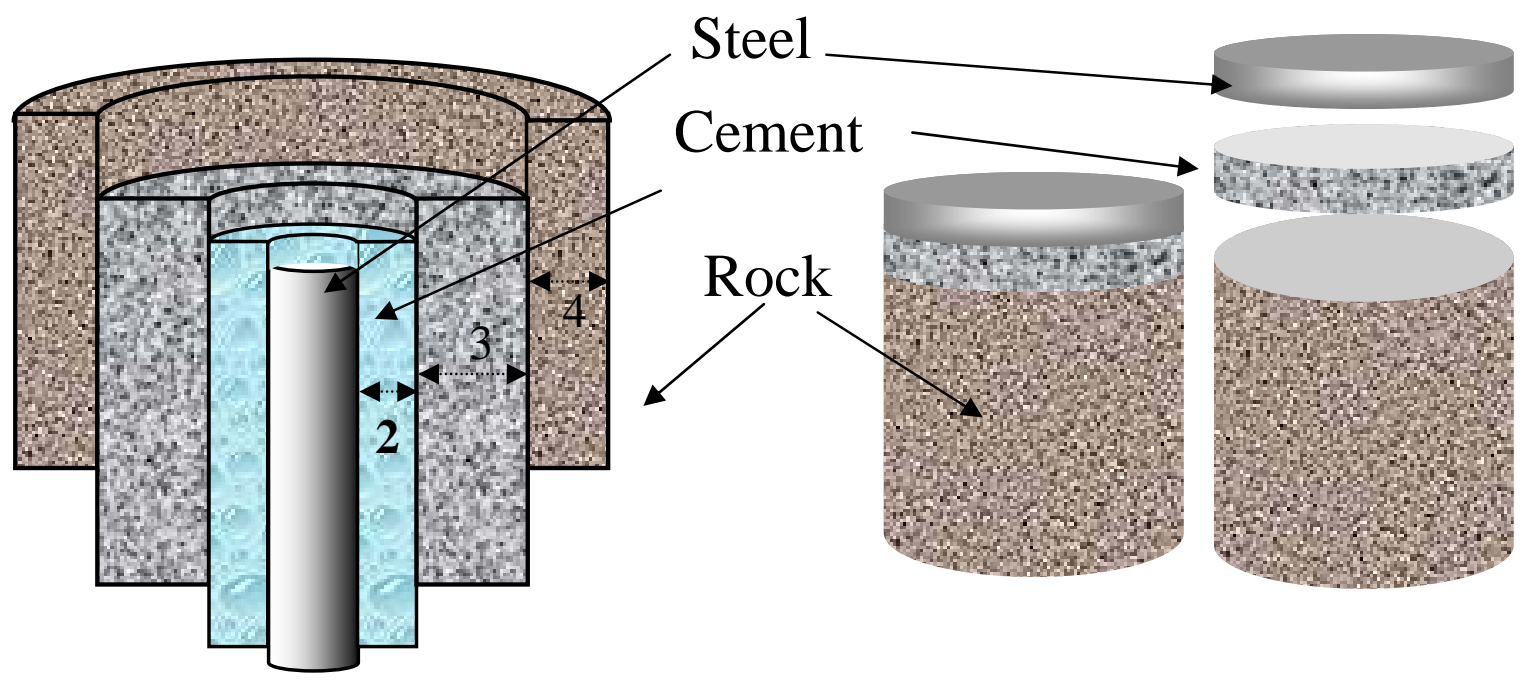

Figure 25. Composite core samples were to simulate physical conditions of a competed wellbore. 


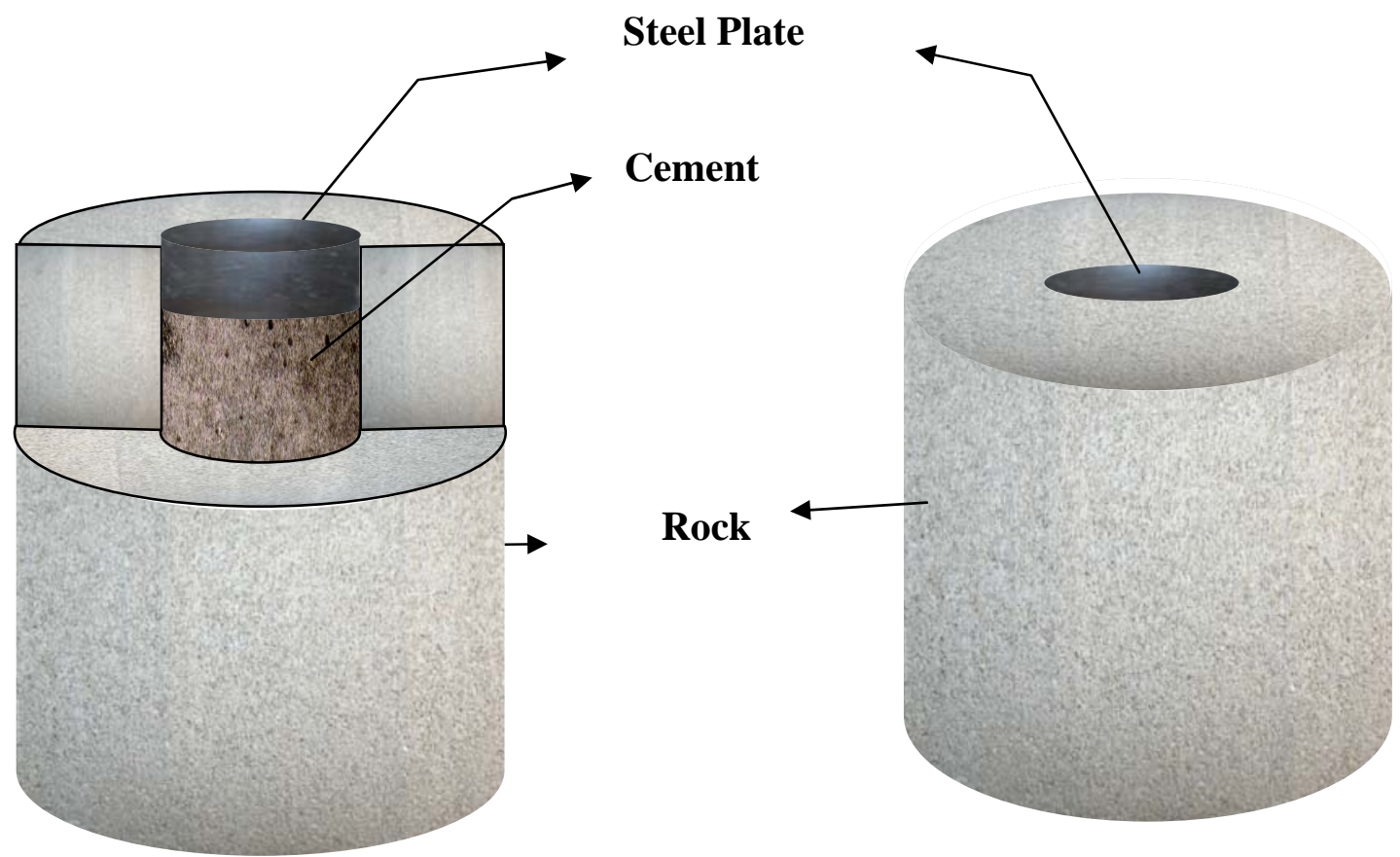

Figure 26. Composite sample as prepared for the high pressure cell, illustrating modified design to avoid melting of core sleeve.

Composite samples of steel, cement and rock were prepared by cementing in place a $5.08 \mathrm{~cm}$ (2.0 in) diameter by $1.27 \mathrm{~cm}$ (0.5 in) thick steel plate. By using a smaller steel diameter inset, the rubber pressure sleeve jacketing the sample core would not be at risk of melting through direct contact with a full diameter steel plate.

After observing the laser/rock interactions of sandstone and limestone under high pressure conditions and the resulting SE values, in-situ demonstrations were then executed to best simulate downhole conditions and material encountered during laser perforation.

The sandstone and limestone clad samples were exposed to the same laser beam conditions as performed under previous high pressure trials. For the sandstone sample, axial and confining pressures were measured at 14,479 and $13996 \mathrm{kPa}$ (2100 and 2030 psig), respectively. Axial and confining pressures for the limestone sample were measured at 14,300 and 13,555 kPa (2074 and 1966 psig), respectively.

Total time of beam exposure was 90 s per composite sample. The time was calculated based on earlier laser exposure times to remove a unit volume of steel, cement and rock materials. The laser fired for thirty second intervals buffered with $20 \mathrm{~s}$ between shots as a precaution to avoid overheating the cell 
assembly. Before and after lasing images of the limestone clad sample are shown in Figure 28.

As a result of the high pressure clad sample trials, the laser penetrated about $6.35 \mathrm{~cm}$ (2.5 in) into the sandstone clad sample, or $1.27 \mathrm{~cm}(0.5 \mathrm{in})$ beyond the steel and cement. The laser penetrated $11.43 \mathrm{~cm}$ (4.5 in) into the limestone clad sample, or $6.35 \mathrm{~cm}$ (2.5 in) beyond the steel and cement. An X-ray CT scan image of the limestone clad sample is shown in Figure 27.

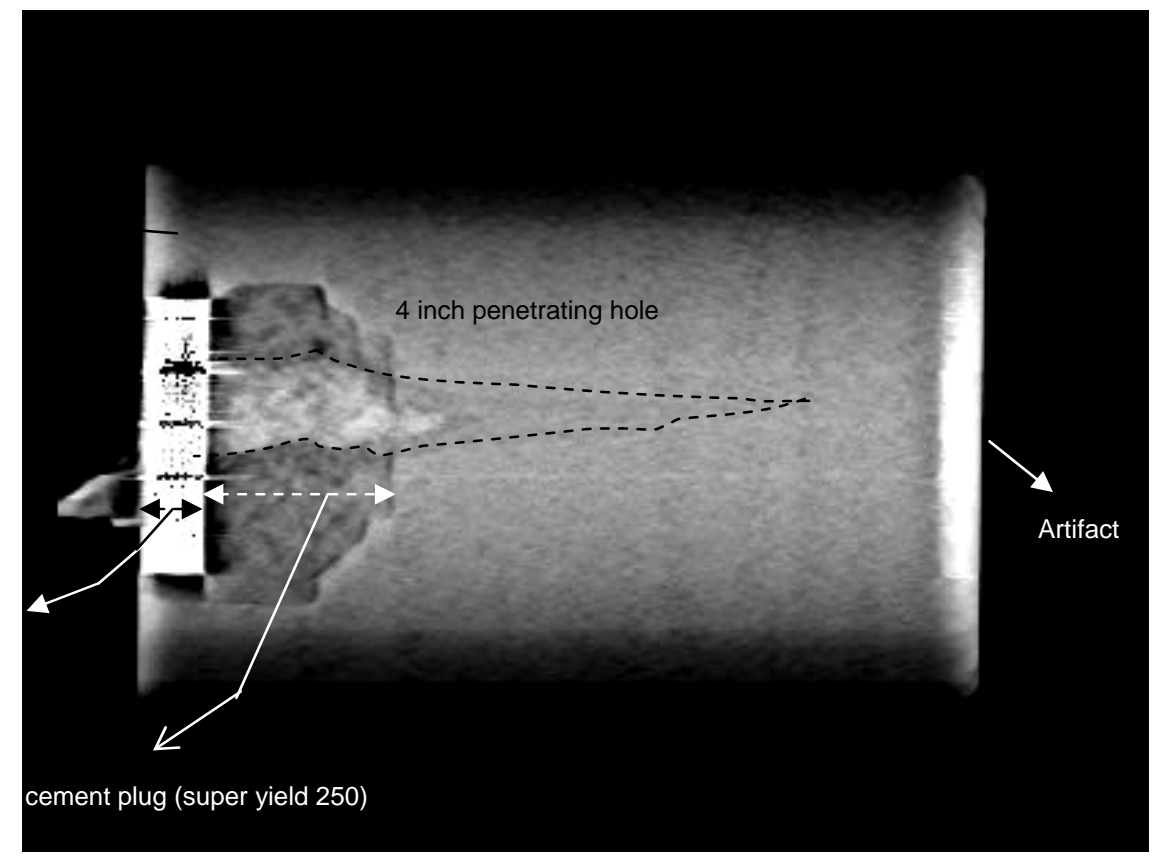

Figure 27. CT scan image of $10.16 \mathrm{~cm}$ (4.0 in) diameter by $15.24 \mathrm{~cm}$ (6.0 in) length limestone clad sample and outline of penetration path after perforation of three $30 \mathrm{~s}$ shots by $5.34 \mathrm{~kW}$ ytterbium fiber laser with a $0.889 \mathrm{~cm}$ (0.35 in) diameter beam.
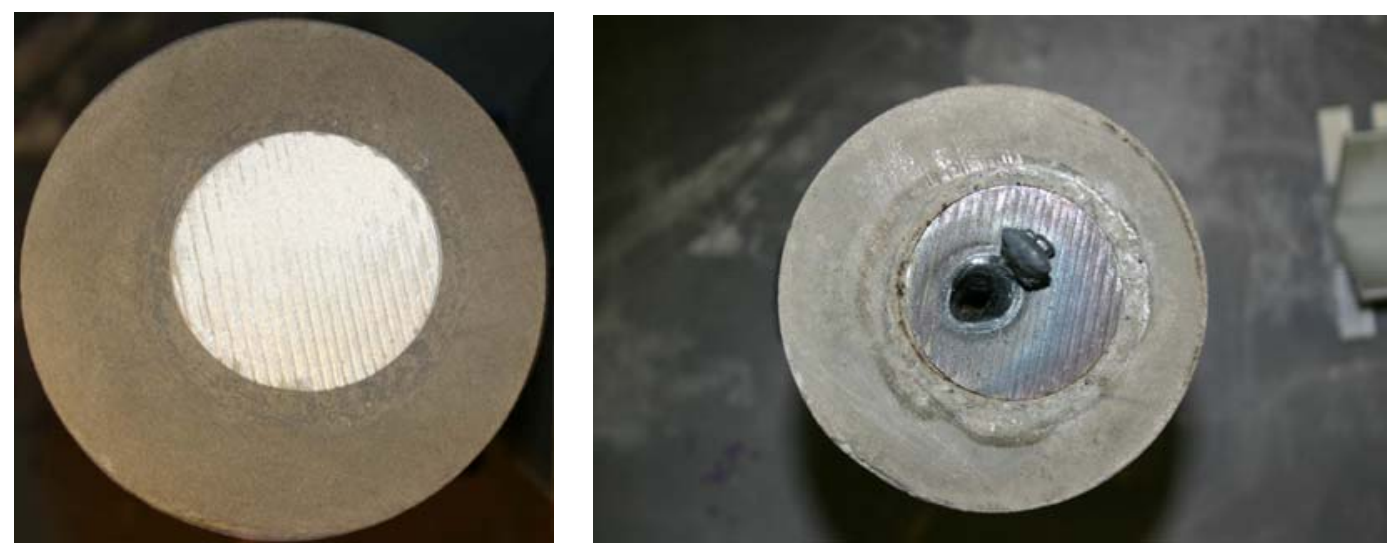

Figure 28. Pre- and post-lased images of $10.16 \mathrm{~cm}$ (4.0 in) diameter by $15.24 \mathrm{~cm}$ (6.0 in) length limestone core inset with $5.08 \mathrm{~cm}$ (2.0 in) diameter by $1.27 \mathrm{~cm}$ (0.5 in) thick steel plate. 


\section{Conclusion}

The recent commercial introduction of high-power fiber lasers represented a significant step forward in realizing field-based applications of photonic energy for well construction and completion. Fiber lasers meet the multiple demands from industry regarding a field deployable system, including overall size limitations, mobile rugged on-site deployment, requisite energy delivery to target, real-time controllability and penetration of multiple materials. From an economic perspective, the order of magnitude improvement in efficiency significantly lowers input energy and waste heat dissipation requirements. They also require minimal maintenance and repair, and are commercially available.

High power laser applications for cutting and boring rocks have been successfully demonstrated under ambient pressure conditions; however, this is the first time samples have been lased at in-situ pressure conditions. Research results demonstrated the beneficial effect of stress and pressure on the laser's ability to perforate reservoir rock. Additionally, we were able to demonstrate the capability of a single wavelength laser to penetrate a combination of steel, cement and rock at in-situ pressures that would be encountered while perforating downhole.

Operating the laser in underbalanced conditions demonstrated the ability of the laser to perform at downhole conditions without requiring a supplemental assist purge system. The differential pressure between the reservoir pore pressure and the wellbore pressure provided the means for ejecting the cuttings.

Operating the laser on rock under axial and confining stress improves the conditions for laser perforation due to a closer grain-to-grain contact and resulting improvement to thermal diffusivity. This extends the influence of the beam energy further into the rock. 


\section{References}

1. DeGolyer and MacNaughton, One Energy Square, Dallas, Texas, 2000.

2. Andersen, et al, “Deep Drilling Basic Research: Volume 2 - Deep Drilling, ” GRI 90/0265.2, June 1990, 78p.

3. W.C. Maurer, Novel Drilling Techniques, Pergamon Press, 1968.

4. W.C. Maurer, Advanced Drilling Techniques, Petroleum Publishing, 1980.

5. W.T. Silfvast, Laser Fundamentals, Cambridge, 1996.

6. W.H. Somerton, Thermal Properties and Temperature-related Behavior of Rock/Fluid System. University of California, Development in Petroleum Science. Elsevier, Amsterdam-London-New York-Tokyo, 1992.

7. R.M. Graves and D.G. O'Brien, "Star Wars Laser Technology Applied to Drilling and Completing Gas wells," SPE 49259, 1998.

\section{Publications}

Publications by GTI staff from October 2004 to September 2005:

1. Gahan, B.C. “Processing Rocks,” Industrial Laser Solutions, Sept.(2005):16-18.

2. Gahan, B.C. "Fiber Laser Offers Fast Track to Clean Perforations” GTI Document No. GTI-05/0226, GasTIPS, 11, No. 2 (Spring 2005), pp. 17-20.

3. Gahan, B.C., Batarseh, S. 2004. "An Overview of High Power Laser Applications Research from Well Construction and Completion,” 2004 International Gas Research Conference (IGRC), Vancouver, BC, November 1-4.

4. Batarseh, S., Gahan, B.C., Sharma, B., Gowelly, S. 2004. "Evaluation of High Power Ytterbium Fiber Lasers for Rock Cutting and Removal Applications,” Paper 1402, $23^{\text {rd }}$ International Congress on Applications of Lasers and Electronics, San Francisco, CA, October 4-7. 


\section{Presentations}

Presentations delivered from October 2004 to September 2005:

High Power Laser Applications for Well Drilling and Completions

Innovations in Exploration Drilling, Memorial University of Newfoundland

St. Johns, NL, Canada, August 23, 2005 (invitation)

Improving Gas Well Drilling and Completion with High Energy Lasers

American Petroleum Institute, Delta Chapter

New Orleans, LA, August 17, 2005 (invitation)

Improving Gas Well Drilling and Completion with High Energy Lasers

American Institute of Chemical Engineers (AIChE), Chicago Section

Chicago, IL, March 9, 2005 (invitation)

Improving Gas Well Drilling and Completion with High Energy Lasers

International Coiled Tubing Association (ICoTA), Gulf Coast Section

Houston, TX, February 8, 2005 (invitation)

An Overview of High Power Laser Applications Research from Well Construction and Completion

2004 International Gas Research Conference (IGRC)

Vancouver, BC, Canada, November 2, 2004

Evaluation of High Power Ytterbium Fiber Lasers for Rock Cutting and Removal

Applications

$23^{\text {rd }}$ International Congress on Applications of Lasers and Electronics

San Francisco, CA, October 4-7, 2004 


\section{List of Acronyms and Abbreviations}

$$
\begin{aligned}
& \text { C = Celsius/centigrade } \\
& \text { cc = cubic centimeter } \\
& \mathrm{CO}_{2} \quad=\text { carbon dioxide } \\
& \mathrm{CW}=\text { continuous wave } \\
& \text { DP = diode-pumped } \\
& \text { DTA = differential thermal analysis } \\
& \text { Eabs = absorbed energy } \\
& \mathrm{E}_{\text {inc }} \quad=\text { incident electromagnetic wave } \\
& \mathrm{E}_{\mathrm{ref}} \quad=\text { reflected energy } \\
& \mathrm{E}_{\mathrm{sc}} \quad=\text { scattered energy } \\
& \text { EDS = energy dispersive system } \\
& \mathrm{E} / \mathrm{O} \quad=\text { electrical to optical } \\
& \mathrm{F} \quad=\text { Fahrenheit } \\
& \text { g } \quad \text { gram } \\
& \mathrm{J}=\text { joule } \\
& \text { HPFL = high power fiber laser } \\
& \text { ID = inside diameter } \\
& \text { LP = lamp-pumped } \\
& \mathrm{m} \quad=\text { meter } \\
& \text { md } \quad=\text { millidarcy (Permeability Unit) } \\
& \mathrm{Nd} \text { :YAG = neodymium-doped yttrium aluminum garnet }\left(\mathrm{Nd}: \mathrm{Y}_{3} \mathrm{Al}_{5} \mathrm{O}_{12}\right) \\
& \mathrm{P}_{\mathrm{a}} \quad=\text { Axial pressure } \\
& \mathrm{P}_{\mathrm{C}} \quad=\text { Confining pressure } \\
& \mathrm{P}_{\mathrm{p}} \quad \text { = Pore pressure } \\
& \mathrm{Pa} \quad=\text { Pascal } \\
& \text { PDPK = pressure decay profile permeameter } \\
& \text { ppm } \quad=\text { parts per million } \\
& \text { psig = pounds per square inch gauge } \\
& \mathrm{S} \quad=\text { seconds } \\
& \mathrm{SE} \quad=\text { specific energy } \\
& \text { SEM = scanning electron microscope } \\
& \mathrm{W} \quad=\text { watt } \\
& \mathrm{X}, \mathrm{X}=\text { times } \\
& \mathrm{XRD} \quad=\mathrm{x} \text {-ray diffraction } \\
& \lambda=\text { wavelength }
\end{aligned}
$$




\section{Appendix A: Experimental Data}




\section{Experiment: High Pressure Perforation}

\section{Material: limestone}

\section{Laser power: $5.34 \mathrm{~kW}$}

Lasing time: $8 \mathrm{~s}$

Spot size: $0.889 \mathrm{~cm}(0.35 \mathrm{in})$

\begin{tabular}{|c|c|c|c|c|c|c|c|c|c|c|c|}
\hline Name & $\begin{array}{c}\text { Conf. } \\
\text { Pressure } \\
(\mathrm{psia})\end{array}$ & $\begin{array}{c}\text { Axial } \\
\text { Pressure } \\
(\mathrm{psia})\end{array}$ & $\begin{array}{c}\text { Pore } \\
\text { Pressure } \\
(\mathrm{psia})\end{array}$ & $\begin{array}{c}\text { Core } \\
\text { dia. } \\
(\mathrm{cm})\end{array}$ & $\begin{array}{c}\text { Core } \\
\text { length } \\
(\mathrm{cm})\end{array}$ & $\begin{array}{c}\text { Weight } \\
\text { before } \\
\text { lasing } \\
(\mathrm{gm})\end{array}$ & $\begin{array}{c}\text { Weight } \\
\text { after } \\
\text { lasing } \\
(\mathrm{gm})\end{array}$ & $\begin{array}{c}\text { Weight } \\
\text { removed } \\
(\mathrm{gm})\end{array}$ & $\begin{array}{c}\text { Density } \\
(\mathrm{gm} / \mathrm{cc})\end{array}$ & $\begin{array}{c}\text { Volume } \\
\text { removed } \\
(\mathrm{cc})\end{array}$ & $\begin{array}{c}\text { Specific } \\
\text { energy } \\
(\mathrm{kJ} / \mathrm{cc})\end{array}$ \\
\hline 1 & 0 & - & - & 10.11 & 13.80 & 2489.60 & 2488.70 & 0.90 & 2.25 & 0.40 & 106.77 \\
\hline 2 & 1029 & 1139 & - & 10.11 & 15.39 & 2785.80 & 2783.70 & 2.10 & 2.26 & 0.93 & 45.92 \\
\hline 3 & 2069 & 2169 & & 10.11 & 15.56 & 2793.40 & 2791.20 & 2.20 & 2.24 & 0.98 & 43.43 \\
\hline 4 & 982 & 1056 & 864 & 10.11 & 15.62 & 2814.80 & 2812.50 & 2.30 & 2.24 & 1.02 & 41.69 \\
\hline 5 & 2100 & 2225 & 1625 & 10.11 & 15.34 & 2731.20 & 2723.90 & 7.30 & 2.24 & 3.26 & 13.11 \\
\hline $\begin{array}{c}\text { Saturated- } \\
\text { Brine }\end{array}$ & 1922 & 1981 & - & 10.11 & 15.34 & 2987.20 & 2983.00 & 4.20 & 2.24 & 1.87 & 22.78 \\
\hline $\begin{array}{c}\text { Saturated- } \\
\text { Oil }\end{array}$ & 1800 & 1930 & - & 10.11 & 15.34 & 2850.80 & 2848.90 & 1.90 & 2.24 & 0.85 & 50.36 \\
\hline
\end{tabular}

Conditions Tested:
Bi axial load
Tri axial load
Perforation of saturated sample (brine, oil) 
Experiment: High Pressure Perforation

Material: sandstone

Laser power: $5.34 \mathrm{~kW}$

Lasing time: $8 \mathrm{~s}$

Spot size: $0.889 \mathrm{~cm}(0.35 \mathrm{in})$

\begin{tabular}{|c|c|c|c|c|c|c|c|c|c|c|c|}
\hline Name & $\begin{array}{c}\text { Conf. } \\
\text { Pressure } \\
\text { (psia) }\end{array}$ & $\begin{array}{c}\text { Axial } \\
\text { Pressure } \\
(\mathrm{psia})\end{array}$ & $\begin{array}{c}\text { Pore } \\
\text { Pressure } \\
\text { (psia) }\end{array}$ & $\begin{array}{c}\text { Core } \\
\text { dia. } \\
(\mathrm{cm})\end{array}$ & $\begin{array}{c}\text { Core } \\
\text { length } \\
(\mathrm{cm})\end{array}$ & $\begin{array}{c}\text { Weight } \\
\text { before } \\
\text { lasing } \\
\text { (gm) }\end{array}$ & $\begin{array}{c}\text { Weight } \\
\text { after } \\
\text { lasing } \\
\text { (gm) }\end{array}$ & $\begin{array}{c}\text { Weight } \\
\text { removed } \\
(\mathrm{gm})\end{array}$ & $\begin{array}{c}\text { Density } \\
(\mathrm{gm} / \mathrm{cc})\end{array}$ & $\begin{array}{c}\text { Volume } \\
\text { removed } \\
(\mathrm{cc})\end{array}$ & $\begin{array}{c}\text { Specific } \\
\text { energy } \\
(\mathrm{kJ} / \mathrm{cc})\end{array}$ \\
\hline 1 & - & - & - & 10.11 & 15.19 & 2589.30 & 2585.00 & 4.30 & 2.12 & 2.03 & 21.09 \\
\hline 2 & 1120 & 1180 & & 10.12 & 15.39 & 2638.60 & 2633.20 & 5.40 & 2.13 & 2.53 & 16.88 \\
\hline 3 & 1101 & 1106 & 864 & 10.10 & 15.34 & 2622.00 & 2617.80 & 4.20 & 2.13 & 1.97 & 21.69 \\
\hline 4 & 2031 & 2000 & & 10.11 & 15.34 & 2616.90 & 2611.70 & 5.20 & 2.13 & 2.44 & 17.50 \\
\hline 5 & 2100 & 2215 & 1565 & 10.11 & 15.34 & 2437.00 & 2430.40 & 6.60 & 2.13 & 3.10 & 13.79 \\
\hline $\begin{array}{c}\text { Saturated- } \\
\text { Brine }\end{array}$ & 1893 & 1991 & - & 10.11 & 15.34 & 2866.30 & 2854.70 & 11.60 & 2.13 & 5.45 & 7.84 \\
\hline $\begin{array}{c}\text { Saturated- } \\
\text { Oil }\end{array}$ & 1844 & 1956 & - & 10.11 & 15.34 & 2776.60 & 2773.20 & 3.40 & 2.13 & 1.60 & 26.76 \\
\hline
\end{tabular}

Conditions Tested:

Bi axial load

Tri axial load

Perforation of saturated sample (brine, oil) 


\section{Experiment: High Pressure Perforation (sandstone composite)}

- Perforation of composite samples: $10.16 \mathrm{~cm}$ (4.0 in) diameter x $15.24 \mathrm{~cm}$ (6.0 in) length sandstone core Inset thickness: $1.27 \mathrm{~cm}$ (0.5 in) steel plate; $3.81 \mathrm{~cm}$ (1.5 in) SY 250 cement Spot size: $0.889 \mathrm{~cm}(0.35 \mathrm{in})$

\begin{tabular}{|c|c|c|c|c|c|c|c|}
\hline Name & $\begin{array}{c}\text { Conf. } \\
\text { Pressure } \\
(\mathrm{psia})\end{array}$ & $\begin{array}{c}\text { Axial } \\
\text { Pressure } \\
(\mathrm{psia})\end{array}$ & $\begin{array}{c}\text { Pore } \\
\text { Pressure } \\
(\mathrm{psia})\end{array}$ & $\begin{array}{c}\text { Core } \\
\text { dia. } \\
(\mathrm{cm})\end{array}$ & $\begin{array}{c}\text { Core } \\
\text { length } \\
(\mathrm{cm})\end{array}$ & $\begin{array}{c}\text { Lasing time } \\
(\mathrm{sec})\end{array}$ & $\begin{array}{c}\text { Depth of } \\
\text { penetration } \\
\text { (inch) }\end{array}$ \\
\hline 1 & 2030 & 2100 & - & 10.1 & 15.2 & $\begin{array}{c}90(\text { On time }) \\
(30 \mathrm{sec} \text { on/20 } \\
\text { sec off })\end{array}$ & 2.5 \\
\hline
\end{tabular}

\section{Experiment: High Pressure Perforation (limestone composite)}

- Perforation of composite samples: $10.16 \mathrm{~cm}$ (4.0 in) diameter x $15.24 \mathrm{~cm}$ (6.0 in) length limestone core Inset thickness: $1.27 \mathrm{~cm}$ (0.5 in) steel plate; $3.81 \mathrm{~cm}$ (1.5 in) SY 250 cement

Spot size: 0.35 ”

\begin{tabular}{|c|c|c|c|c|c|c|c|}
\hline Name & $\begin{array}{c}\text { Conf. } \\
\text { Pressure } \\
(\text { psia })\end{array}$ & $\begin{array}{c}\text { Axial } \\
\text { Pressure } \\
(\text { psia })\end{array}$ & $\begin{array}{c}\text { Pore } \\
\text { Pressure } \\
(\text { psia })\end{array}$ & $\begin{array}{c}\text { Core } \\
\text { dia. } \\
(\mathrm{cm})\end{array}$ & $\begin{array}{c}\text { Core } \\
\text { length } \\
(\mathrm{cm})\end{array}$ & $\begin{array}{c}\text { Lasing time } \\
(\mathrm{sec})\end{array}$ & $\begin{array}{c}\text { Depth of } \\
\text { pentration } \\
\text { (inch) }\end{array}$ \\
\hline 1 & 1966 & 2074 & - & 10.15 & 15.2 & $\begin{array}{c}90(\text { On time) } \\
(30 \mathrm{sec} \text { on/20 } \\
\text { sec off })\end{array}$ & 4.5 \\
\hline
\end{tabular}




\section{Appendix B: DOE Project Review Presentation}

June 15, 2005

Morgantown, WV 
Slide 1

gti

DOE NETL Project Update: Drilling With the Power of Light DOE NETL Morgantown, WV

Brian C. Gahan

Samih Batarseh

Gas Technology Institute

June 15, 2005

Slide 2

\section{DOE/GTI BP2 SOW}

- DOE NETL (2003-07)

Task 2.0: Continuation of Fundamental Research and Development - In-Situ Conditions

Task 3.0: Systems Development Issues in Laser Well Construction

Task 4.0: High Energy Laser Perforation and Completion Techniques 
Slide 3

\section{Downhole Laser Applications}

- Drilling

- Perforating

- Seismic Shot Holes

- Casing Cutting/ Abandonment

- Offshore Platform Abandonment

- Casing "Windows" for Multi-Laterals

- Downhole Slotted

gti

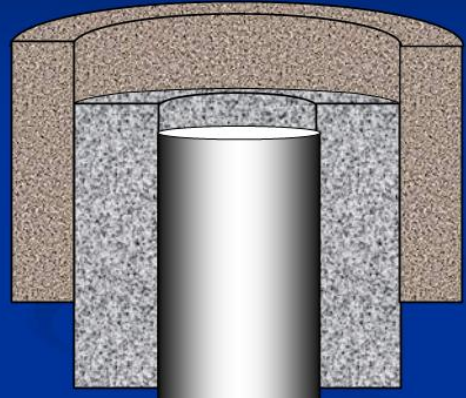
Liners/Screens

Slide 4

\section{Downhole Laser Applications}

- Drilling

- Perforating

- Seismic Shot Holes

- Casing Cutting/ Abandonment

- Offshore Platform Abandonment

- Casing "Windows" for Multi-Laterals

- Downhole Slotted gti

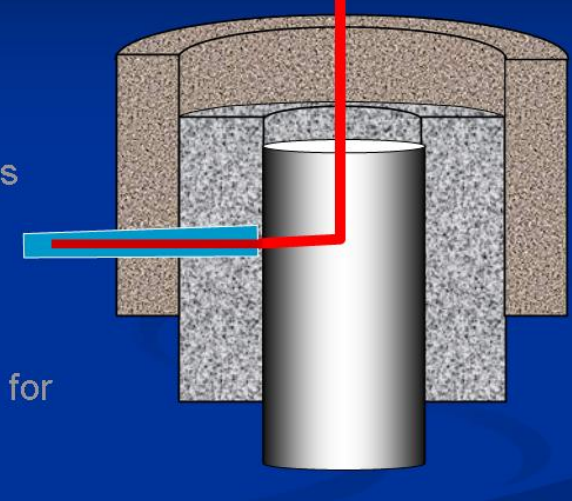
Liners/Screens 
Slide 5

\section{Benefits of Laser Perforation}

- Non-Explosive Technology

- Real-Time Control: Input vs. Output

- Potential for "Extended Perforation" and Other Completion Methods

- Stimulate While Creating Perforations

Slide 6
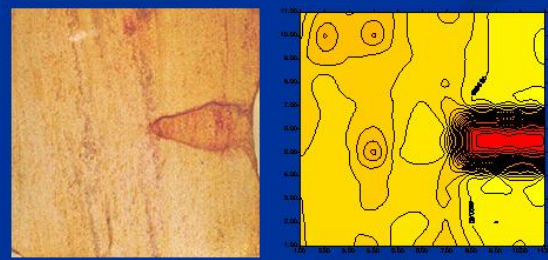

Downhole Laser Applications

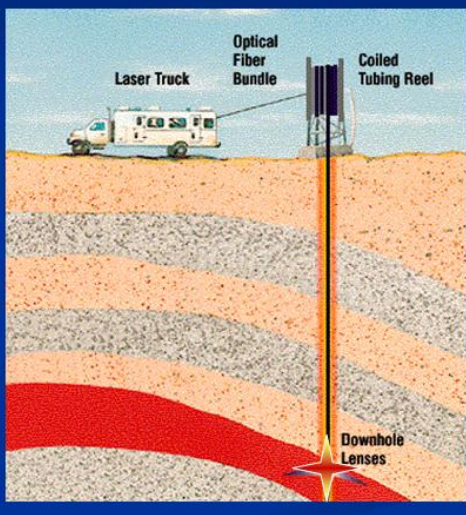

Field Applications Concept 
Slide 7

Laser Applications Background

GTI High Power Laser R\&D

- GRI Feasibility Study

(1997-00)

- GTI/DOE BP1 - Phase I

- GTI/DOE BP1 - Phase II

- GTI/DOE BP2

- Laser Perforation POC

- Halliburton/GRI $\$ 1.5 \mathrm{M}$

- Complements GTI/DOE Task 4.0

- Applications Focused

gti

- Filled in During DOE Funding Delay and Rescope

Slide 8

\section{Specific Energy}

$$
\begin{gathered}
\mathrm{SE}=\frac{\text { Energy Input }}{\text { Volume Removed }}=\frac{\mathrm{P}}{\mathrm{dV} / \mathrm{dt}} \\
=\frac{\mathrm{kW}}{\mathrm{cm}^{3} / \mathrm{sec}}=\frac{\mathrm{kJ}}{\mathrm{cm}^{3}}
\end{gathered}
$$

gti 
Slide 9

\section{GRI Feasibility Study}

\section{Can Lasers Penetrate Rock?}

- Laser Drilling Experiments (1997 to 2000)

- Three High-Powered Military Lasers

\begin{tabular}{|l|c|c|c|}
\hline \multicolumn{1}{|c|}{ Type } & Power $(\mathrm{kW})$ & $\boldsymbol{\Lambda}(\mu \mathrm{m})$ & Branch \\
\hline COIL & 6.8 & 1.34 & USAF \\
\hline $\mathrm{CO}_{2}$ & 50,150 & 10.6 & USAF \\
\hline MIRACL & 1600 & 3.4 & US Army \\
\hline
\end{tabular}

gti - Various Rock Lithologies Studied

Reference: SPE 56625

Slide 10

\section{GTI/DOE Study - Phase I}

\section{How Much Energy Does it Take?}

- Laser Drilling Experiments (2000 - 2001)

- Three High-Powered Industrial Lasers

\begin{tabular}{|l|c|c|c|}
\multicolumn{1}{|c|}{ Type } & Power $(\mathrm{kW})$ & $\boldsymbol{\Lambda}(\mu \mathrm{m})$ & Location \\
\hline $\mathrm{Nd}: \mathrm{YAG}$ & 1.6 & 1.06 & $\mathrm{ANL}$ \\
\hline $\mathrm{CO}_{2}$ & 6 & 10.6 & ANL \\
\hline Diode & 4 & 0.8 & NA Tech \\
\hline
\end{tabular}

gti a Lithologies Studied: SS, LS, Sh 
Slide 11

\section{Nd:YAG Laser}

Neodymium Yttrium Aluminum Garnet

Slide 12

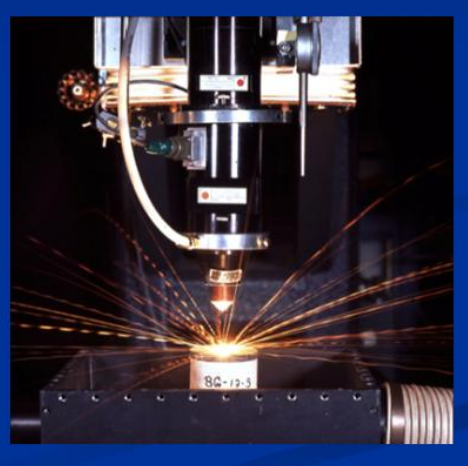

gti
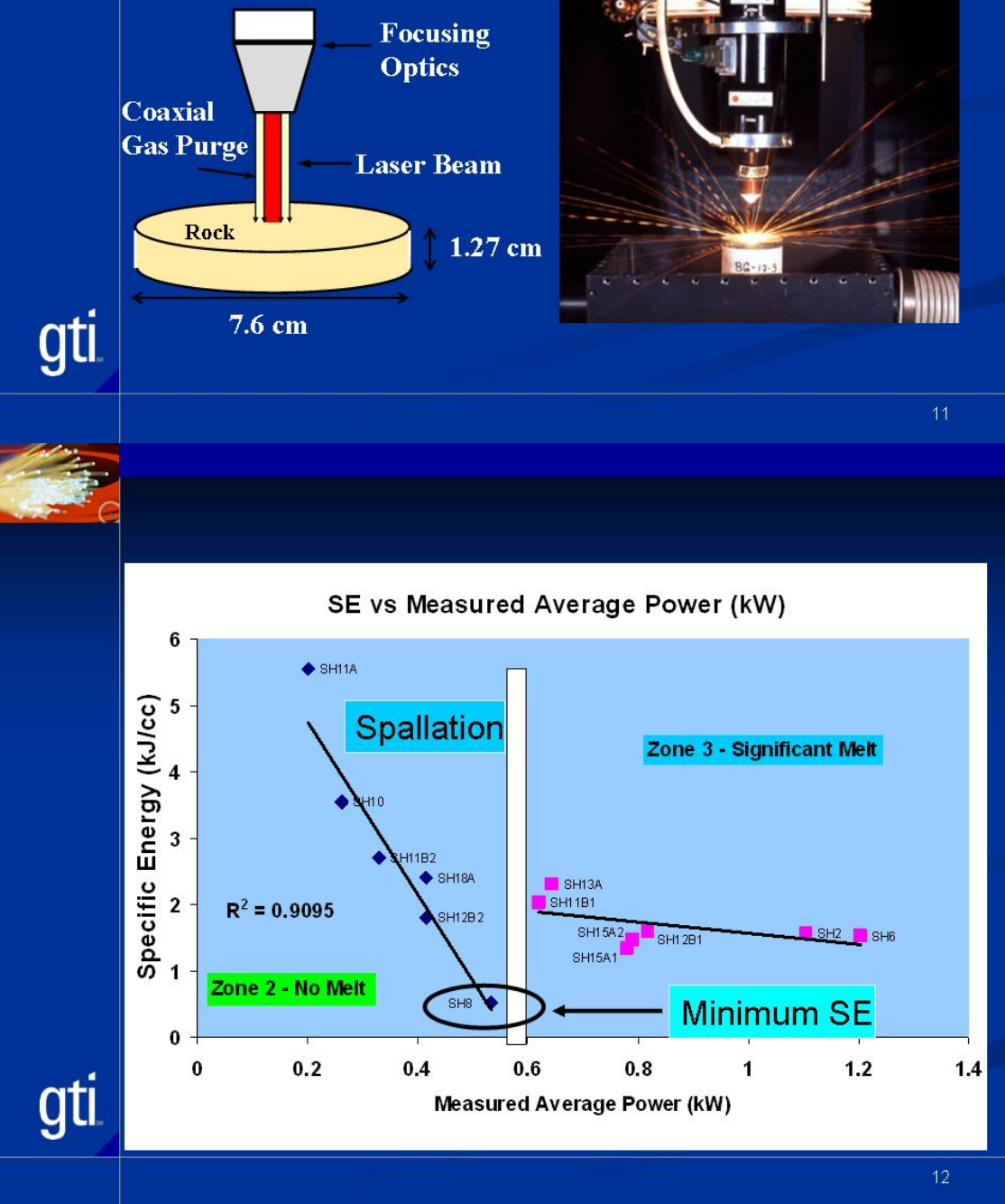
Slide 13

\section{Saturated vs. Dry Rock}

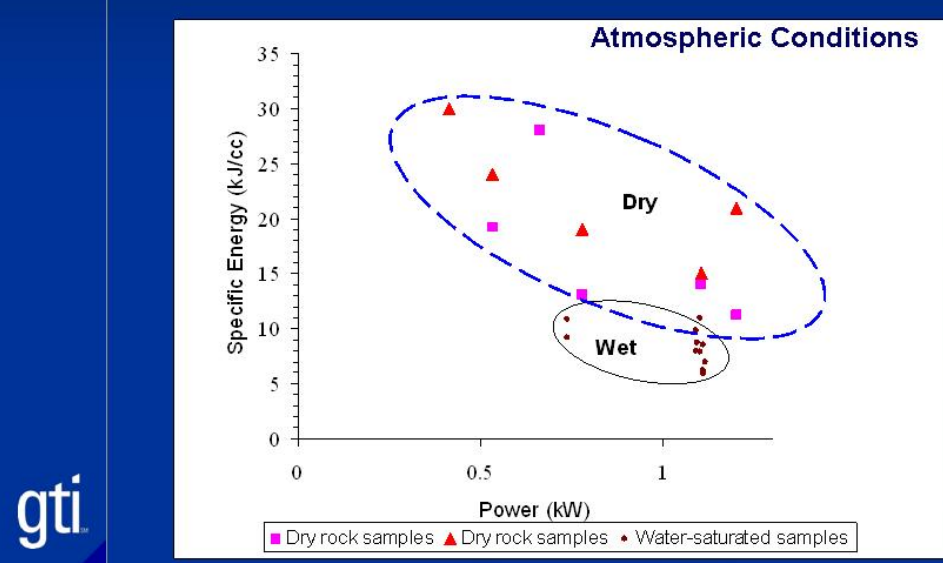

Slide 14

\section{Paradigm Shift Results}

- Change in Application Theory - Rate of Application: Blasting vs Chipping

- Unlimited Downhole Applications due to Precision and Control (i.e., direction, power, etc.)

- Off-Ramp Approach to Commercialization and Technology Integration

- Completions Less Complex Than Drilling

- Allows Technology Leveraging

- Rolling Integration Into Industry 
Slide 15

\section{GTI/DOE Study - Phase II}

\section{How Can Lasers Create Larger Holes?}

- Laser Drilling Experiments (2002 - 2003)

- Two High-Powered Industrial Lasers

\begin{tabular}{|l|c|c|c|}
\hline \multicolumn{1}{|c|}{ Type } & Power $(\mathrm{kW})$ & $\Lambda(\mu \mathrm{m})$ & Location \\
\hline $\mathrm{Nd}: \mathrm{YAG}$ & 1.6 & 1.06 & ANL \\
\hline $\mathrm{CO}_{2}$ & 6 & 10.6 & ANL \\
\hline
\end{tabular}

- Lithologies Studied: SS, LS

gti

Reference: SPE 71466

Slide 16

\section{GTI/DOE Study - Phase II}

- Test Effects of Laser Application Techniques on Specific Energy

- Avoid Melt

- Minimize SE Values

- Apply Multiple Beam Bursts in Varied Geometric Patterns

- Mimics Results of Rock Cutters

- Cumulative Effects of Multiple Bursts

- Not Continuous Blast

gti 
Slide 17

\section{GTI/DOE Study - Phase II}
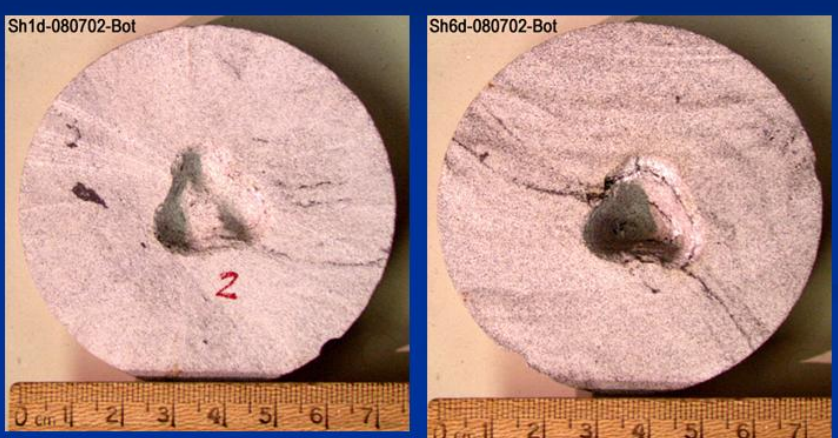

Photos of the lowest SE result (SH1D-2, left), and highest SE (SH6D, right). Sample SH6D exhibits a small amount of melt inside the hole.

gti

Slide 18

\section{HES Laser Perf POC Tasks}

\subsection{Laser Selection and Testing}

2.0 Preliminary Tests and Analysis

3.0 In-Situ Rock Tests

4.0 In-Situ Clad Tests

5.0 Final Reports

gti 
Slide 19

\section{Downhole Laser Requirements}

- Technical

- Provide Required Output Power

- Deliver Beam to Downhole Target

- Operate at Downhole Conditions

- Cut / Drill Multiple Materials

- Mobile, Rugged On-site Deployment

Slide 20

\section{Downhole Laser Requirements}

- Economic

- Existing, Commercially Available

- Minimal Maintenance and Repair

- High Energy Conversion Efficiencies

- Minimal Energy Losses

- Attenuation

- Absorbtion

gti 
Slide 21

\section{Laser Comparisons - 4kW}

\begin{tabular}{|c|c|c|c|c|}
\hline & $\mathrm{CO}_{2}$ & LP:YAG & DP:YAG & HPFL \\
\hline E/O Efficiency, \% & $5-10$ & $2-3$ & 4-6 & $16-20$ \\
\hline $\begin{array}{l}\text { Electric Power, kW } \\
\text { (no chiller) }\end{array}$ & $40-80$ & $130-200$ & $\sim 80$ & $20-25$ \\
\hline $\begin{array}{l}\text { Footprint, m² } \\
\text { (no chiller) }\end{array}$ & 6 & 5 & 3 & 0.5 \\
\hline Water, $\mathrm{m}^{3} / \mathrm{hr}$ & $6-8$ & $20-25$ & $\sim 15$ & $<2$ \\
\hline Maintenance, Khrs & $1-2$ & 0.5 & $2-3$ & $10-15$ \\
\hline $\begin{array}{l}\text { Pump Replace, } \\
\text { Khrs }\end{array}$ & $\mathrm{n} / \mathrm{a}$ & $0.5-1$ & 2.5 & \\
\hline
\end{tabular}

Slide 22

\section{Laser Comparisons - 4kW}

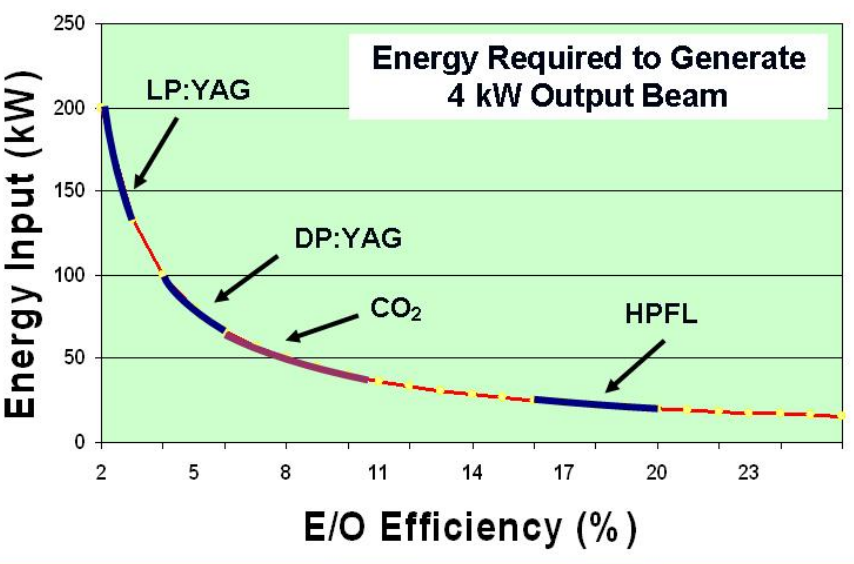


Slide 23

\section{HPFL Advantages}

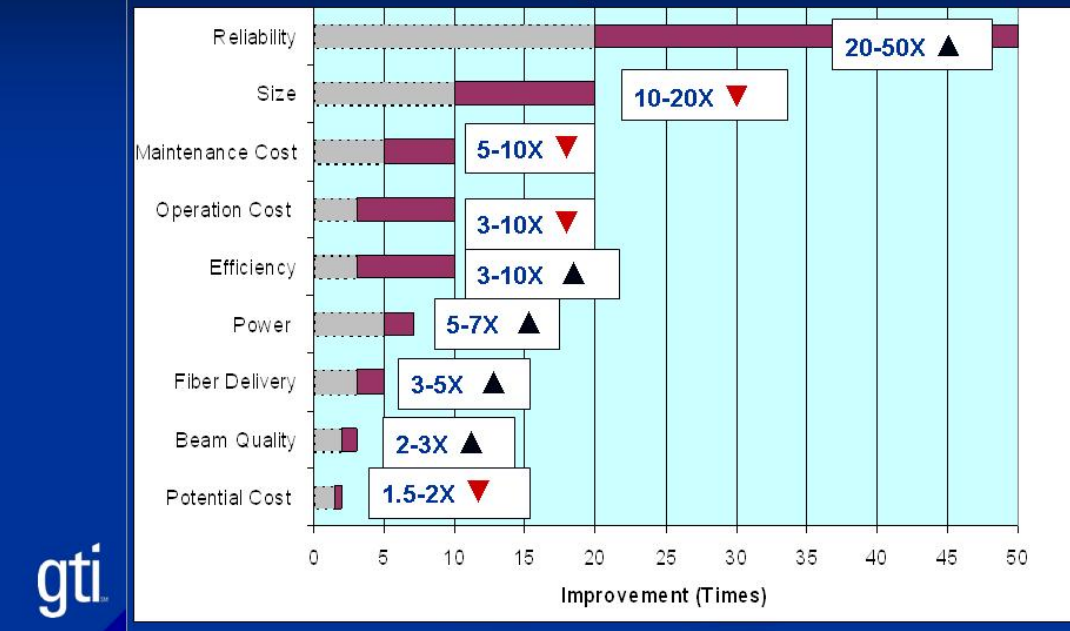

Slide 24

\section{Fiber Laser Background}

Path to Technology Breakthrough

- 1963 - First Demonstration

- 1980's - Fiber Optic Communications

• Signal Boosters (amplifiers)

- 2000's - High Power Fiber Lasers

- Single to Multimode Configuration

- 100-10,000 W over 18 months

gti 
Slide 25

\section{Fiber Laser Spectral Range}

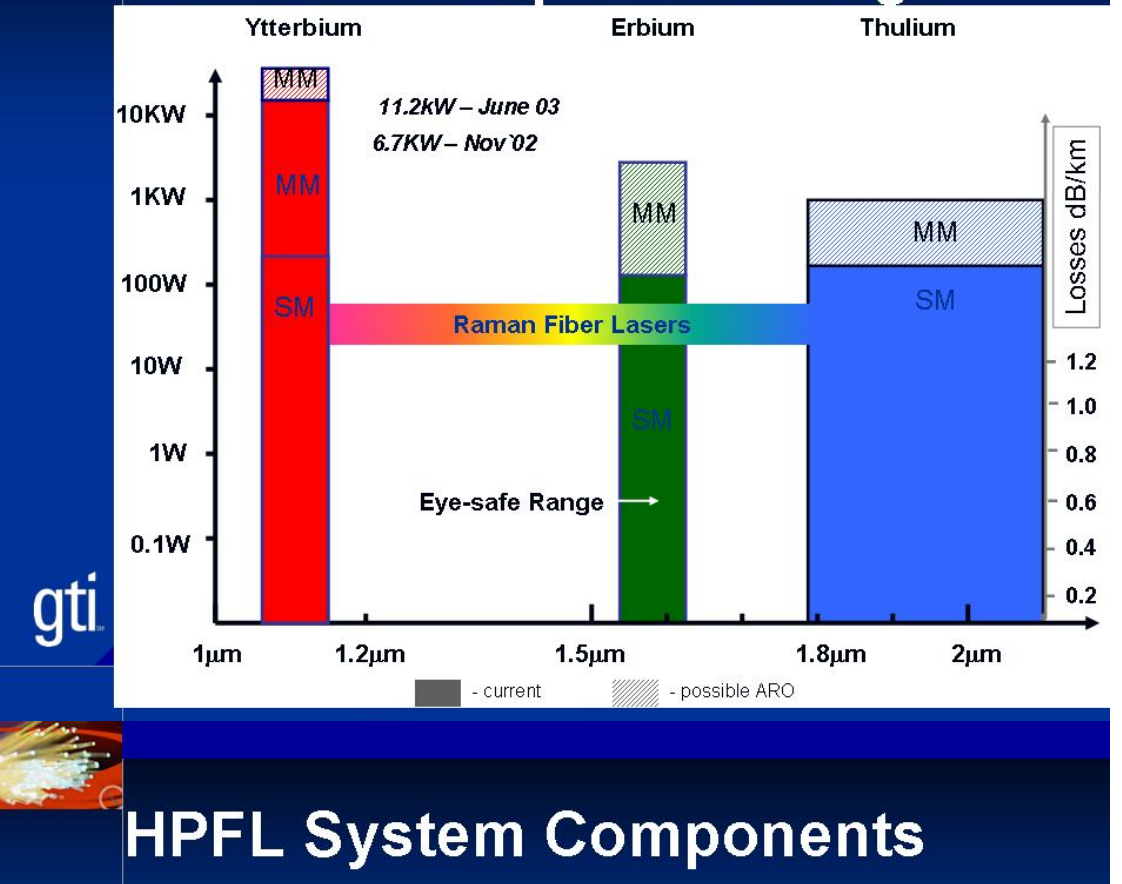

Slide 26

\section{HPFL System Components}

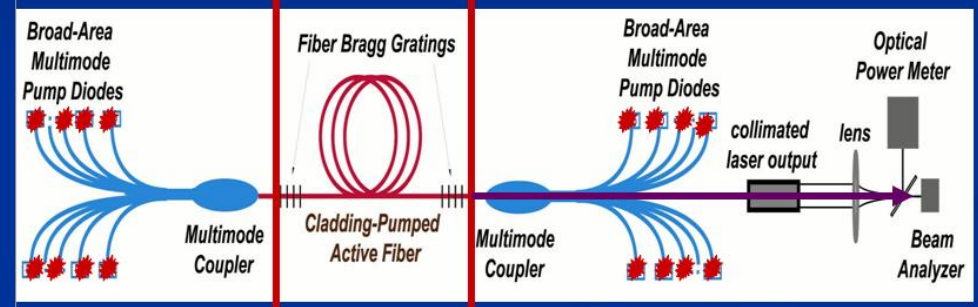

Source: IPG Photonics

gti 
Slide 27

GTI High Power Fiber Laser

Largest US Research HPFL

- $5.34 \mathrm{~kW}, 1.07$ micron

- E/O Efficiency $\geq 20 \%$

- Size: $60 \times 80 \times 160 \mathrm{~cm}$

r Footprint: $0.5 \mathrm{~m}^{2}$

- Weight: $400 \mathrm{~kg}$

Slide 28

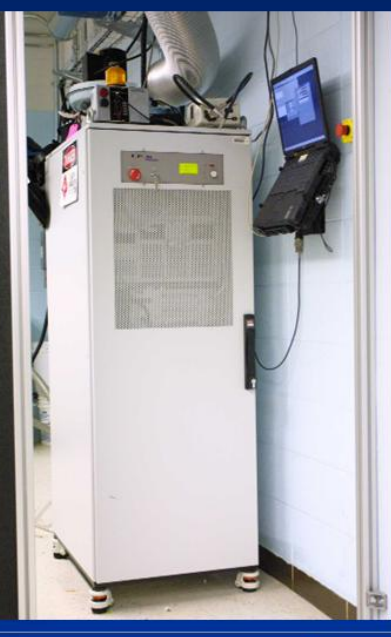

\section{gti}

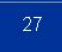

\section{GTI High Power Fiber Laser}

gti

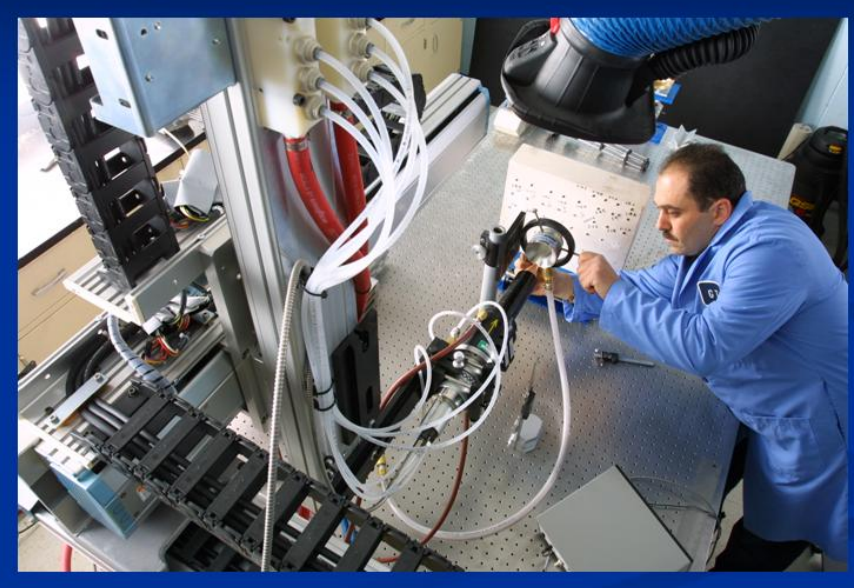


Slide 29

\section{GTI High Power Fiber Laser}

Slide 30

\section{HES Laser Perf POC Tasks}

1.0 Laser Selection and Testing

2.0 Preliminary Tests and Analysis

3.0 In-Situ Rock Tests

4.0 In-Situ Clad Tests

5.0 Final Reports

gti 
Slide 31

\section{HES Experimental Tasks}

- Deep Penetration Tests

- Evaluate SE Calculation

- Optimizing HPFL Parameters

- Saturation Tests

- Oil, Water and Gas

- Fiber Efficiency Test

- Compare Results with Other Laser Data

gti

- Simulated Casing Tests

- Optical Fluid Transmission Test

Slide 32

\section{Material Removal Mechanisms}

- Several Methods Observed

- Function of Thermal Properties

- Carbonates - Dissociation $\mathrm{CaCO}_{3} \rightarrow \mathrm{CaO}+\mathrm{CO}_{2}$

- Sandstones - Spallation

- Shales - Spallation

- Steel - Melt

gti 
Slide 33

\section{HPFL Perforation: Limestone}

Slide 34

\section{HPFL Perforation: Limestone}

Natural

Fractures

Lased

Tunnel

HPFL Perforation in Reservoir Limestone

gti Length: 6 inches Power: $5.34 \mathrm{~kW}$ Beam: CW

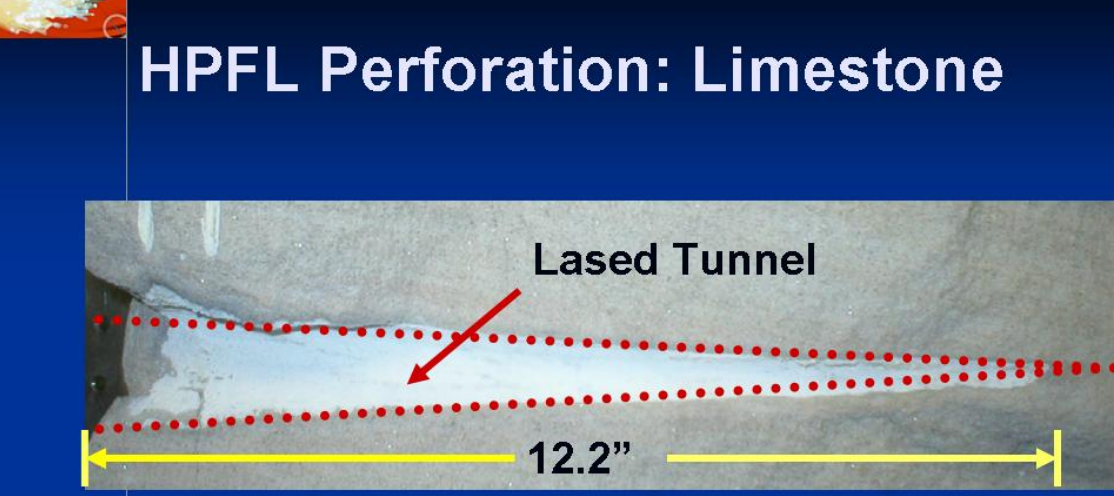

gti

HPFL Perforation in Quarry Limestone

Length: 12.2 inches Power: $5.34 \mathrm{~kW}$ Beam: CW 
Slide 35

\section{HPFL Perforation: Sandstone}

Slide 36

\section{HPFL Perforation: Composite}

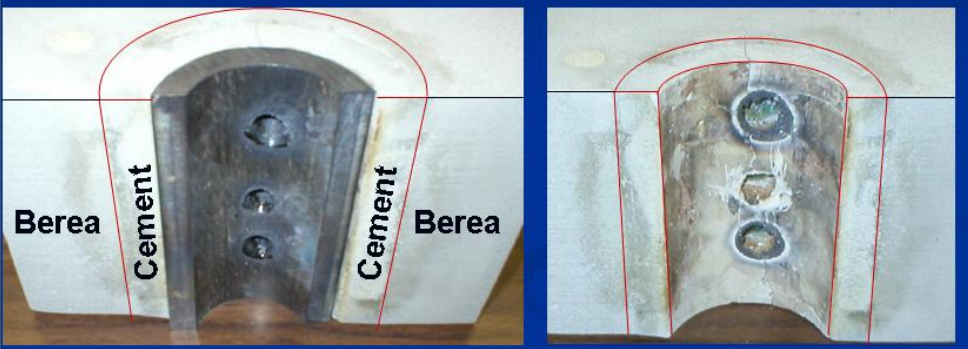

HPFL Perforation Through Steel, Cement, and SS gti Power: $4.4 \mathrm{~kW}$ Beam: CW 
Slide 37

\section{Small Block Perf Test}

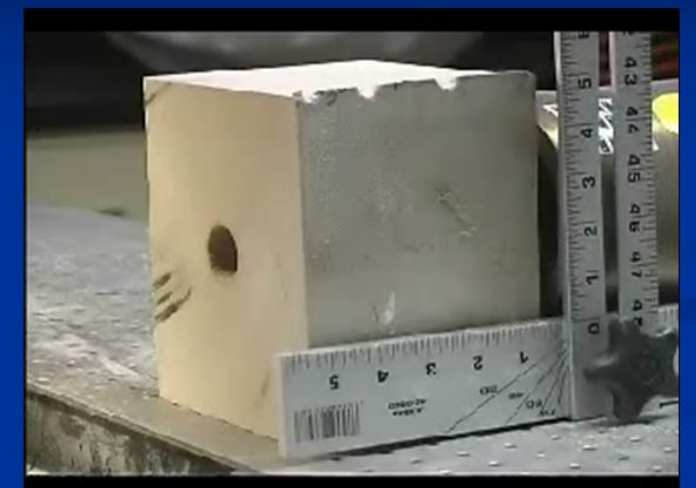

gti Creating $1 \times 3$ Inch Tunnel in Small Berea Block

Slide 38

\section{Large Block Perf Test}

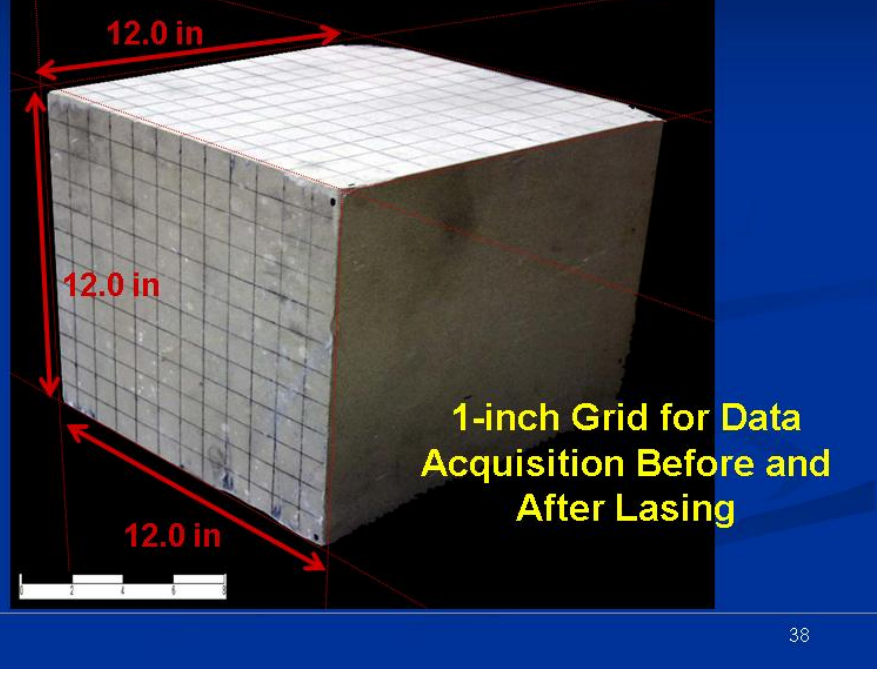


Slide 39

Large Block Perf Test

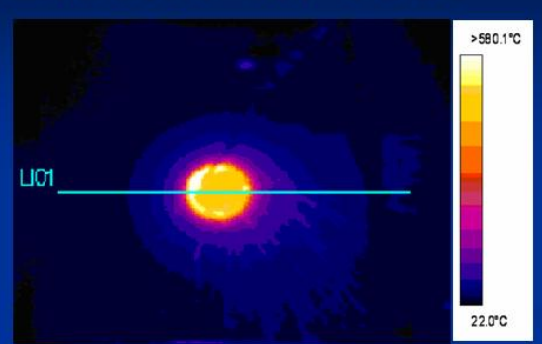

gti.

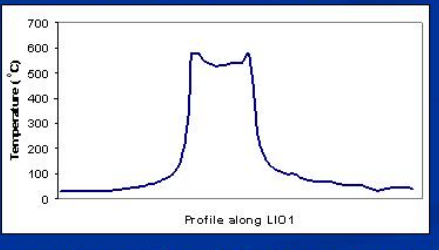

Temperature Profile During Lasing

Slide 40

Large Block Perf Test

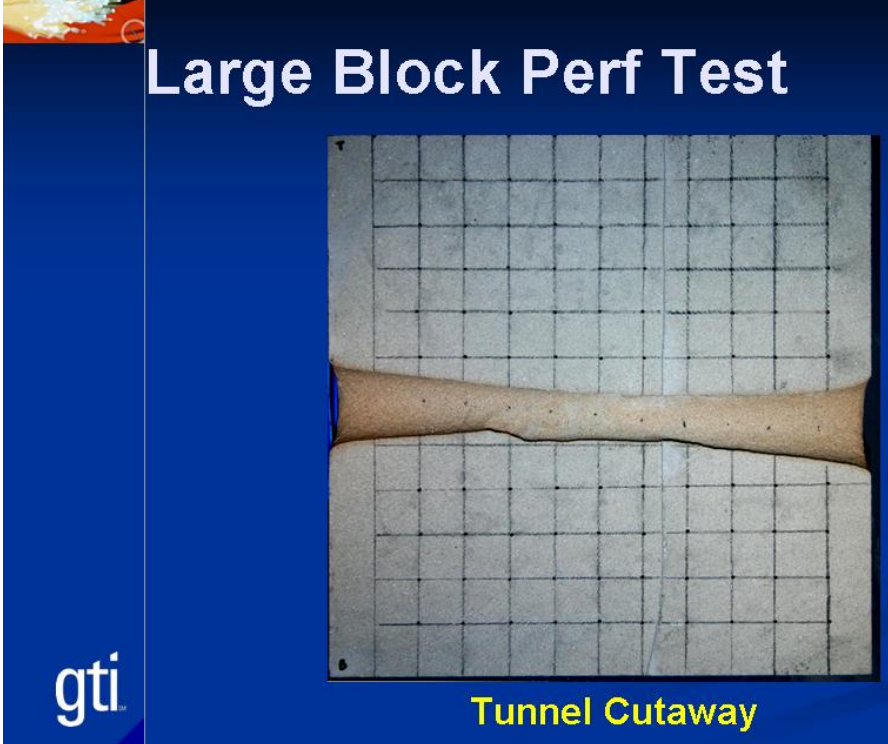




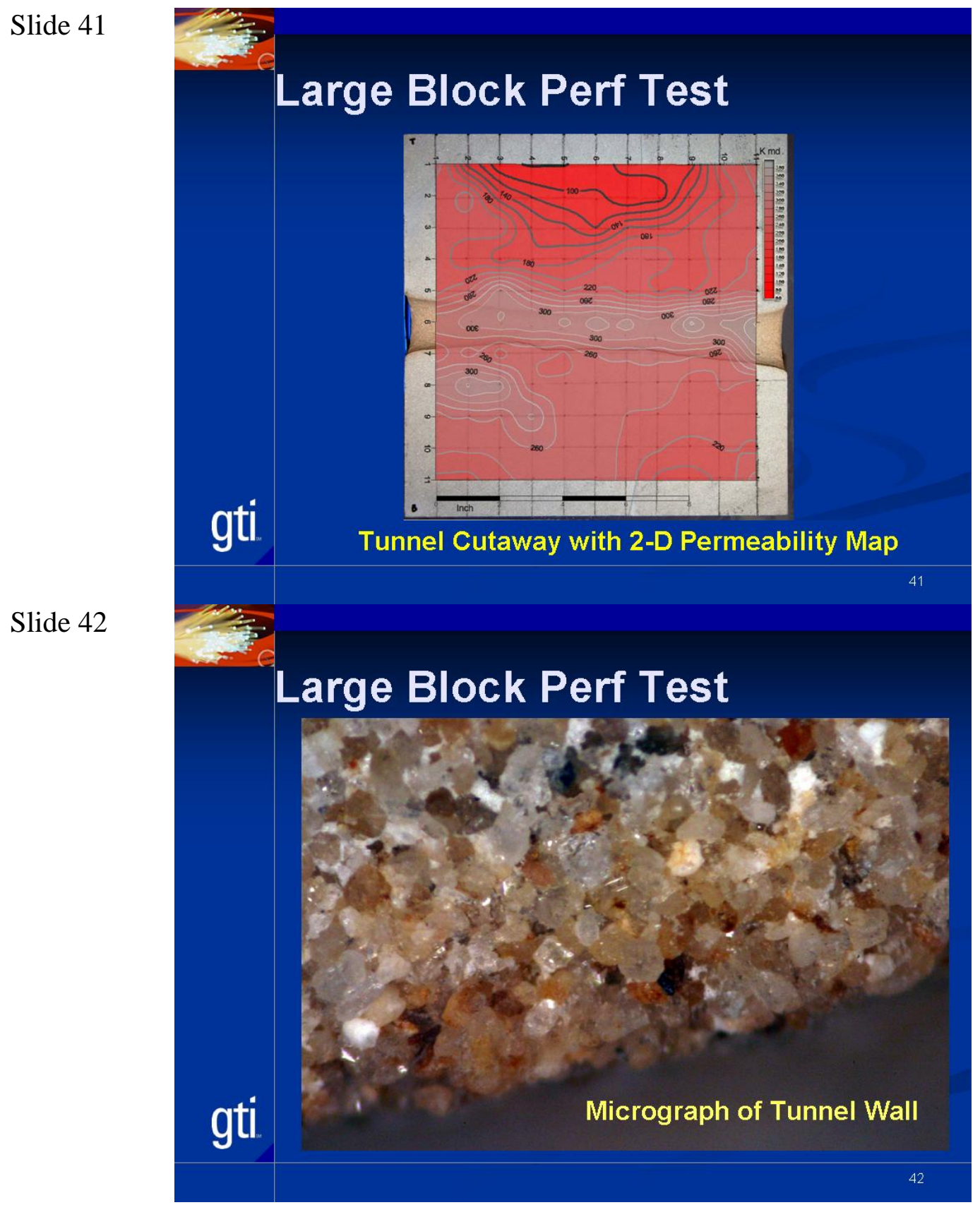


Slide 43

\section{Large Block Perf Test}

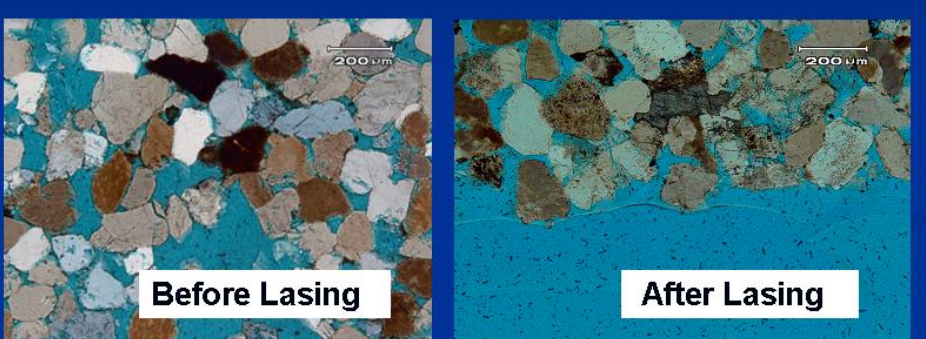

gti Thin Section Comparison of Tunnel Surface

Slide 44

\section{Large Block Perf Test}
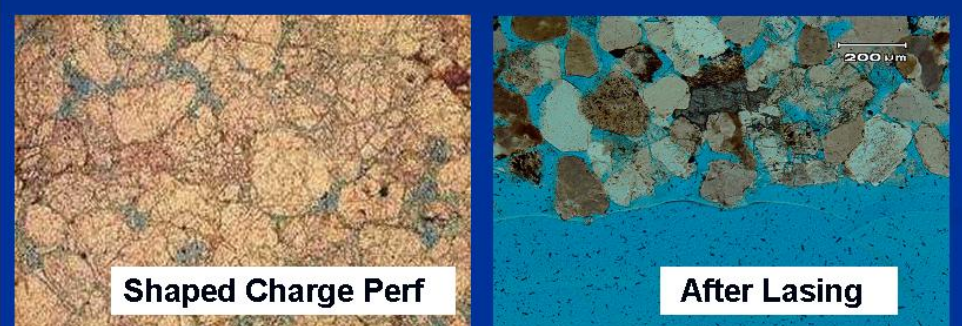

gti

Thin Section Comparison of Tunnel Surface 
Slide 45

\section{Comparison of Lowest SE}

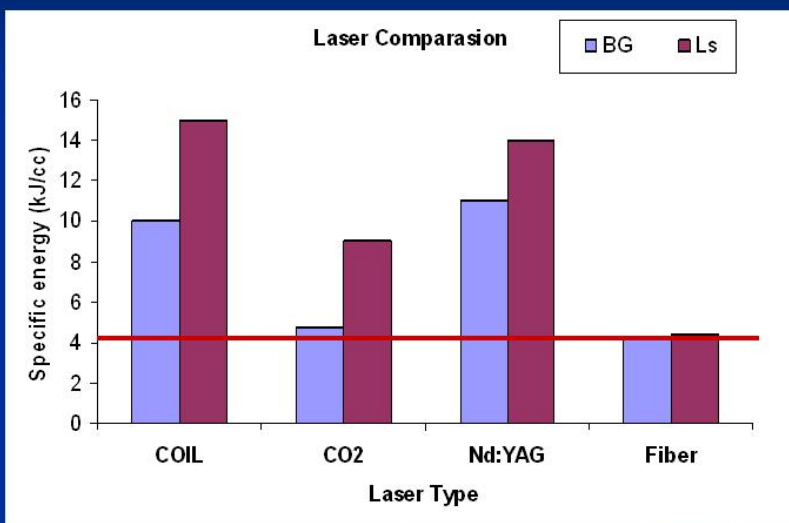

gti

Slide 46

\section{HES Laser Perf POC Tasks}

1.0 Laser Selection and Testing

2.0 Preliminary Tests and Analysis

3.0 In-Situ Rock Tests

4.0 In-Situ Clad Tests

5.0 Final Reports

gti 
Slide 47

\section{HES Perf Tests - Pressure}

- High Pressure Cell for Laser Applications

- Simulates Downhole Pressure Conditions

- Initial Tests Successful (Triaxial)

- Testing Under Various Configurations

Slide 48

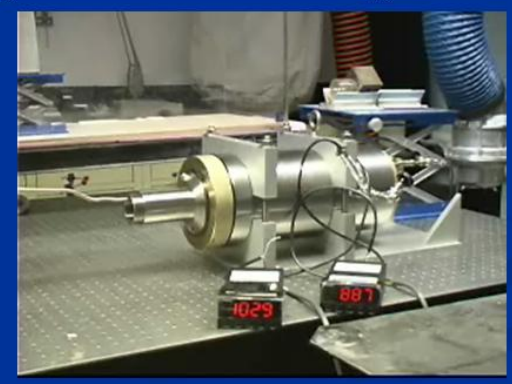

\section{Conclusions}

- Lasers Can Break/Cut All Rock

- Previous Literature Outdated

- HPFL: Breakthrough Technology

- Meets Field Deployment Needs

- Commercially Available

- Potential Non-Explosive Perf Option

gti 
Slide 49

\section{Conclusions}

- Successful Well Perforation Lab Demo

- Longest Laser Tunnel to Date in SS

- Minimal SE Observed

- Optimal Fluid Flow Conditions Result

- Temperature Control Key to SS Spallation

- Multiple Applications - Multiple Industries

gti

Slide 50

\section{Next Steps in Laser R\&D}

- Additional Fundamental Research

- Beam Wavelength Effects (Jeff Labs FEL)

- Expand Simulation of Downhole Conditions

- Modeled Effects of Energy Transfer

- Field Experiments - Perforation

- Develop Prototype Tool

- Test Suite of Conditions

- Explore Drilling Issues and Applications

- i.e., Microhole and Laser Assist 
Slide 51

\section{Publications 2004-2005}

- Gahan, B.C. "Application of Fiber Lasers with Rock and NonMetal Materials," Industrial Laser Solutions, September (2005).

- Gahan, B.C. "Fiber Laser Offers Fast Track to Clean Perforations," GasTIPS (Spring 2005)

- Gahan, B.C., Batarseh, S. 2004. "An Overview of High Power Laser Applications Research from Well Construction and Completion," 2004 International Gas Research Conference (IGRC), Vancouver, BC.

- Batarseh, S., Gahan, B.C., Sharma, B., Gowelly, S. 2004. "Evaluation of High Power Ytterbium Fiber Lasers for Rock Cutting and Removal Applications," 23rd International Congress on Applications of Lasers and Electronics, San Francisco, CA.

\section{Slide 52}

\section{Publications 2004-2005}

- Gahan, B.C., Batarseh, S., Reilly II, J.F., Wilcox, B.H. 2004. "Geological Investigation of the Lunar and Martian Surface and Subsurface Using High Power Lasers," American Institute of Aeronautics and Astronautics (AIAA) Space 2004 Conference and Exhibit, San Diego, CA.

- Gahan, B.C., Batarseh, S., Sharma, B., Gowelly, S. 2004. "Analysis of Efficient High-Power Fiber Lasers for Well Perforation," SPE Paper 90661, SPE Annual Technical Conference and Exhibition, Houston, TX.

- Batarseh, S., Gahan, B.C. 2004. "Deep Hole Penetration for Oil Production Using Ytterbium Fiber Laser," SPIE High-Power Laser Ablation V, Taos, NM.

- Gahan, B.C., Shiner, B. 2004. "New High-Power Fiber Laser Enables Cutting-Edge Research," GasTIPS (Winter 2004). 
Slide 53

\section{Accepted Publications 2005}

- "Influence of Downhole Pressure Conditions on Laser Perforation," 2005 SPE ATCE, Houston, TX.

- "Innovation in Wellbore Perforation Using High Power Lasers," 2005 SPE IPTC, Doha, Qatar.

- $\quad$ "High Pressure Testing Advances Underground Fiber Laser Rock Cutting Applications," 2005 ICALEO, Miami, FL.

- GasTIPS, Fall 2005

Slide 54

\section{GTI Leading Laser Apps R\&D}

- Unique Capabilities, Expertise, Network

- Successful R\&D Results

- Advanced HPFL Lab

- Attracting R\&D With Industry Partners

- Exclusive Laser Industry Partner (IPG)

- Near and Long Term Project Portfolio

gti 
